\title{
CHARACTERISTICS AND REMOVAL OF FILTER CAKE FORMED BY FORMATE-BASED DRILLING MUD
}

\author{
A Thesis \\ by \\ MOHAMMED B. ALOTAIBI
}

\begin{abstract}
Submitted to the Office of Graduate Studies of
Texas A\&M University

in partial fulfillment of the requirements for the degree of

MASTER OF SCIENCE
\end{abstract}

May 2008

Major Subject: Petroleum Engineering 


\title{
CHARACTERISTICS AND REMOVAL OF FILTER CAKE FORMED BY FORMATE-BASED DRILLING MUD
}

\author{
A Thesis \\ by \\ MOHAMMED B. ALOTAIBI
}

\begin{abstract}
Submitted to the Office of Graduate Studies of
Texas A\&M University

in partial fulfillment of the requirements for the degree of

MASTER OF SCIENCE
\end{abstract}

Approved by:

Chair of Committee, A. Daniel Hill

Committee Members, Zhengdong Cheng

Hisham A. Nasr-El-Din

Ding Zhu

Head of Department, Stephen A. Holditch

May 2008

Major Subject: Petroleum Engineering 


\author{
ABSTRACT \\ Characteristics and Removal of Filter Cake Formed by \\ Formate-Based Drilling Mud. (May 2008) \\ Mohammed B. Alotaibi, B.S., King Fahd University of \\ Petroleum and Minerals, Dhahran-Saudi Arabia \\ Chair of Advisory Committee: Dr. A. Daniel Hill
}

Formate-based mud has been used to drill deep gas wells in Saudi Arabia since 2004. This mud typically contains XC-polymer, starch, polyanionic cellulose, and a relatively small amount of calcium carbonate particles, and is used to drill a deep sandstone reservoir $\left(310^{\circ} \mathrm{F}\right)$. Calcium carbonate particles are frequently used as weighting material to maintain the pressure that is required for well control and minimize the leak-off. Such solids become consolidated and trapped in the polymeric material and this makes the filter cake a strong permeability barrier.

Various cleaning fluids were proposed to remove drilling mud filter cake; including: solid-free formate brine and formate brine doped with organic acids (acetic, formic, and citric acids), esters, and enzymes. The main objective of this research is to assess the effectiveness of these cleaning fluids in removing drilling mud filter cake. A dynamic high-pressure/high-temperature (HPHT) cell was used to determine characteristics of the drilling mud filter cake. Drilling mud and completion fluids were obtained from the field. Compatibility tests between potassium formate brine, cleaning 
fluids, and formation brine were performed at $300^{\circ} \mathrm{F}$ and 200 psi using HPHT visual cells. Surface tensions of various cleaning fluids were also measured at high temperatures.

The conventional method for cleaning the filter cake is by circulating solid-free formate brines at a high flow rate. This mechanical technique removes only the external drilling fluid damage. Citric acid at $10 \mathrm{wt} \%$, formic acid, and lactic acid were found to be incompatible with formate brine at room temperature. However, these acids were compatible with formate brine at temperatures greater than $122^{\circ} \mathrm{F}$. Only acetic acid was compatible with formate brine. A formula was developed that is compatible at room and reservoir temperature. This formula was effective in removing filter cake. A corrosion inhibitor was added to protect downhole tubulars. In general detail, this research will discuss the development of this formula and all tests that led to its development. 


\section{DEDICATION}

This work is dedicated to:

my lovely supportive parents,

my beloved patient wife, Taiba

and my wonderful children, Muhand and Raghad

with love and appreciation. 


\section{ACKNOWLEDGEMENTS}

All kinds of praise and all thanks belong to the God, the One, the Lord of the Universe, the Creator, the Most Gracious and the Most Merciful. Deep affection is especially due to my parents who supported and encouraged me throughout my study. My love and thanks to my wife for her patience and support while I was studying for my degree.

I would like to thank Saudi Aramco for giving me this opportunity to further my education to receive a Master of Science Degree.

I would like to express my gratitude to my advisor, Professor A. Daniel Hill, for his support and guidance throughout this research.

I would like to extend my appreciation to my committee members, Dr. Ding Zhu and Dr. Zhengdong Cheng, for serving on the defense committee. Special thanks to Dr. Hisham Nasr-El-Din in Saudi Aramco for the useful discussion and helpful comments.

Finally, I would like to give thanks to my family who has been a source of neverending encouragement and support. 


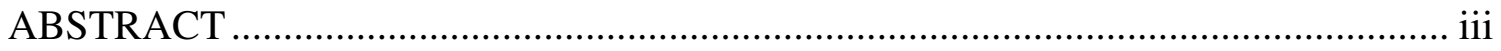

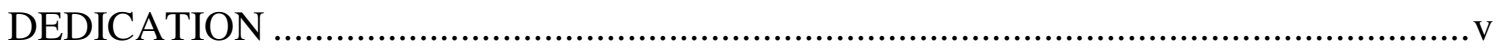

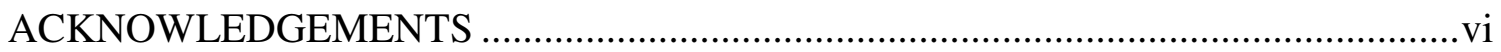

TABLE OF CONTENTS .................................................................................... vii

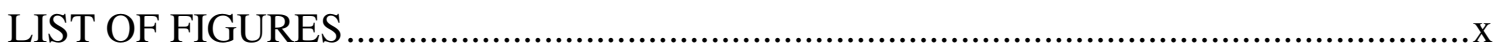

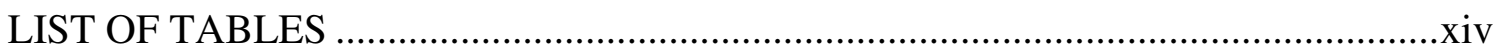

CHAPTER

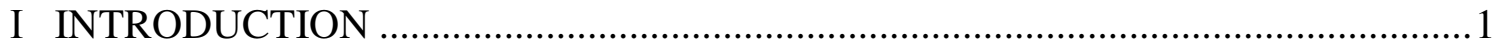

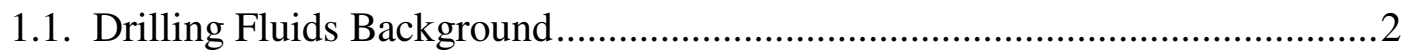

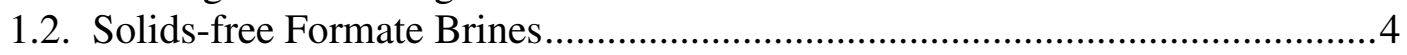

1.3. Compatibility of Formate Brines with Other Fluids ..........................................5

1.4. Conventional Filter Cake Clean-up Techniques ..............................................6

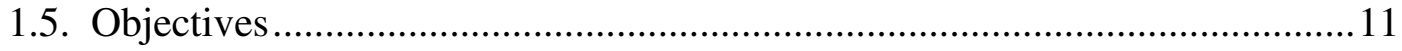

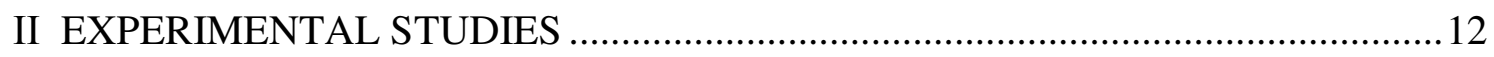

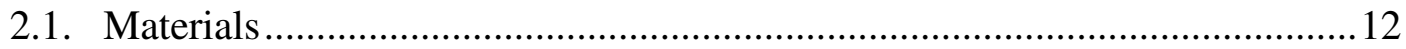

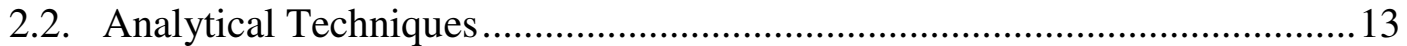

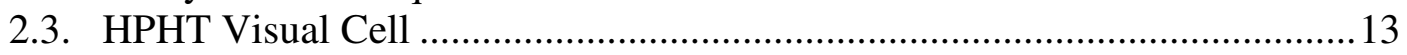

2.4. Dynamic HPHT Filter Press Cell ...............................................................15

2.5. Experimental Procedure for Dynamic HPHT Filter Press ..............................16

2.6. HPHT Pendant Drop Instrument ...................................................................2

2.7. Experimental Procedure for HPHT Pendant Drop .......................................2 20 


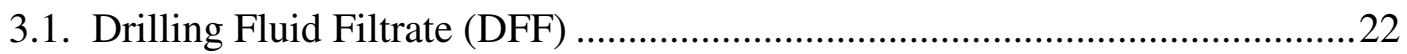

3.1.1 DFF Mixed with Ethyl Lactate Ester at Room Temperature ..................22

3.1.2 DFF Mixed with Ethyl Lactate Ester at $300^{\circ} \mathrm{F}$.........................................23

3.1.3 DFF Mixed with Formation Brine at Room Temperature ……………....24

3.2. Solids-free Potassium Formate Brine (PFB) ..................................................26

3.2.1 PFB Mixed with Unyazah Formation Brine (UFB) at Room

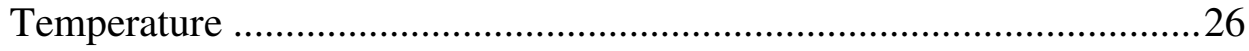

3.2.2 PFB Mixed with UFB at Temperatures $113-127^{\circ} \mathrm{F} \ldots \ldots \ldots \ldots \ldots \ldots \ldots \ldots \ldots \ldots \ldots \ldots . . .27$

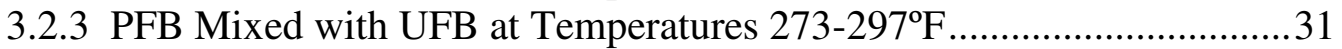

3.3. Organic Acids Prepared in PFB Solution.......................................................33

3.3.1 $10 \mathrm{wt} \%$ Citric Acid Mixed with PFB ....................................................33

3.3.2 $10 \mathrm{wt} \%$ Formic Acid Prepared in PFB Solution .......................................36

3.3.3 $10 \mathrm{wt} \%$ Acetic Acid Prepared in PFB Solution .......................................39

3.3.4 5 and $10 \mathrm{wt} \%$ Ethyl Lactate Ester Prepared in PFB Solution ...................39

3.3.5 Chelating Agent (DTPA) Prepared in PFB Solution ................................41

3.4. Xanthan and Cellulose Enzymes Prepared in PFB Solution............................43

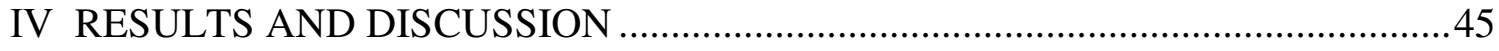

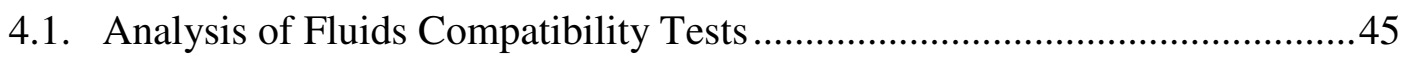

4.1.1 DFF Mixed with UFB at Room Temperature ……………………….....45

4.1.1.1 10\% DFF Mixed with 90\% UFB (Sample No. 1) ........................45

4.1.1.2 30\% DFF Mixed with 70\% UFB (Sample No. 2) ........................46

4.1.1.3 50\% DFF Mixed with 50\% UFB (Sample No. 3) ........................48

4.1.2 UFB Mixed with PFB Solution at Room Temperature ..............................49

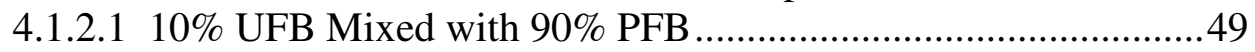

4.1.2.2 30\% UFB Mixed with 70\% PFB ...............................................49

4.1.2.3 50\% UFB Mixed with 50\% PFB ……………….......................53

4.1.2.4 70\% UFB Mixed with 30\% PFB ..............................................53

4.1.2.5 90\% UFB Mixed with 10\% PFB ..............................................53

4.1.3 UFB Mixed with PFB Solution at High Temperature..............................56

4.1.3.1 10\% UFB Mixed with 90\% PFB ..............................................56

4.1.3.2 30\% UFB Mixed with 70\% PFB .............................................56

4.1.3.3 50\% UFB Mixed with 50\% PFB ……………….....................59

4.1.3.4 70\% UFB Mixed with 30\% PFB .............................................59

4.1.3.5 90\% UFB Mixed with 10\% PFB ................................................62

4.1.4 Organic Acids Mixed with PFB Solution …………………………......62

4.1.4.1 $10 \mathrm{wt} \%$ Citric Acid Mixed with PFB at Room Temperature ......62

4.1.4.2 $10 \mathrm{wt} \%$ Formic Acid Mixed with PFB at Room Temperature....67 
CHAPTER $\quad$ Page

4.2. Analysis of Dynamic HPHT Filter Press Cell Experiments .........................69

4.2.1 Drilling Fluid Experiment ..........................................................69

4.2.2 5 vol\% Ethyl Lactate Ester (ELE) ….......................................... 70

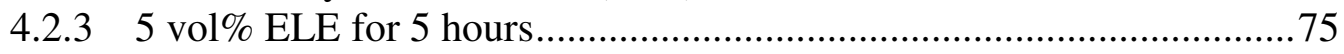

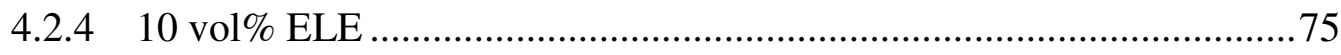

4.2.5 Solids-free Potassium Formate Brine............................................. 76

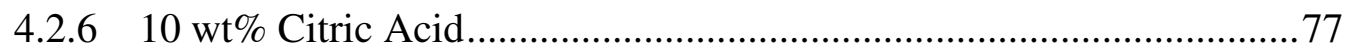

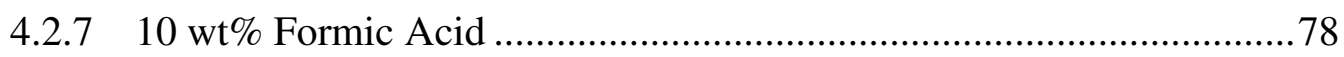

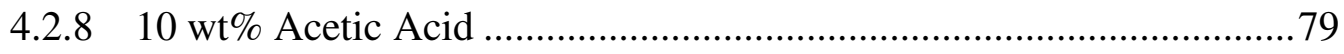

4.2.9 $10 \mathrm{wt} \%$ Acetic Acid Mixed with 10 wt\% Cellulose Enzyme ...............8 80

4.2.10 $10 \mathrm{wt} \%$ Acetic Acid Mixed with $5 \mathrm{wt} \%$ Cellulose Enzyme ..................81

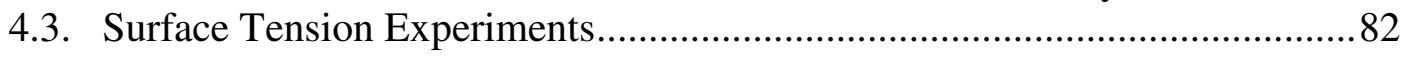

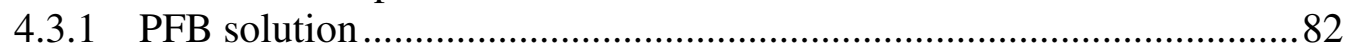

4.3.2 $10 \mathrm{wt} \%$ Formic Acid Prepared in PFB Solution .................................83

4.3.3 $10 \mathrm{wt} \%$ Acetic Acid Prepared in PFB Solution.......................85

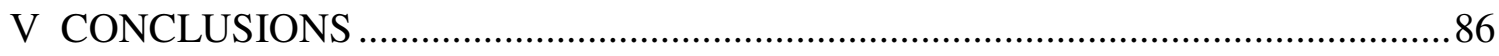

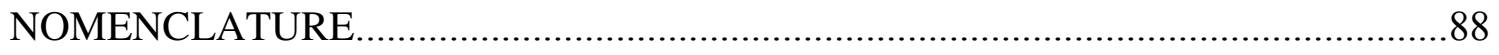

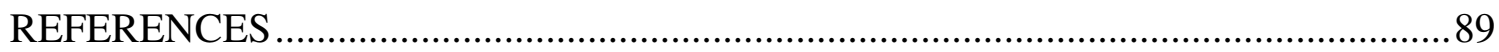

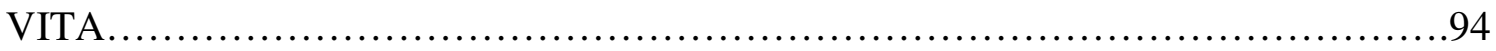




\section{LIST OF FIGURES}

FIGURE $\quad$ Page

1 HPHT visual cell with automotive temperature control..................................... 14

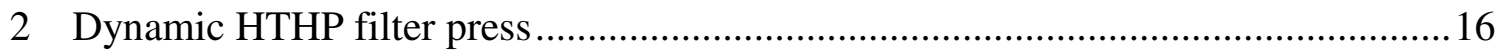

3 Flow sheet of PD-E700LL-H ................................................................... 21

4 Compatibility of DFF with lactate ester at room temperature ...............................23

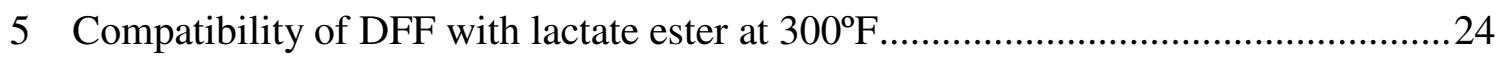

6 Compatibility of DFF with formation brine at room temperature............................25

7 Compatibility tests between PFB and UFB at room temperature ..........................26

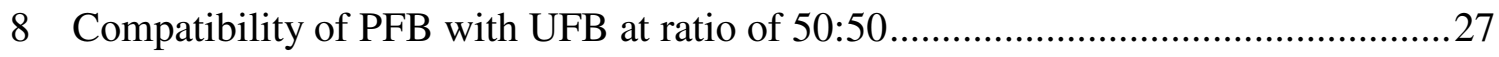

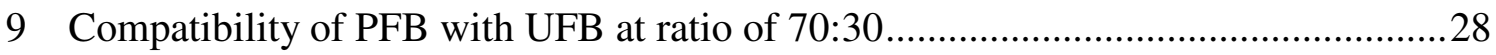

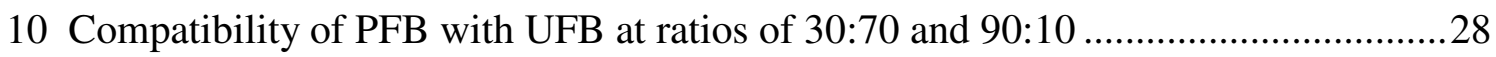

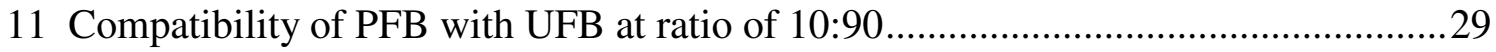

12 Compatibility tests between PFB and UFB at temperature range of $113-127^{\circ} \mathrm{F} \ldots \ldots . . .30$

13 The weight difference of the solid precipitate at room and higher temperatures.......30

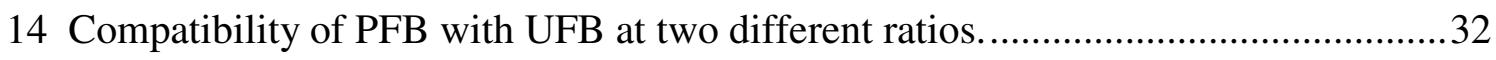

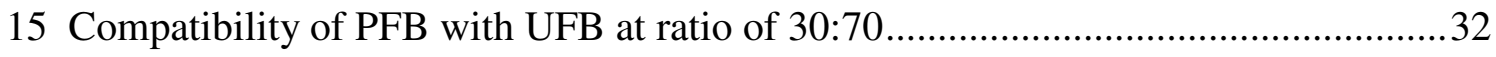

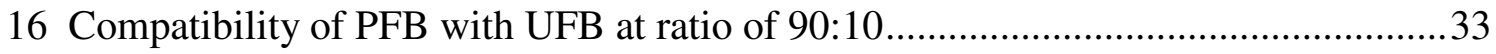

17 Compatibility of $10 \mathrm{wt} \%$ citric acid with PFB at room temperature ........................34

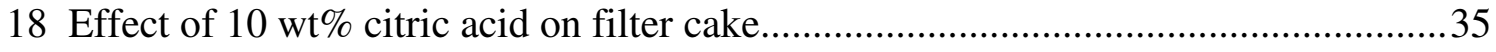

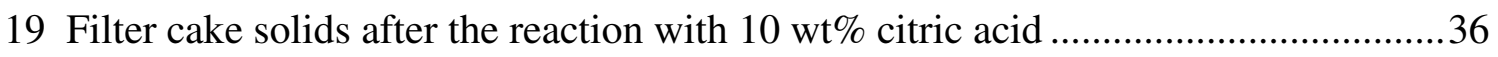


FIGURE

Page

$2010 \mathrm{wt} \%$ formic acid prepared in PFB solution at room temperature .............................

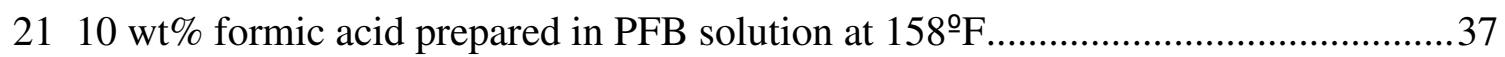

22 Solids filtered from the $10 \mathrm{wt} \%$ formic acid solution that prepared at room

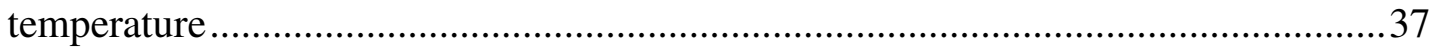

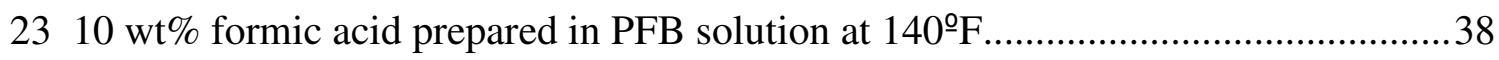

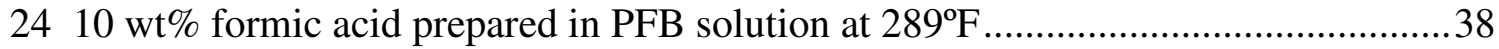

$2510 \mathrm{wt} \%$ ethyl lactate ester prepared in PFB solution at room temperature ................40

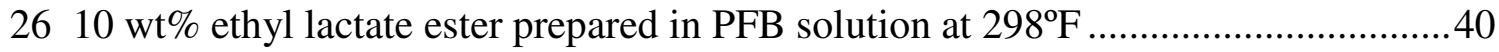

$275 \mathrm{wt} \%$ ethyl lactate ester prepared in PFB solution prepared at room temperature ...41

28 DTPA prepared in PFB solution at a ratio of 50:50 .........................................42

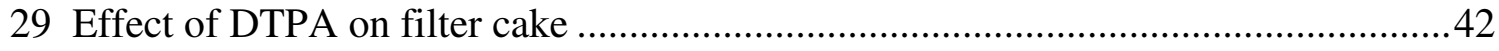

$3010 \mathrm{wt} \%$ of xanthan and cellulose enzymes prepared in PFB solution ......................43

31 Effect of $10 \mathrm{wt} \%$ of xanthan and cellulose enzymes on the filter cake.....................44

32 Secondary and backscattered electron images of precipitated solids in sample no. 1

33 Secondary and backscattered electron images of precipitated solids in sample no. 2

34 Secondary and backscattered electron images of precipitated solids in sample no. 3

35 Backscattered electron images and EDS X-ray spectrum of the solids precipitates at room temperature from mixing $10 \%$ UFB with $90 \%$ PFB.

36 Backscattered electron images and EDS X-ray spectra of solids precipitated from mixing $30 \%$ UFB with $70 \%$ PFB at room temperature.

37 Backscattered electron images and EDS X-ray spectra of solids precipitated from mixing $70 \%$ UFB with $30 \%$ PFB at room temperature. 
38 Backscattered electron images and EDS X-ray spectrum of the solids precipitates at room temperature from mixing $90 \%$ UFB with $10 \%$ PFB.

39 Backscattered electron images and EDS X-ray spectrum of the solids precipitates from mixing $10 \%$ UFB with $90 \%$ PFB.

40 Backscattered electron images and EDS X-ray spectra of solids precipitated from mixing $30 / 70 \mathrm{UFB}-\mathrm{PFB}$ at $120^{\circ} \mathrm{F}$.

41 Backscattered electron images and EDS X-ray spectra of solids precipitated from mixing 50:50 UFB and PFB at $117.5^{\circ} \mathrm{F}$.....

42 Backscattered electron images and EDS X-ray spectra of solids precipitated from mixing $70: 30 \mathrm{UFB}-\mathrm{PFB}$ at $115.5^{\circ} \mathrm{F}$

43 Backscattered electron images and EDS X-ray spectrum of the solids precipitates at $122^{\circ} \mathrm{F}$ from mixing $90 \%$ UFB with $10 \%$ PFB.

44 Backscattered electron images and EDS X-ray spectra of solids precipitated during mixing of $10 \mathrm{wt} \%$ citric acid with PFB at room temperature.

45 Backscattered electron images and EDS X-ray spectra of solids filtered from $10 \mathrm{wt} \%$ citric acid-PFB solution at room temperature.

46 Backscattered electron images and EDS spectra of solids formed from $10 \%$ formic acid reaction with PFB at room temperature.

47 Filter cake after filtration test and 5 vol\% ethyl lactate ester (ELE), temperature $=303^{\circ} \mathrm{F}$ and pressure $=200 \mathrm{psi}$

48 EDS X-ray spectrum of the disk cross-section after 5 vol\% ethyl lactate ester.........73

$49 \mathrm{BSE}$ image of the disk cross-section $\mathrm{KCl}$ patches in the interior of the disk............73

50 BSE image of the disk showing bright showing absence of solids in the interior of the disk

51 EDS X-ray spectrum of filter cake solids on ceramic disk

52 Filter cake after filtration test and 5 vol\% ethyl lactate ester (ELE), temperature $=300-315^{\circ} \mathrm{F}$ and pressure $=200 \mathrm{psi}$ 
53 Filter cake after filtration test and 10 vol\% ethyl lactate ester (ELE), temperature $=300^{\circ} \mathrm{F}$ and pressure $=200 \mathrm{psi}$.

54 Filter cake after filtration test and solids-free potassium formate brine, temperature $=300^{\circ} \mathrm{F}$ and pressure $=200 \mathrm{psi}$

55 Filter cake after filtration test and $10 \mathrm{wt} \%$ citric acid solution, temperature $=301^{\circ} \mathrm{F}$ and pressure $=200 \mathrm{psi}$

56 Filter cake after filtration test and $10 \mathrm{wt} \%$ formic acid solution, temperature $=304^{\circ} \mathrm{F}$ and pressure $=200$ psi.

57 Filter cake after filtration test and $10 \mathrm{wt} \%$ acetic acid solution, temperature $=300^{\circ} \mathrm{F}$ and pressure $=200 \mathrm{psi}$

58 Filter cake after filtration test and $10 \mathrm{wt} \%$ acetic acid mixed with $10 \mathrm{wt} \%$ enzyme solution, temperature $=242^{\circ} \mathrm{F}$ and pressure $=220 \mathrm{psi}$.

59 Filter cake after filtration test and $10 \mathrm{wt} \%$ acetic acid mixed with $5 \mathrm{wt} \%$ enzyme

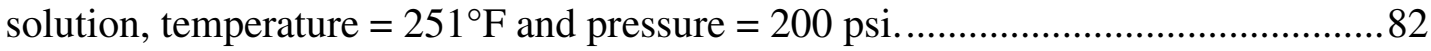

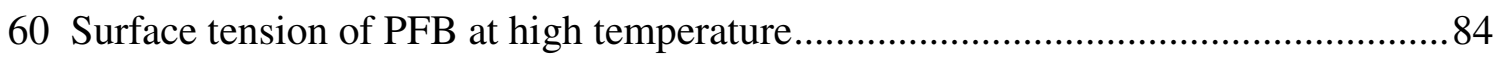

61 Surface tension of $10 \mathrm{wt} \%$ formic acid at high temperature .................................. 84

62 Surface tension of $10 \mathrm{wt} \%$ acetic acid at high temperature .....................................85 


\section{LIST OF TABLES}

TABLE Page

1 Compatibilities of the most common oxidizers with formate brines ...................... 11

2 Formulation and properties of formate drilling fluid, lab sample ......................... 12

3 Properties of formate-based drilling fluid, field sample ...................................... 12

4 Unyazah formation brine composition and ions concentration..............................25

5 Five mixing ratios used at room and high temperatures ...................................25

6 Solids filtered from field drill-in fluid sample ................................................... 70

7 Formula of ethyl lactate ester cleaning solution................................................ 72

8 EDXRF result for solids on the surface of the ceramic disk after 5 vol\% ethyl

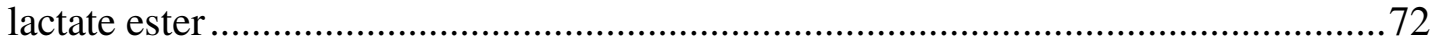




\section{CHAPTER I}

\section{INTRODUCTION}

The objective of multilateral-well technology is to improve the well productivity by maximizing reservoir contact, resulting in field development with a fewer number of wells. Long horizontal wells (up to eight $\mathrm{km}$ ) are drilled in Saudi Arabia fields, but the greatest opportunity, and technological challenge, lies with MRC wells. A Maximum Reservoir Contact (MRC) well definition is a long horizontal well with more than five $\mathrm{km}$ of total contact with the reservoir rock (Hussain et al., 2005).

It is well recognized that near-wellbore flow properties are altered by drillingfluid and fluid filtrate invasion during overbalanced drilling operations. The degree of alteration, generally called formation damage, depends on a large number of parameters, such as the nature and characteristics of the drilling fluid, formation properties, and operating conditions (Ding et al., 2006).

Formation damage caused by drilling-fluid invasion may create substantial reductions in oil and gas production rate in many wells. Productivity losses are especially critical for long horizontal wells, which are often have an openhole completion. In such cases, the near-wellbore damage is not bypassed by perforations and may lead to very large skin values. Therefore, prevention of formation damage generated by a drilling fluid may not always be possible because, first, the drilling time of the horizontal segment in the producing zone is usually many times longer than in a typical

This thesis follows the style of SPE Journal. 
vertical well, leading to a much deeper filtrate invasion; and second, the very low drawdown pressure that is needed to produce from a typical horizontal well reduces the viscous forces available to cleanup near-wellbore damage (Yildiz, 2006; Longeron et al., 2000).

Formation damage and the subsequent increase in skin factor was influenced primarily by the type and properties of the drilling fluid used in the reservoir section, but can be limited by careful attention to drilling practices while in the reservoir. Skin can result from unnecessary and repeated damage to the mud filter cake during drilling, tripping, and reaming operations (Liu and Civan, 1994).

\subsection{Drilling Fluids Background}

Drilling fluids are either water-based or oil-based. These fluids are made up of a base fluid, water or diesel (HC), weighting agents and other additives that aid in removing the cuttings from the well and keep the mud in a fluid state. Traditionally, the drilling industry has used water-based muds (WBMs) because they are inexpensive and have minimal impact on the surrounding environment. The density of the WBMs can be increased by adding calcium carbonate particles. High levels of suspended solids, however, in drilling fluids can cause high frictional losses during fluid circulation. These loses create high ECDs and limit pump rates. Low pump rates can result in inefficient hole cleaning (Njobuenwu and Wobo, 2007).

In difficult drilling situations, such as horizontal, extended reach, deep wells, and reactive shales, drillers rely usually on oil-based muds (OBMs). However, despite their 
high-performance properties, OBMs are costly to dispose-off and contain toxic materials, such as mineral oil.

The main concern with WBM is the thermal degradation of chemical additives that often occurs while drilling high temperature wells. Such degradation can lead to strong variations in rheological and filtration characteristics and loss of fluid properties (Melbouci and Sau Arjun, 2006). Moreover, even if no degradation of components occurs, the viscosity of hydro-soluble polymer solutions commonly used in drilling fluid formulations strongly decreases at high temperatures. Improperly formulated and maintained drilling fluid systems can cause significant near-wellbore formation damage and create potential for the plugging of screens and slotted liners (Pitoni et al., 1999).

The usual problems that encountered with conventional $\mathrm{KCl} /$ polymers drilling fluid in gas wells in Saudi Arabia are:

- Downhole fluid and barite losses in the horizontal section. The leak-off also happens during the completion phase when drilling fluid lose their suspension properties at high bottom hole temperatures due to degradation of the polymers (Saasen et al., 2002; Bradshaw et al., 2006).

- Differential sticking due to large pressure overbalance (800-1,600 psi). Sometimes, sloughing shales, which interbedding the main gas reservoirs, need to be stabilized (Simpson et al., 2005).

- Excessively high rheological properties, resulting in unacceptable surface pump pressures when conventional non-damaging brines such as calcium chloride and 
calcium bromide are used as base fluids with calcium carbonate as a weighing and bridging agent (Oswald et al., 2006).

Using formate based mud can solve these concerns that have been usually encountered with conventional water and oil-based muds (Svendsen et al., 1998; Svoboda, 2002; Messler et al., 2004; Downs et al., 2006).

\subsection{Solids-free Formate Brines}

Solids-free formate-based brines were first recognized as having the ability to extend the thermal stability of bio-polymers in the late 1980s and early 1990s. Their first applications in the field were in the early 1990s, and their use as the basis of reservoirdrilling and completion fluids has become widespread since then (Downs, 1993). Their ability to preserve conventional polymers at temperatures greater than $250^{\circ} \mathrm{F}$, and in some cases up to $360^{\circ} \mathrm{F}$, has been the primary reason for their selection (Messler et al., 2004). Polymer stabilization in a formate brine is typically achieved by the promotion of hydrogen bonding. This promotion raises the transition temperature and thus maintaining the fluid viscosity at elevated temperatures (Lomba et al., 2002). The formate salts also have an unusually high solubility in water, at a wide range of densities, and reduce the rate of hydrolytic and oxidative degradation of many viscosifiers and fluid loss agents at high temperatures (Downs et al., 2005). Formate also has the advantage that much of the weight is provided by the base brine resulting in lower solids content (Weekse et al., 2002). Sodium and potassium formate based drilling fluid have been used in drilling HPHT gas wells in Saudi Arabia since 2004 (Simpson et al., 2005). 
Formate brine also has the ability to delay cross-linking time for gel fluids in conformance control operation. It has been used due to the high density that can be sustained with this type of brines. At higher densities, formate brines tend to precipitate out the polymers and cross-linkers (Bouwmeester and Van Gijtenbeek, 2005).

\subsection{Compatibility of Formate Brines with Other Fluids}

Compatibility of formate-based drilling fluid with formation brine was discussed in several publications (Downs et al., 2005; Hands et al., 1998; Byrne et al., 2002). Byrne et al. presented specific procedure for formate testing at reservoir conditions. The conclusion from Byrne paper was that the formate-based fluid is compatible with formation brines at high temperatures and the common precipitation was noticed only at room temperature condition. Acetic and formic acids at a concentration of $15 \mathrm{wt} \%$ were prepared in a formate brine solution to remove the filter cake damage. The compatibility of the organic acids with formte brine was not discussed although they were used in that paper. There was no evidence of adverse formate/formation brine reaction at reservoir conditions. Some of the formation brines incorporated in these tests were highly saline with salt saturations greater than $200,000 \mathrm{ppm}$.

Downs et al. proved that there might be precipitate from mixing formate brine solution with the reservoir fluids (Downs et al., 2005). They concluded that any precipitates formed are not scale-i.e. they are inherently water-soluble (e.g. $\mathrm{KCl})$. The precipitates that created in the lab experiments might be due to the unrealistic mixing ratios and room temperature condition. 
A recent study on formate brine compatibility with formation brine was published in last April (Javora et al., 2007). Several tests were conducted at three ratios $(75 / 25,50 / 50$, and $25 / 75)$ and at temperatures 70 and $180^{\circ} \mathrm{F}$. They noticed some solids precipitates and the amount of those solids depended on two conditions: temperature and mixing ratio. The composition of the solids was not identified in Javora et al. paper.

Svendsen et al. tested citric and acetic acids at a concentration of $10 \mathrm{wt} \%$ to remove filter cake damage that generated by formate based mud (Svendsen et al., 1995). They found the citric acid was better than acetic acid. The organic acids compatibility with formate brine solution was not studied in that paper.

Larsson and Nahringbauer presented a procedure to prepare a potassium hydrogen diformate in the lab by dissolving recrystallized potassium formate in formic acid during heating (Larsson and Nahringbauer, 1968). The salt crystals were found to be unsuitable for X-ray work. XRD and SEM analysis result in my research study shows the potassium hydrogen diformate was present when formic acid mixed with formate brine. Potassium hydrogen citrate, also, was noticed when citric acid was mixed with formate brine. More details about potassium hydrogen diformae and citrate will be shown in Chapter IV.

\subsection{Conventional Filter Cake Clean-up Techniques}

The clean-up of the formate drill-in fluid (DIF) filter cake that deposited in long horizontal sections is a permanent problem. Traditionally, cleaning up a reservoir filter cake has been accomplished with conventional chemical and mechanical means. The chemical means include formate brines (Hands et al., 1998), live mineral and organic 
acids (Huang et al., 2000), enzymes (McKay et al., 2000; Al Otaibi and Nasr-El-Din, 2005), chelating agents (Bradshaw et al., 2006), or a combination of formate brines and organic acids (Svendsen et al., 1995). The combination of high reservoir temperature and long shut-in times after acid treatment lead to a high probability of severe corrosion of the well completion. In addition to the corrosion concerns with common acids, the rapid removal of the filter cake with strong acids could create localized, high leak-off of the treating fluid resulting in an uneven distribution of acid across the horizontal open-hole section.

Different breakers were used to remove filter cake damage caused by formatebased DIF. The breakers were composed mainly of potassium formate mixed with different organic acids, including: $10 \mathrm{wt} \%$ citric acid and a dispersant, $10 \mathrm{wt} \%$ acetic acid, $10 \mathrm{wt} \%$ citric acid, and a proprietary breaker formulation. The highest removal efficiency was $90 \%$, which was attained by potassium formate brine mixed with $10 \%$ citric acid. The other three fluids gave insufficient removing efficiency, which was below 70\% (Svendsen et al., 1995).

Hands et al. compared the clean-up issues of oil-based mud and formate brine system. Mechanical (jetting) and chemical (acids) means were tested in the lab to assist with drilling fluid selection and mud cake clean-up. Another mud cake clean-up test was also mentioned by using drawdown pressure alone. In general, jetting techniques did not contribute much to the clean-up process compared to the drawdown test. The formate system gave better return permeability after drawdown than oil based mud. Acid and acid/solvent mixtures had been used to remove the mud filter cake for the two drilling 
fluid systems. Return permeability results were high for the formate brine systems compared to the oil based mud (Hands et al., 1999).

Hands et al. also utilized the sodium/potassium formate brines to remove the filter cake formed by sodium formate DIF, which included some calcium carbonate particles, xanthan and starch polymers. The formate brines blend (sodium/potassium) was used, without any solids additives, in a sandstone gas well. The well production rate was high and for that reason no acid stimulation job was recommended (Hands et al., 1998).

More than 40 core flood tests were conducted by Byrne et al. The conclusion from those tests was recommending using the formate DIF since it gave better return permeability results compared to conventional oil or water-based mud. Filter cake damage, by formate DIF, was cleaned by using $15 \mathrm{wt} \%$ acetic acid mixed with solidsfree formate brine. $15 \mathrm{wt} \%$ formic acid also was used, however it did not cause any matrix dissolution compared to $\mathrm{HCl}$ (Byrne et al., 2002).

The formate-based reservoir drilling fluid can be processed through normal solids-control equipment to remove the majority of bridging agent and drill solids. The processed fluid can be reused as a completion fluid during the completion phase, thus saving the additional cost from the operator for solids-free completion brine (Bungert et al., 2000).

In order to avoid using highly reactive acids, other fluids have been exploited such as enzymes to break down biopolymers in the cake to simple glucose units. McKay et al. reported a case history of clay inhibition in the reservoirs by using a low solids 
formate based mud system. Formate blend had been used as a drilling fluid instead of synthetic oil-based mud. A mixture of two enzymes systems was applied in this treatment to remove the filter cake and to enhance the cleanup/back production of filter cake through the oversized gravel. The enzyme breakers were incorporated within the gravel pack carrier fluid (a VES solution) in order to degrade the filter cake polymers (McKay et al., 2000).

Enzymes, however, have some limitations; for example they will only attack specific polymers chains, and the calcium carbonate components will not be removed (Battistel et al., 2005). Enzymes are also quickly denatured and lose their activity and might even represent a potential source of formation damage at high temperatures.

Chelating agent was used by Bradshaw et al. as a breaker to remove filter cake damage (Bradshaw et al., 2006). The sodium formate drilling fluid was displaced by using the same fluid but solids-free. Then, the open hole was displaced to the chelating agent breaker solution. The soaking time, for different wells, ranged from 15 to 110 days.

Oxidizers can be used to degrade the polymers in common water-based drilling fluid filter cakes. The oxidizers work by generating free radicals that attack the links between the polysaccharide components of the polymer. Attack can occur on the polymer backbone or a side chain. Typical polymeric components of water-based drilling fluid filter cakes that can be degraded by oxidizers are xanthan gum, scleroglucan, and starches. The effectiveness of oxidizers is limited by $\mathrm{pH}$ (practical $\mathrm{pH}$ range is 4 to 10). Oxidizer efficiency is also dependent on temperature (practical range 
of most is between 120 and $250^{\circ} \mathrm{F}$ ). Below $130^{\circ} \mathrm{F}$, oxidizer effectiveness drops dramatically below $\mathrm{pH}$ 8. Most of the common oxidizers, also, are not compatible with formate brines as shown in Table 1 (Schlumberger, 2007).

Complete removal of filter cake in long horizontal wellbore by using conventional breakers might be difficult. Reaction rate is the most effective factor in controlling the distribution of the cleaning fluid in the horizontal leg. Acids as an example will react with calcium carbonate very rapidly at downhole condition. Therefore, rapid consumption of calcium carbonate is likely at the point at which acid is introduced to the wellbore. This can lead to localized clean up, excessive local losses and inability to circulate acid to the rest of the wellbore section (Buijse et al., 2004).

Esters had been introduced lately to solve the fluid distribution and corrosion concern which are usually encountered with others conventional breakers (Moses and Harris, 2004). The action of the ester in the clean-up fluid is delayed, i.e., the ester does not dissociate by hydrolysis to produce organic acid and alcohol until after the clean-up fluid has been placed in the wellbore. The reaction products will be generated as solution temperature increased. The ester reaction kinetics and filter cake clean-up by using two different esters were discussed in previous publications (Al Otaibi et al., 2006; Nasr-ElDin et al., 2005).

Lactic, formic and acetic acids had been tested in detail at high temperatures. Formic and lactic acids showed excellent results, within short soaking time, in removing the damage. Ethyl-lactate ester has been included only in this research study for mainly two reasons. First, the generated lactic acid has strength similar to that of formic acid 
and both have dissociation constants that are about 10 times greater than that of acetic acid (Leschi et al., 2006). Secondly, the lactate ester hydrolysis reaction to lactic acid depends on the temperature and also the acid concentration increases gradually with time (Al Moajil et al., 2007). Formate ester generates formic acid immediately and it is independent of the reaction time.

Table 1: Compatibilities of the most common oxidizers with formate brines

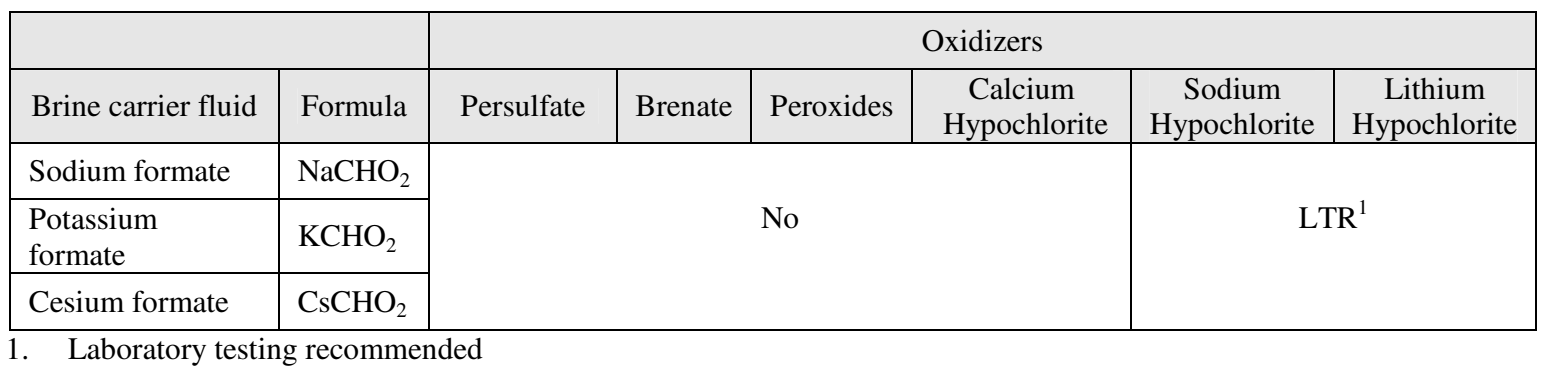

\subsection{Objectives}

The main objectives of my thesis are to: (1) Study the compatibility of potassium formate brine with formation brine, organic acids, esters, and other cleaning fluids, (2) Evaluate the ability of different organic acids to remove filter cake damage, (3) Study the removing efficiency of lactic acid precursor, at different concentrations, on filter cake, and (4) Compare the mechanical technique by using potassium formate brine at dynamic condition with other chemical means. 


\section{CHAPTER II}

\section{EXPERIMENTAL STUDIES}

\subsection{Materials}

Field DIF samples were used in all lab experiments. Those samples were obtained from a gas field in Saudi Arabia. The type of the drilling fluid used is a potassium formatepolymer system. The composition and properties of a lab drilling fluid sample that had been recommended for field $\mathrm{J}$ are given in Table 2 . The properties of the field drilling fluid sample were also measured in the lab as shown in Table 3. Solids-free potassium formate brine was utilized to remove the filter cake mechanically. Acid precursor solutions and organic acids were used to dissolve the calcium carbonate particles present in the filter cake.

Table 2: Formulation and properties of formate drilling fluid, lab sample

\begin{tabular}{|l|c|c|l|c|c|}
\hline Material & Quantity (per bbl) & Units & Property & Value & Units \\
\hline Fresh water & $0.277-0.299$ & $\mathrm{bbl}$ & Density & $80-90$ & $\mathrm{Ib} / \mathrm{ft}^{3}$ \\
\hline $\begin{array}{l}\text { Potassium formate (98 } \\
\text { pcf) }\end{array}$ & $0.423-0.701$ & $\mathrm{bbl}$ & $\mathrm{pH}$ & $10.5-11$ & - \\
\hline Defoamer & 0.01 & $\mathrm{gal}$ & Plastic Viscosity & $16-22$ & $\mathrm{cp}$ \\
\hline XC-polymer & $0.5-1$ & $\mathrm{Ib}$ & Yield Point & $18-25$ & $\mathrm{lb} / 100 \mathrm{ft}^{2}$ \\
\hline PAC-Regular & $0.5-2$ & $\mathrm{bbl}$ & 10 sec. gel & $5-7$ & $\mathrm{lb} / 100 \mathrm{ft}^{2}$ \\
\hline PAC-Low Viscosity & $2-3$ & $\mathrm{Ib}$ & 10 min. gel & $6-10$ & $\mathrm{lb} / 100 \mathrm{ft}^{2}$ \\
\hline Soda Ash & $0.5-1$ & $\mathrm{Ib}$ & HPHT Filtrate, $300-325^{\circ} \mathrm{F} / 500 \mathrm{psi}$ & $16-18$ & $\mathrm{~cm}^{3} / 30 \mathrm{~min}$ \\
\hline Sodium bicarbonate & $0.2-0.5$ & $\mathrm{Ib}$ & HPHT Filter Cake Thickness & $1-2$ & $33^{\text {nd }} \mathrm{in.}$ \\
\hline $\mathrm{CaCO}_{3}$ fine & 10 & $\mathrm{Ib}$ & Total Solids & $5-8$ & $\mathrm{vol} \%$ \\
\hline $\mathrm{CaCO}_{3}$ medium & 10 & $\mathrm{Ib}$ & Iron Content & $<1.5$ & $\mathrm{mg} / 1$ \\
\hline
\end{tabular}


Table 3: Properties of formate-based drilling fluid, field sample

\begin{tabular}{|l|c|c|}
\hline \multicolumn{1}{|c|}{ Property } & Value & Units \\
\hline Density & 92.6 & $\mathrm{Ib}_{\mathrm{ft}^{3}}$ \\
\hline $\mathrm{pH}$ & 10.39 & - \\
\hline Plastic Viscosity & 17 & $\mathrm{cp}$ \\
\hline Yield Point & 14 & $1 \mathrm{~b} / 100 \mathrm{ft}^{2}$ \\
\hline 10 sec. gel & 3 & $1 \mathrm{~b} / 100 \mathrm{ft}^{2}$ \\
\hline 10 min. gel & 4 & $1 \mathrm{~b} / 100 \mathrm{ft}^{2}$ \\
\hline HPHT Filtrate, $300^{\circ} \mathrm{F} / 500 \mathrm{psi}$ & 17 & $\mathrm{~cm}^{3} / 30 \mathrm{~min}$ \\
\hline HPHT Filter Cake Thickness & 2 & $33^{\text {nd }}$ in. \\
\hline
\end{tabular}

\subsection{Analytical Techniques}

Solids present in the filter cake, returned cleaning solution, and mixed fluids were separated, dried and then examined using XRD, XRF and ESEM techniques. The density of various solutions at various temperatures up to $158^{\circ} \mathrm{F}$ and 14.69 psi was measured using a Paar densitometer model DMA-35. Extrapolation was used in obtaining the cleaning fluids density at higher temperatures. The $\mathrm{pH}$ of all solutions examined was measured using an Orion model 250A meter and Cole Parmer Ag/AgCl single junction pH electrode.

\subsection{HPHT Visual Cell}

High pressure high temperature (HPHT) visual cell is used commonly to test the fluids compatibility at reservoir conditions. The loaded sample can be seen through a glass window to observe any chemical reaction or any solids precipitates at high temperatures, Figure 1. 


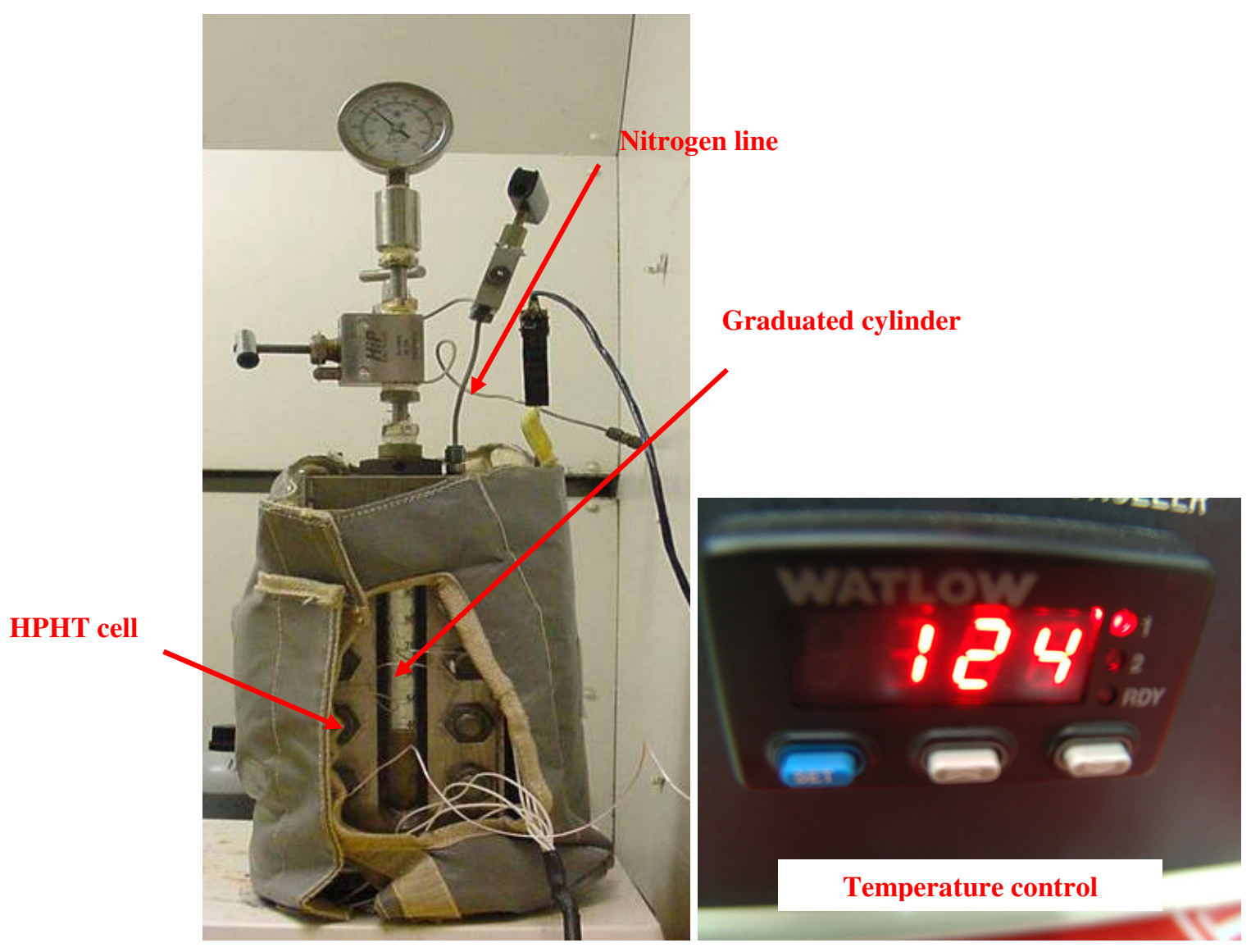

Figure 1: HPHT visual cell with automotive temperature control

The steps that are usually followed to load a liquid sample in HPHT visual cell are:

- Use a clean graduated cylinder (100 ml).

- Load the sample in the visual cell and connect the pressure line.

- Apply a pressure by using $\mathrm{N}_{2}$ (usually from 200 to $300 \mathrm{psi}$ ) to avoid any liquid vaporization at high temperature.

- Adjust the cell temperature by using an automotive temperature control and usually it heats up quickly.

- Record any observations (reaction, precipitates...etc) during the soaking time. 


\subsection{Dynamic HPHT Filter Press Cell}

The Dynamic high pressure high temperature (HPHT) filter press measures filtration properties under varying dynamic down hole conditions, Figure 2. A motor driven shaft fitted with propellers turns at varying speeds inside a standard $500 \mathrm{ml} \mathrm{HPHT}$ cell. RPM settings from 1 to $1,600 \mathrm{rpm}$ impart laminar or turbulent flow to the fluid inside the cell, and by varying the shaft length, the shear stress may be increased or decreased. The power is driven to the stirring shaft by a timing belt that is easily accessible for quick adjustment and removal. Other features include a variable speed motor controlled through an SCR controller with RPM's indicated on a digital tachometer. The test procedure is exactly the same as that in the conventional static HPHT filtration test. The only difference is the fluid is circulating inside the cell, while filtrate is being collected. Two interchangeable bottom caps for the cell are provided to accommodate quarter inch thick ceramic or sandstone disks, standard screens as well as conventional filter paper, sintered metal or similar thin materials (OFI Testing Equipment, 2007). Detailed experimental procedure will be discussed in the next section. 


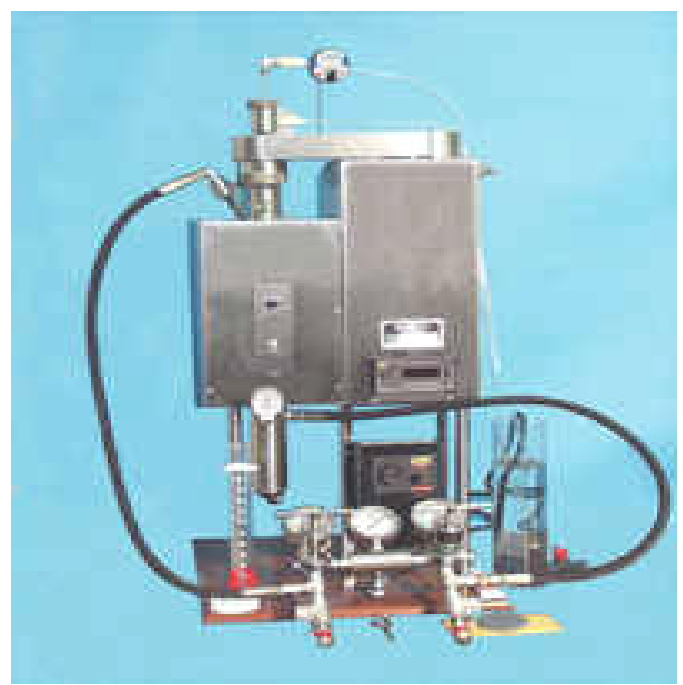

Figure 2: Dynamic HTHP filter press

\subsection{Experimental Procedure for Dynamic HPHT Filter Press}

1. To prepare for running a test, the cell is removed from the heating jacket. To do this, loosen the belt tensioning screw at the top of the right side of the motor housing. Loosen the two screws holding the motor clamp and support plate. These screws are on the side of the belt guard in the top of the motor housing cover about 7/8 inches from the edge. Open the belt guard and remove the belt. Disconnect the two water line tubes at the top of the shaft. These lines are for circulating water inside the shaft in order to keep the packing gland at a workable temperature level.

2. Lift the cell out of the heating well. Remove the top packing gland cap and shaft by loosening the set screws enough for the cap to slip out of the cell body.

3. Begin pre-heating the heating jacket to the desired temperature by plugging in the power cord and turning the thermostat to about mid-scale. When the heating jacket is turned off, the thermostat is turned fully counter clockwise and the pilot light will be 
on. Place a thermometer in the heating well. The pilot light will turn on when the heating well reaches the temperature for which the thermostat is set.

4. Remove the outlet or bottom cell cap. Inspect and replace where necessary all ORings on the cell, cell cap and valve stems. Apply "Never Seez" to all O-Rings as additional protection from the temperature. Invert the cell with the outlet end up and place an O-ring in the cell body O-Ring groove. On top of this place the appropriate filter medium.

Note A: To prepare ceramic or sandstone discs for filtration, the disc must first be soaked for at least 10 minutes in the base fluid (water or oil, etc.), otherwise the disc will seal up excessively when pressure is initially applied to the cell.

Note B: When filter paper is used above $400^{\circ} \mathrm{F}$ a stainless steel, Dynalloy filter disk should be used instead of paper filters.

5. Re-install the appropriate cell cap. Tighten the set screws and be sure they are fully seated into the cap detents.

6. Tighten (to close) the bottom or outlet valve stem.

7. Set the cell upright with the filter end down, and fill with fluid from the top. Allow at least 2.5 inches of space from the top of the fluid to the O-Ring groove in order to leave room for heat expansion of the fluid and for the shaft displacement of fluid.

8. Install the propeller on the end of the shaft. It fits over the shaft and is locked in place with a set screw. Be sure to seat the set screw on the flat spot at the end of the shaft. Optional shaft extenders adjust the distance from the filter medium and therefore alters the shear rate. The extenders allow for $1 / 2$ inch adjustments in the 
distance between the propeller and the filter medium up to $11 / 2 \mathrm{inch}$. Also a four blade propeller is available as an optional item.

9. After making sure all inlet O-Rings are installed, greased with "Never Seez" and are in good condition, re-install the gland cap on the top of the cell. Above $300^{\circ} \mathrm{F}$ the $\mathrm{O}$ Rings should be replaced after each test. Fully tighten the set screws in the detents after the proper alignment is determined.

10. Place the cell in the heating jacket which has been preheating. The cell should drop down over the locator pin in the bottom of the heating well. The cell pressure inlet valve stem will be facing away from the motor housing in order to facilitate fastening the pressure manifold to the stem.

11. The inlet and outlet valve stem should be tightly closed. Attach the high pressure line (with 1,500 psi gauge) from the nitrogen manifold to the inlet valve stem. Completely insert the locking pin, and close the bleeder valve on the manifold block. Follow the same procedure with the low pressure line and connect it to the back pressure receiver.

12. Check the T-Screws on the pressure regulators to be sure they are unscrewed (counter-clockwise) and that no pressure is being applied to the system.

13. Open the nitrogen bottle valve and note the bottle pressure as registered on the middle manifold gauge.

14. For filtration tests above $212^{\circ} \mathrm{F}$ the sample must be tested under pressure.

15. Close the drain valve on the receiver. This valve is also used as the bleeder valve. With a crescent wrench, open the outlet valve stem $1 / 2$ turn, which will pressurize 
the receiver. Open the inlet valve stem to apply the same amount of pressure to the fluid inside the cell.

16. Transfer the thermometer from the heating well to the thermometer well in the cell. The time required to heat the sample to test temperature will vary from 30 minutes to one hour depending on the test temperature, but it should never exceed one hour.

Caution: When the closed cell is heating in the jacket, the pressure in the cell will rise rapidly due to the thermal expansion of the sample. This should be carefully monitored during the heating phase.

17. Replace the belt over the sheaves and tighten the belt tension just enough to prevent slippage. The tightening screw which is attached to the motor support is a two piece screw which allows for locking the screw to the housing at the proper tension. Also tighten the two motor support clamping screws in the top of the motor housing in from of the belt guard. Loosen these and then re-tighten, if adjustments must be made in the belt tension.

18. Attach the water lines to the swivel at the top of the shaft. The inlet line in the center of the cap should be connected to a cold water source with the $1 / 8$ inch connector, $1 / 4$ inch plastic hose and fittings provided. The drain line from the center of the swivel body can be run into any convenient drain. Experience will determine the amount of water flow necessary for proper cooling. Do not operate the mixer shaft with the O-Rings in the swivel Dry. The water keeps these O-Rings lubricated and also reduces the load on the motor. If no cooling water is to be used, the swivel body can be removed from the shaft by removing the top retaining ring. 
19. Set the mixing speed to the desired value between 100 and $1,600 \mathrm{rpm}$ using the speed control knob on the motor control.

\subsection{HPHT Pendant Drop Instrument}

Surface tension of fresh solutions was measured using a high pressure/high temperature pendant drop instrument model PD-E700LL-H manufactured by Eurotechnica Ingenieurbüro $\mathrm{GmbH}$, Germany. The image analysis module of the instrument was a Krüss model DSA10-MK2L. The wetted surfaces of the instrument (the cell and needle) were constructed from Hastelloy-C, which can resist corrosion at high temperatures.

Surface tension measurements were carried out by generating a pendant drop at the end of a capillary tube $(\mathrm{OD}=1.575 \mathrm{~mm})$ in compressed nitrogen gas. An image of the drop was recorded using a digital camera (Teli CCD Camera CS8420C-02) and the drop shape was digitized. Surface tension was measured for the solution as a function of temperature. All surface tension measurements were conducted at a pressure of $72 \mathrm{psi}$.

\subsection{Experimental Procedure for HPHT Pendant Drop}

1. Fill tank A with liquid while valve "A" closed, Figure 3.

2. Back off the pressure generator (PG1), to fill the (PG1), while " $\mathrm{A}$ " is open.

3. Close valve "A", closed (PG1), however "D" closed and "C" open.

4. Keep turning (PG1) until only liquid comes out from the capillary without air, then close "C".

5. Heat the system to the test temperature, maximum temperature that can be reached is $390^{\circ} \mathrm{F}$. 
6. Open "C", and rotate "PG1", until liquid comes out from the capillary.

7. Open "E", apply $\mathrm{N}_{2}$ (50-100 psi) from line "B", (for $\sim 3$ minutes).

8. Close "E", open "F", back off (PG2) up to the middle, then let some Nitrogen vent through $\mathrm{T} 2$ by opening " $\mathrm{G}$ ".

9. Close "G" and apply pressure through "B" until the test pressure.

10. When you opening " $\mathrm{C}$ " rotate (PG1), until few drop coning from the capillary ( 5 drops), then start taking the reading.

11. Repeat (9), when ever pressure needs to be change.

12. If condensate start formed on the glass window closed "F" and let the system vent through "E" slowly, "E" has to be open.

13. To increase the pressure higher than the Nitrogen coming from the supply, use (PG2) to increase the pressure, " $F$ " is open.

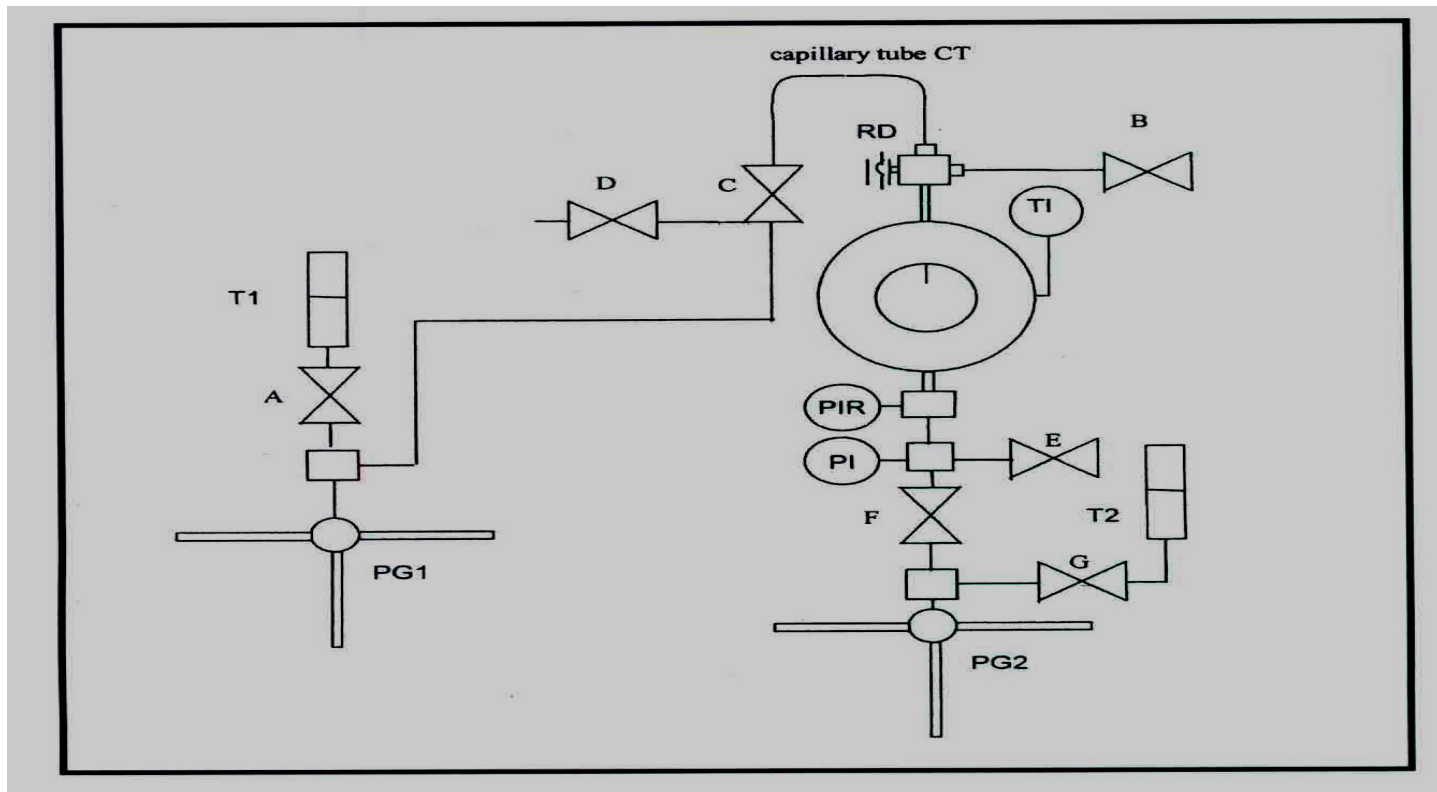

Figure 3: Flow sheet of PD-E700LL-H 


\section{CHAPTER III}

\section{FLUIDS COMPATIBILITY}

\subsection{Drilling Fluid Filtrate (DFF)}

\subsubsection{DFF Mixed with Ethyl Lactate Ester at Room Temperature}

The HPHT filter press instrument was utilized to filter the liquid part (filtrate) from the formate based drilling fluid and make it a solids-free fluid. The objective behind this step was to simulate the actual field operation since the liquid phase only entered the formation while most of the solids were retained on the filter cake layer. At the beginning, ethyl lactate ester was selected because it showed a great dissolving efficiency in removing filter cake damage that was initiated by another water-based mud system (Al Otaibi et al., 2006; Nasr-El-Din et al., 2005). A 10 vol.\% of ethyl lactate ester solution was mixed with drilling fluid filtrate at a ratio of 50:50 and at room temperature, Figure 4. The viscosity of the filtrate solution was dropped after mixing with the ester, and no precipitate was noticed for 24 hours. The ratio was changed in the second test to be 30:70, between drilling fluid filtrate and the ester solution, Figure 4 . The same behavior was noticed, and for that reason no further tests were performed. Filtrate of drilling fluid was expected to compose of potassium formate brine, polyanionic cellulose (PAC), XC-polymer and calcium carbonate particles. The ester solution, however, will not decompose to alcohol and lactic acid at room temperature. 


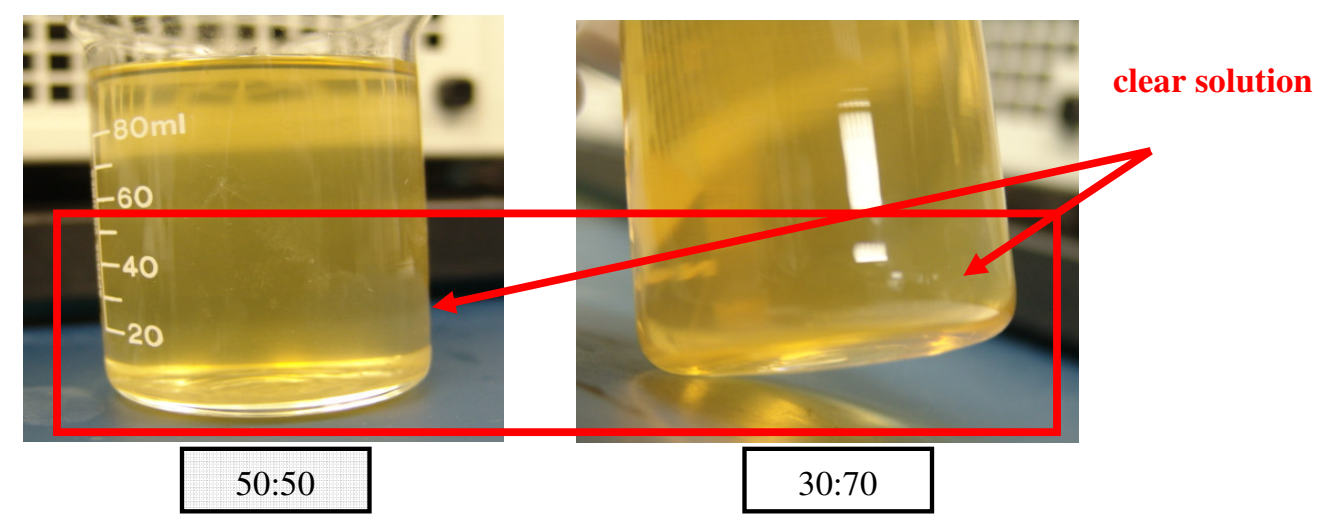

Figure 4: Compatibility of DFF with lactate ester at room temperature

\subsubsection{DFF Mixed with Ethyl Lactate Ester at $300^{\circ} \mathrm{F}$}

The same samples in Figure 4 were loaded in the HPHT cell to examine their behavior at reservoir temperature, $300^{\circ} \mathrm{F}$. The samples were left for one day in the cell, and no precipitate or phase separation was observed as shown in Figure 5. The generated alcohol and lactic acid at high temperatures did not cause any precipitate with drilling fluid filtrate. The mixing process should be done gradually while increasing the solution temperature but it is too difficult to maintain that without applying a pressure to avoid any vaporization. The viscosity of the solution was clearly dropped compared to the room temperature sample. 


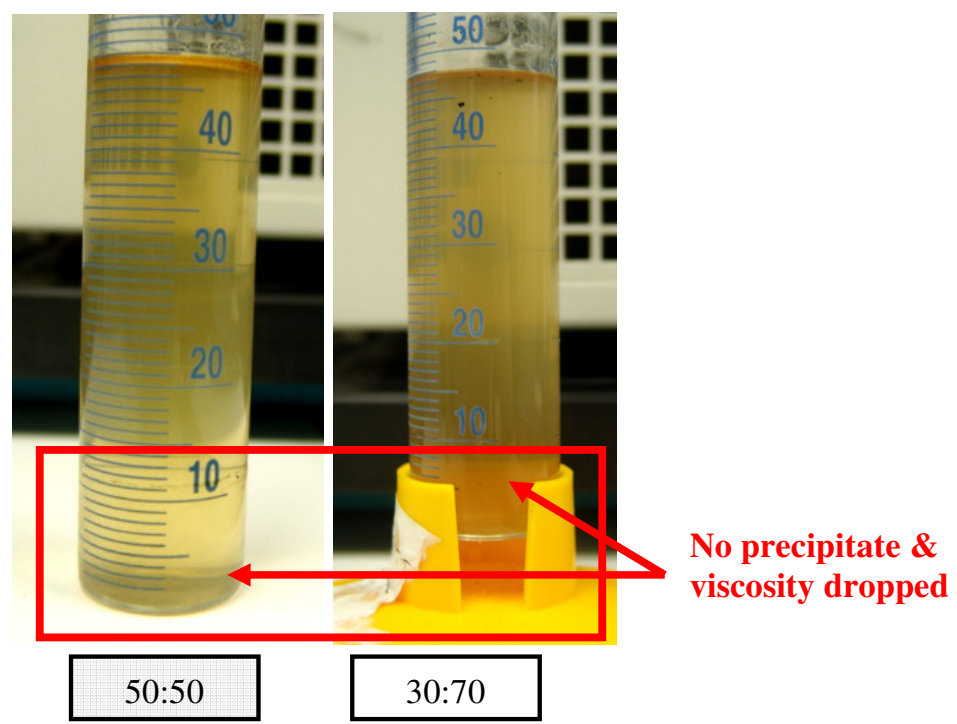

Figure 5: Compatibility of DFF with lactate ester at $300^{\circ} \mathrm{F}$

\subsubsection{DFF Mixed with Formation Brine at Room Temperature}

Formation brine recipe of Unyazah reservoir (gas reservoir) was requested from the field engineer and then a synthetic brine sample was prepared in the lab at room temperature, Table 4. Drilling fluid filtrate was mixed with the formation brine at five different mixing ratios and at room temperature. Table 5 shows the five mixing ratios that were used and the observation at room temperature. All five solutions showed a solid precipitate, and a phase separation after 30 minutes of the mixing time as shown in Figure 6. The tests at higher temperatures were cancelled because all samples were precipitated and also separated at room temperature. 
Table 4: Unyazah formation brine composition and ions concentration

\begin{tabular}{|l|c|}
\hline Compound & Concentration, g/l \\
\hline $\mathrm{NaCl}$ & 142.57 \\
\hline $\mathrm{CaCl}_{2} \cdot 2 \mathrm{H}_{2} \mathrm{O}$ & 76.759 \\
\hline $\mathrm{MgCl}_{2} \cdot 6 \mathrm{H}_{2} \mathrm{O}$ & 9.8259 \\
\hline $\mathrm{Na}_{2} \mathrm{SO}_{4}$ & 0.1479 \\
\hline $\mathrm{NaHCO}_{3}$ & 0.7889 \\
\hline
\end{tabular}

\begin{tabular}{|c|c|c|c|c|c|c|c|c|c|}
\hline \multicolumn{8}{|c|}{ Ions, mg/l } & \multirow{2}{*}{$\mathrm{pH}$} & \multirow{2}{*}{ Density, $\mathrm{lb} / \mathrm{ft}^{3}$} \\
\hline $\mathrm{Na}$ & $\mathrm{Ca}$ & $\mathrm{Mg}$ & $\mathrm{SO}_{4}$ & $\mathrm{Cl}$ & $\mathrm{CO}_{3}$ & $\mathrm{HCO}_{3}$ & TDS & & \\
\hline 56,356 & 20,926 & 1,175 & 100 & 126,935 & 0 & 573 & 206,065 & 6.031 & 70.86 \\
\hline
\end{tabular}

Table 5: Five mixing ratios used at room and high temperatures

\begin{tabular}{|c|c|c|c|c|c|}
\hline & \multicolumn{5}{|c|}{ Drilling fluid filtrate : formation brine } \\
\hline Mixing ratio & $10: 90$ & $30: 70$ & $50: 50$ & $70: 30$ & $90: 10$ \\
\hline Observation & \multicolumn{5}{|c|}{ Phase separation and different amounts of solid precipitate } \\
\hline
\end{tabular}

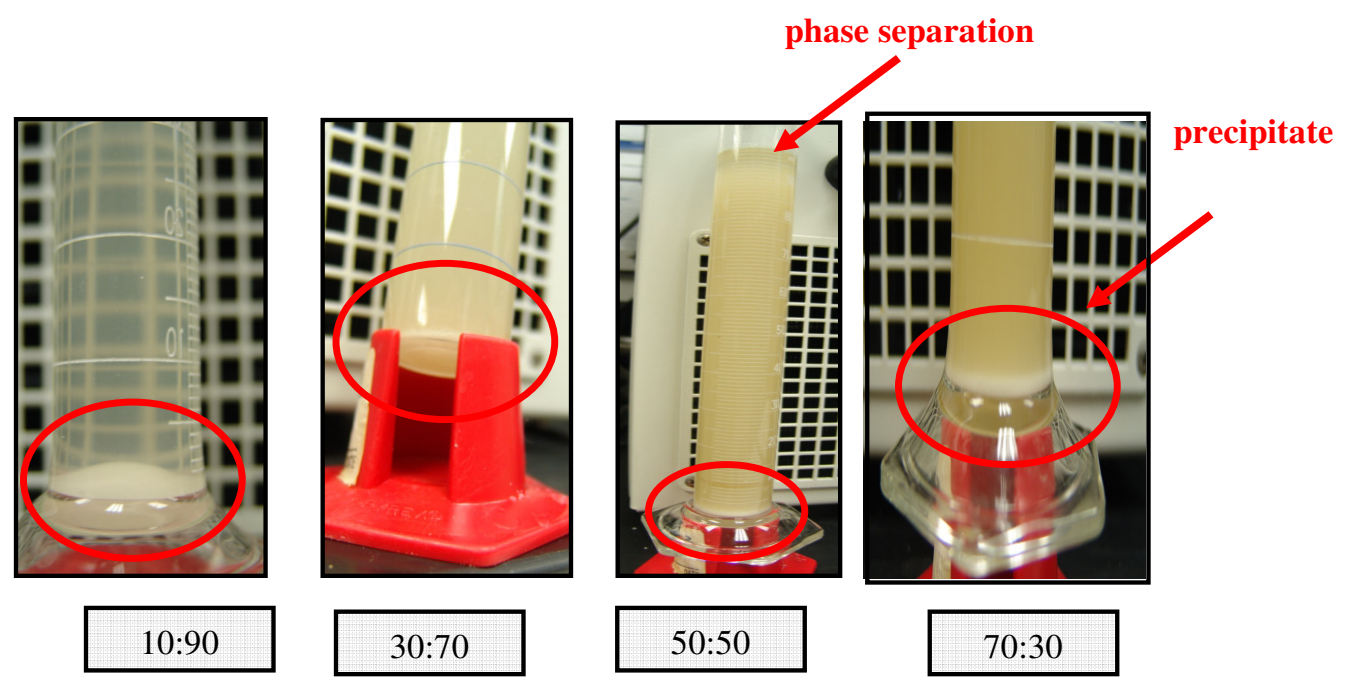

Figure 6: Compatibility of DFF with formation brine at room temperature 


\subsection{Solids-free Potassium Formate Brine (PFB)}

\subsubsection{PFB Mixed with Unyazah Formation Brine (UFB) at Room Temperature}

The used potassium formate brine (PFB) in all experiments was received from the field, and the $\mathrm{pH}$ and the density were measured at room temperature and equal to 8.05 and 95.83 pcf, respectively. Compatibility tests between PFB and UFB were tried first at room temperature and five different mixing ratios. The resulted solid precipitates in all new solutions were filtered by using filter paper size of $1.2 \mu \mathrm{m}$. The largest amount of precipitate was noticed at ratio of 50:50 between PFB and UFB. The weight of the precipitate as a function of mixing ratio is shown in Figure 7. The solid precipitate for the first sample (10:90) was almost negligible $(0.11 \mathrm{~g})$. All mixtures were cloudy during and after the mixing, and clear precipitate was also noticed for all samples except the one at 10:90.

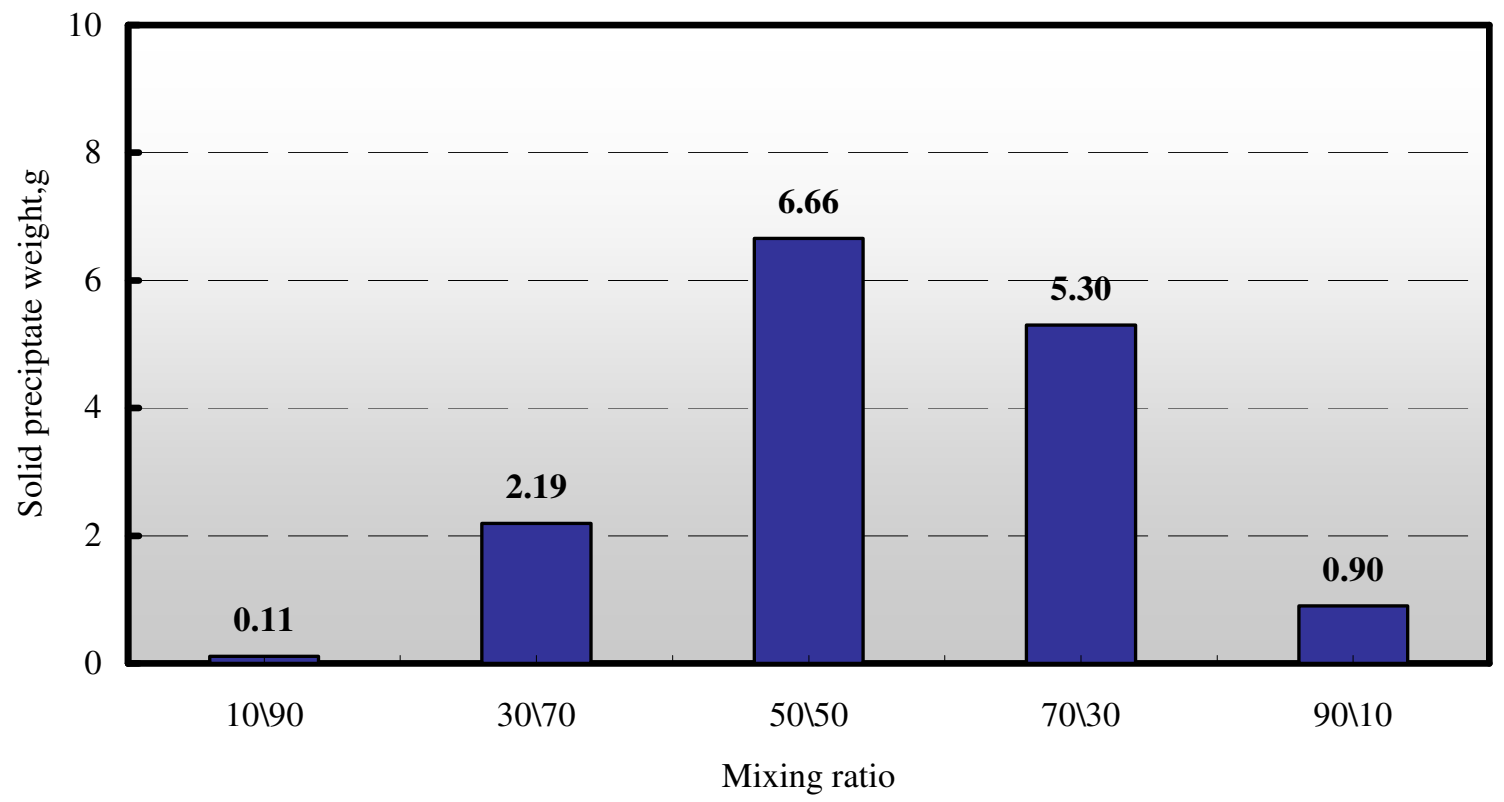

Figure 7: Compatibility tests between PFB and UFB at room temperature 


\subsubsection{PFB Mixed with UFB at Temperatures $113-127^{\circ} \mathrm{F}$}

Some authors discussed the solid precipitate concern while mixing PFB with formation brine, and they said the precipitate was only noticed at room temperature and not at reservoir conditions (Downs et al., 2005; Byrne et al., 2002). Based on that, a new set of compatibility tests between PFB and UFB were conducted but at higher temperatures. A hot plate was utilized to heat up the UFB in a glass beaker and then PFB was added slowly to it. The temperature ranges were between 113 and $127^{\circ} \mathrm{F}$ before and during the mixing. A magnetic stirrer was used for agitation and a temperature thermometer was used for measuring the temperature manually.

Five different mixing ratios were used as done in the previous step. As noticed in room temperature tests, the largest solid precipitates were observed after mixing PFB with UFB at ratio 50:50, Figure 8.

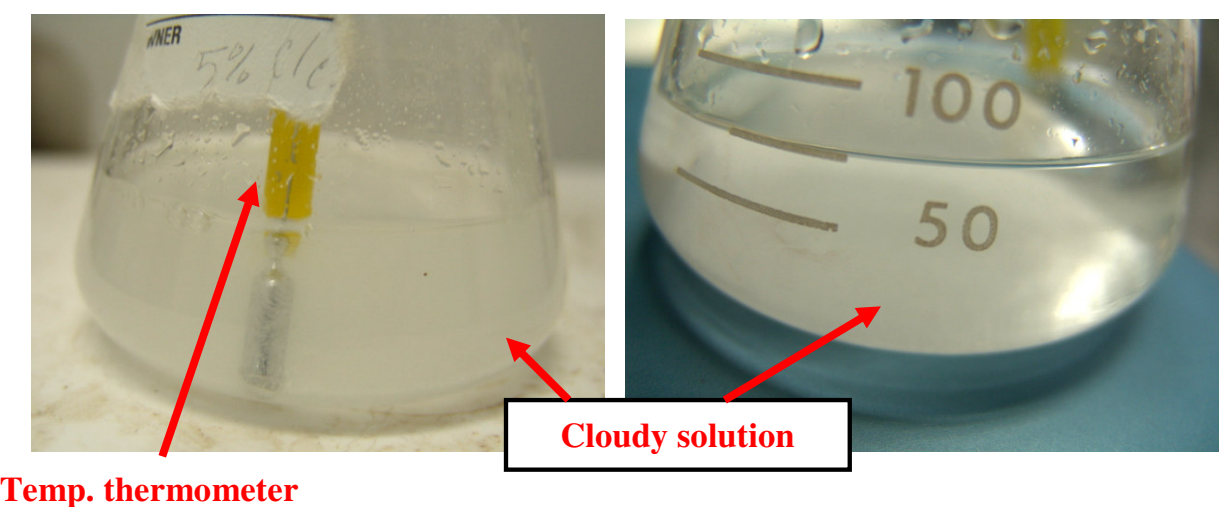

Figure 8: Compatibility of PFB with UFB at ratio of 50:50 
The amount of solids precipitates was decreased as the fluid ratio changed to $70: 30$ as shown in Figure 9. During the mixing of the solution, the temperature range was between 113 and $122^{\circ} \mathrm{F}$.

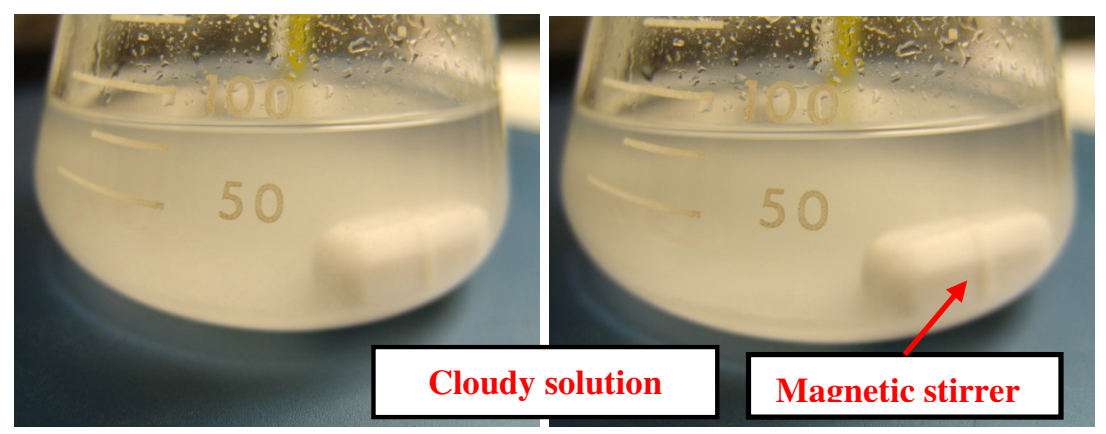

Figure 9: Compatibility of PFB with UFB at ratio of 70:30

Fewer amounts of precipitates were noticed as the fluid ratios of PFB and UFB changed to $30: 70$ and 90:10, Figure 10 . The temperature range for the 30:70 test was $113-118^{\circ} \mathrm{F}$. It was difficult to maintain the same temperature degree for all tests because the hot plate temperature in the lab was affected by the air condition. The solution temperature was also affected by PFB temperature before added to the UFB solution. In the second test (90:10), the temperature range was between 113 and $127^{\circ} \mathrm{F}$.
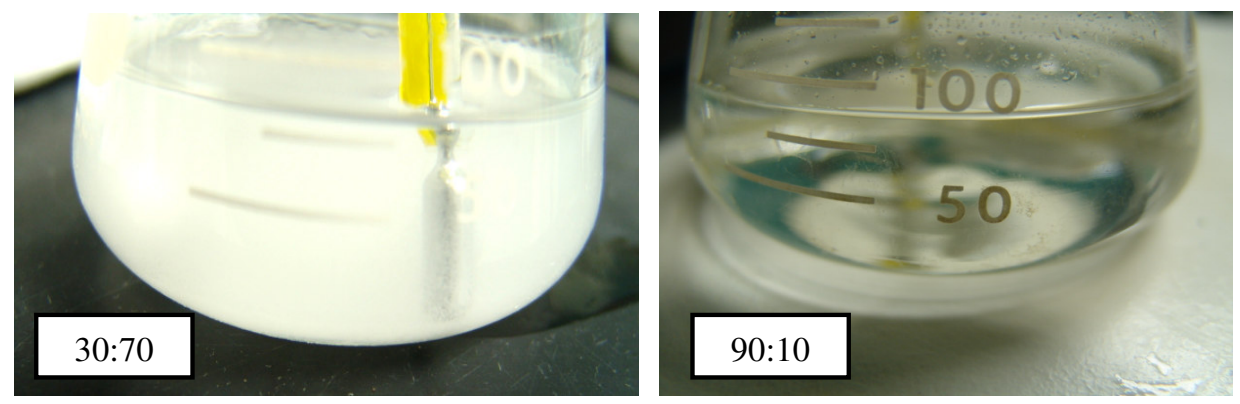

Figure 10: Compatibility of PFB with UFB at ratios of 30:70 and 90:10 
In the last mixture, PFB was decreased to $10 \mathrm{ml}$ while the volume of UFB was increased to $90 \mathrm{ml}$. The result was a clear solution and no precipitates had been noticed during and after the mixing, Figure 11.

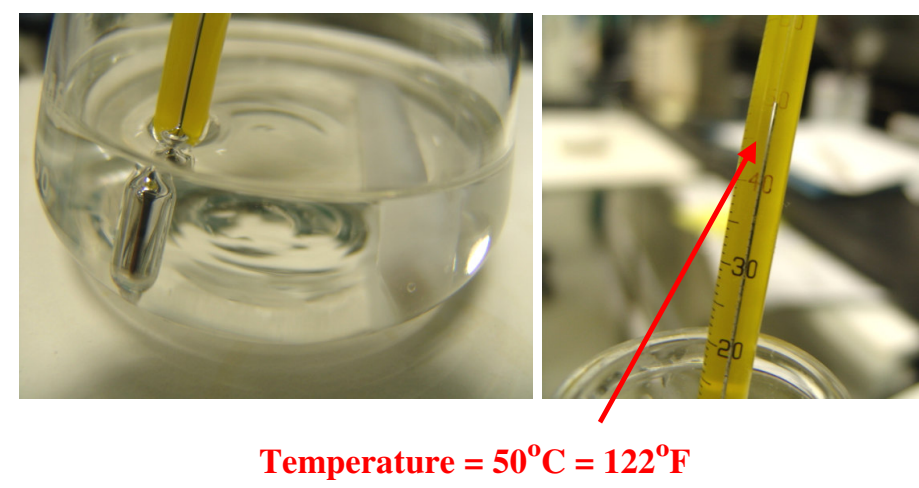

Figure 11: Compatibility of PFB with UFB at ratio of 10:90

Figure 12 shows the weight of the solids which were precipitated as a result of mixing PFB with UFB at a wide temperature range $\left(113-127^{\circ} \mathrm{F}\right)$. The solid precipitates at room temperature are greater than what was observed at temperatures 113 to $127^{\circ} \mathrm{F}$ except at one ratio (10:90), Figure 13. The small amount of precipitate that was noticed for the 10:90 mixture at both conditions was almost negligible and may be due to the contamination of the glass beaker and filtration kit. For that reason, it will not considered in the following comparison. As temperature increased, more salt will be dissolved in the solution and that confirms the compatibility results at room and high temperatures. 


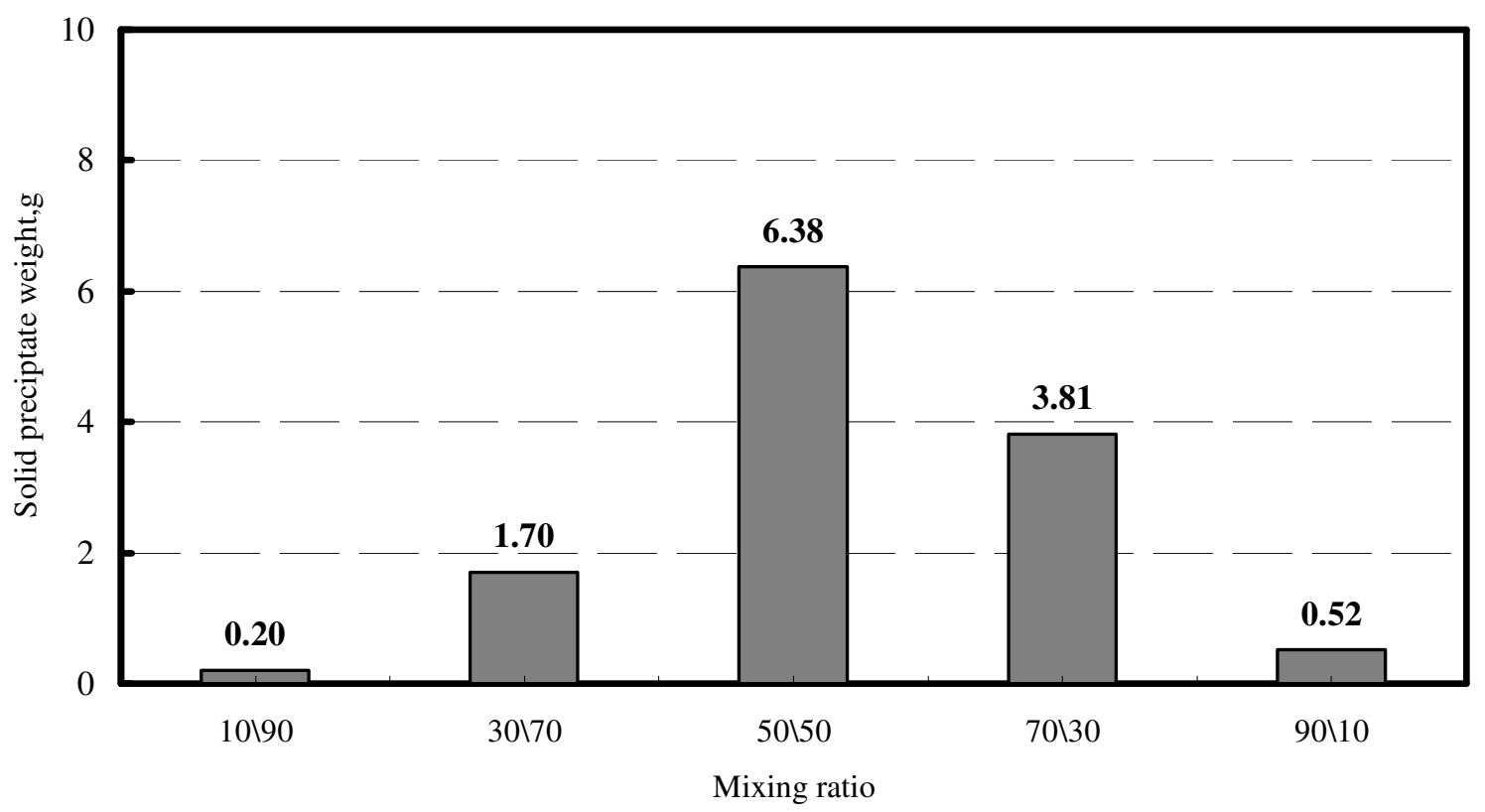

Figure 12: Compatibility tests between PFB and UFB at temperature range of $113-127^{\circ} \mathrm{F}$

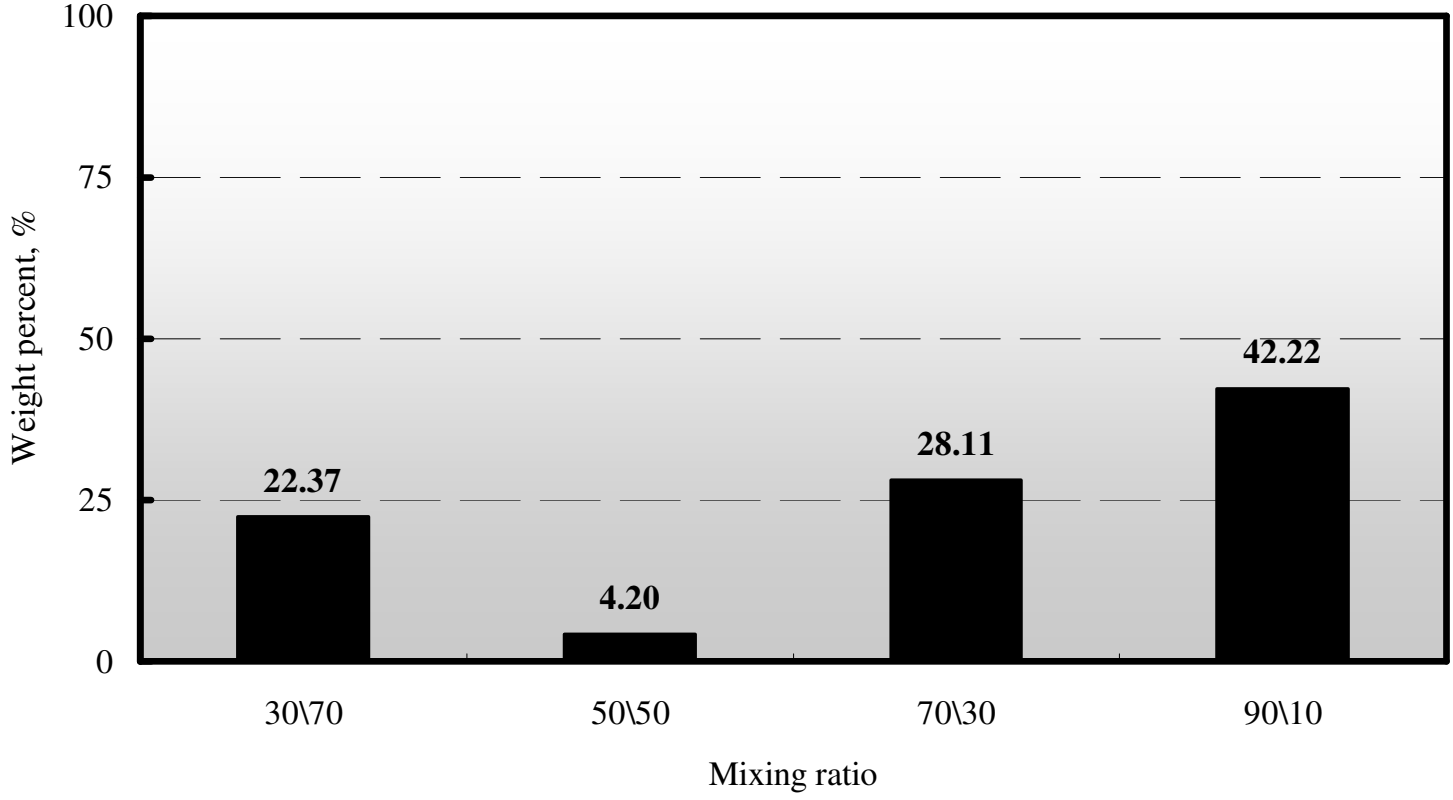

Figure 13: The weight difference of the solid precipitate at room and higher temperatures 


\subsubsection{PFB Mixed with UFB at Temperatures $273-297^{\circ} \mathrm{F}$}

At reservoir temperature, it was difficult to conduct the test without applying enough pressure to avoid any fluid vaporization. For that reason, a new set of mixtures were prepared at temperatures $122-140^{\circ} \mathrm{F}$ and were reused at higher temperatures. They were loaded immediately in HPHT visual cell at temperatures $273-297^{\circ} \mathrm{F}$ and pressure 250 300 psi. All samples were left in the cell for 21.5-23 hours.

The first sample (50:50) was mixed at $122^{\circ} \mathrm{F}$ and at atmospheric pressure as done in previous tests. The mixture was then loaded in the HPHT cell at temperature of $289^{\circ} \mathrm{F}$ and pressure of 300 psi, Figure 14. The cell was disconnected after 21.7 hours and the temperature was reduced to room temperature using the control button. A solid precipitate was noticed in the mixture before loading the sample. Decreasing the solution temperature caused more precipitations to settle down. The solution at high temperature was supersaturated and it precipitated as the temperature decreased.

The next sample is $70: 30 \mathrm{PFB} / \mathrm{UFB}$ solution that was prepared first at $138^{\circ} \mathrm{F}$ and it was cloudy and had some precipitate. Then, the sample was loaded directly in HPHT cell at $286^{\circ} \mathrm{F}$ and $250 \mathrm{psi}$. The cell was disconnected to remove the sample after 23 hours of soaking, Figure 14.

More solids precipitates were noticed as the ratio changed to 30:70 of PFB/UFB. The sample was first prepared at $140^{\circ} \mathrm{F}$ and then loaded in HPHT cell at $273^{\circ} \mathrm{F}$ for 21.3 hours, Figure 15. 

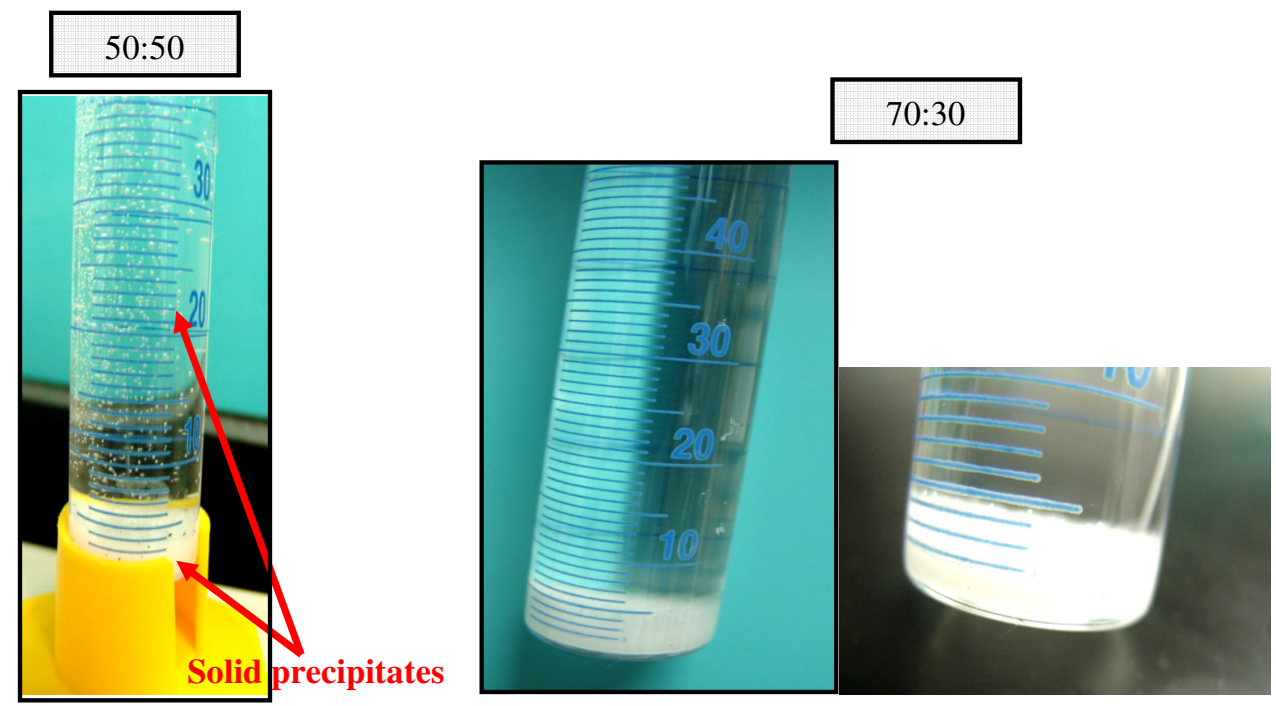

Figure 14: Compatibility of PFB with UFB at two different ratios
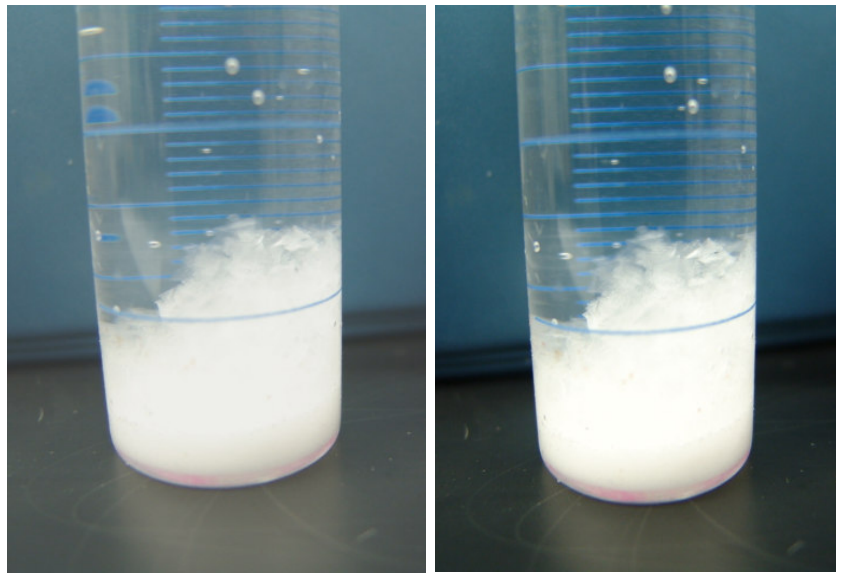

Figure 15: Compatibility of PFB with UFB at ratio of 30:70 
Less amount of solid precipitate was observed in the 90:10 PFB/UFB mixture. The sample was prepared at $133^{\circ} \mathrm{F}$ before loading in the $\mathrm{HPHT}$ cell at $289^{\circ} \mathrm{F}$. The cell was disconnected and the sample had some precipitate as shown in Figure 16.
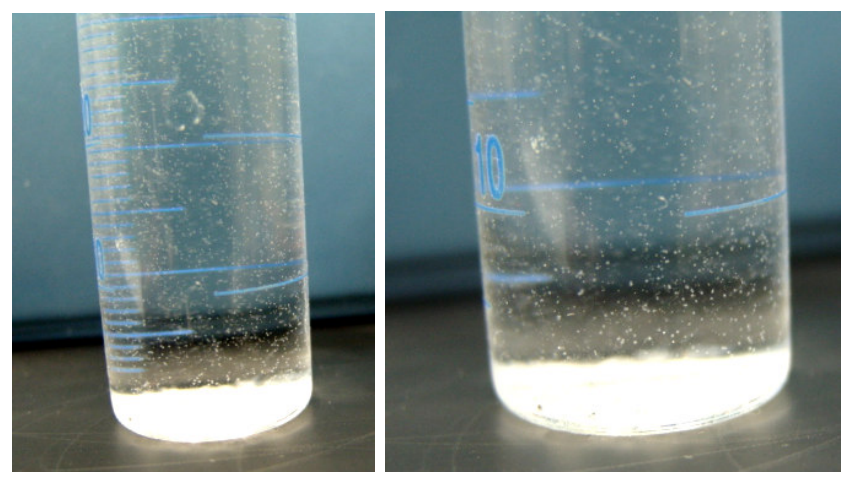

Figure 16: Compatibility of PFB with UFB at ratio of 90:10

The weight of the solid precipitate for 10:90 PFB/UFB mixture was measured and it was the lowest compared to others mixtures. The solution was prepared first at $122^{\circ} \mathrm{F}$ and then loaded in the cell at $297^{\circ} \mathrm{F}$. The solid precipitate weight was measured and it will not be mentioned since the mixing method was not performed at reservoir temperatures and also the results were unreliable.

\subsection{Organic Acids Prepared in PFB Solution}

\subsubsection{0 wt\% Citric Acid Mixed with PFB}

A $10 \mathrm{wt} \%$ of citric acid was prepared in $90 \mathrm{pcf}$ PFB at room temperature. It was shown by others that citric acid has the highest dissolving efficiency to the filter cake damage, which was generated by formate based fluid, compared to other breakers (Svendsen et al., 1995). The citric acid was mixed for 3 hours and a white precipitate was noticed 
during the mixing at low acid concentration. The color of the mixture changed with time to a white color. The white precipitate changed to a big solid ball during the mixing. The fluid was filtered by using $1.2 \mu \mathrm{m}$ filter paper and a thick layer of white precipitate was noticed on the paper. It means that citric acid was not compatible with PFB solution at room temperature as shown in Figure 17.

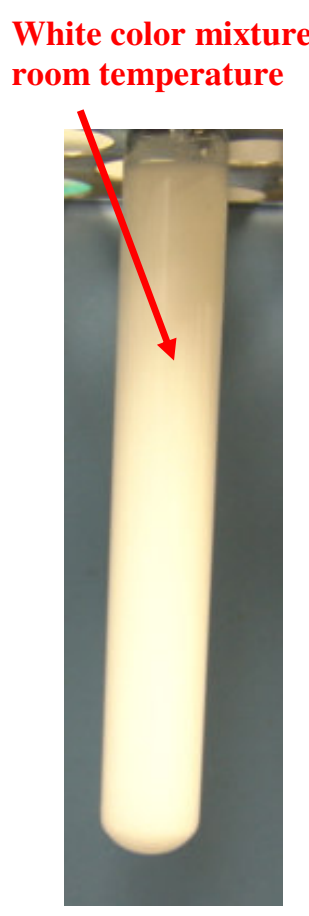

After heating the solution at 158 아
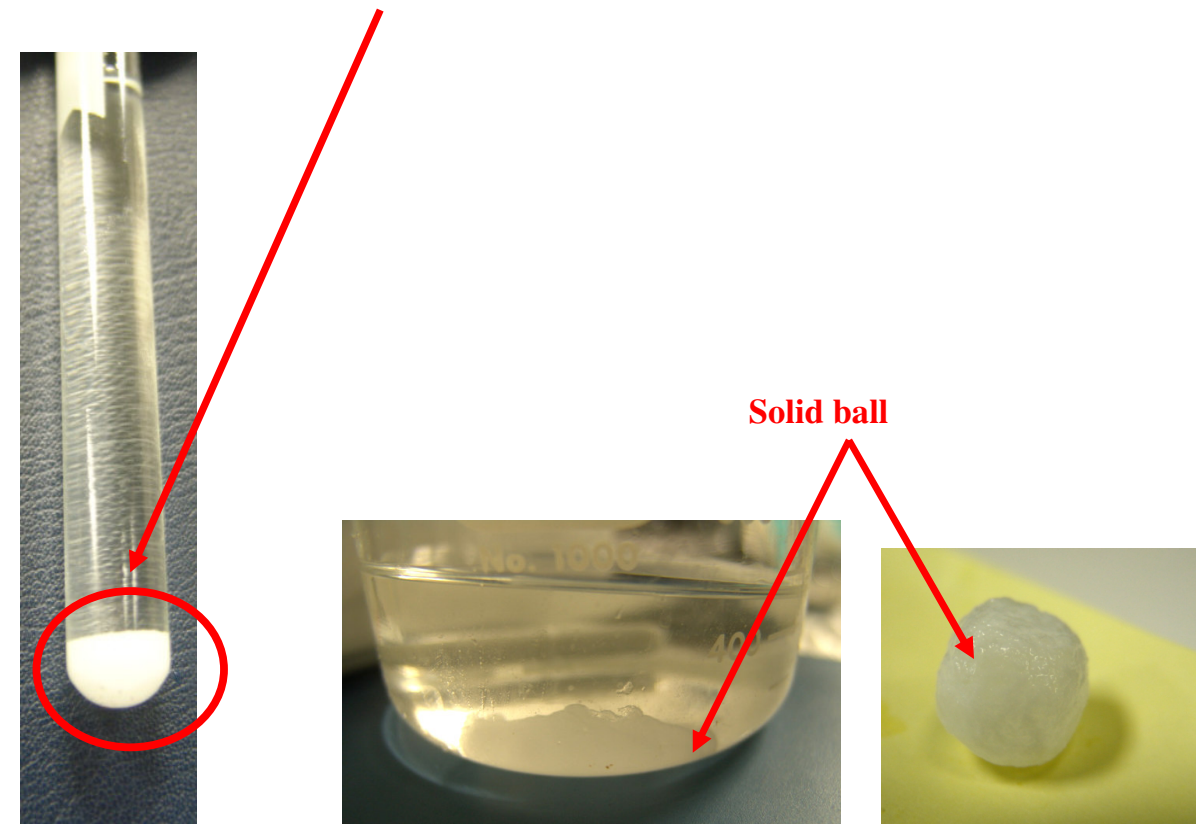

Figure 17: Compatibility of $10 \mathrm{wt} \%$ citric acid with PFB at room temperature

A $10 \mathrm{wt} \%$ citric acid was prepared in PFB solution but at $158^{\circ} \mathrm{F}$ and at atmospheric pressure. No solid precipitates were noticed during and after the mixing. The same sample was loaded in the HPHT visual cell to examine the fluids compatibility at reservoir temperature. The cell temperature and pressure were $298^{\circ} \mathrm{F}$ and $200 \mathrm{psi}$, 
respectively. The mixture was clear and no precipitates were observed during and after 21.5 hours of soaking.

A small cube of filter cake layer was removed from a damaged ceramic disk and placed in a graduated cylinder full of $10 \mathrm{wt} \%$ citric acid solution, Figure 18 . The objective of this step was to examine the effect of the acid solution on filter cake damage and to observe any chemical reaction at high temperatures. The cell pressure was fixed at $230 \mathrm{psi}$ and the reaction was started when the cell temperature increased to $291^{\circ} \mathrm{F}$. At the beginning, small bubbles were released and that was a good indication that the acid reacted with the uncovered calcium carbonate particles with biopolymers.

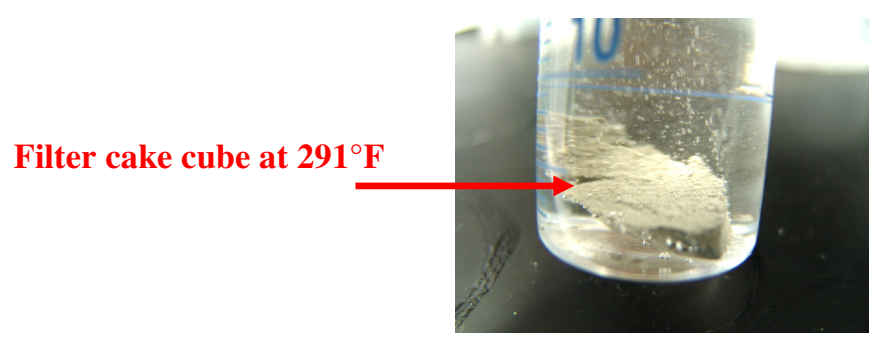

Figure 18: Effect of $10 \mathrm{wt} \%$ citric acid on filter cake

The weight of the filter cake sample was recorded before and after the soaking. The result showed only $10 \%$ of the filter cake was dissolved by citric acid. The filter cake solid after reaction was filtered as shown in Figure 19. 

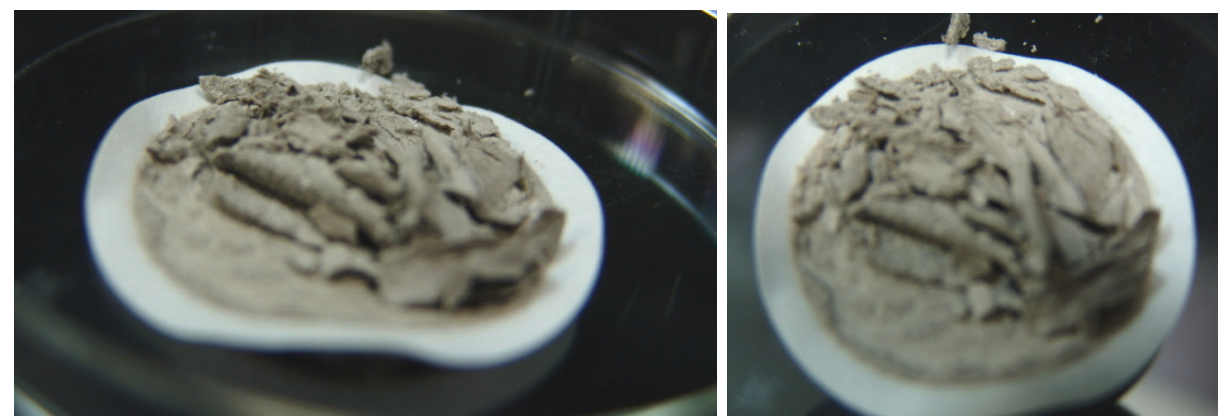

Figure 19: Filter cake solids after the reaction with $10 \mathrm{wt} \%$ citric acid

\subsection{2 $10 w t \%$ Formic Acid Prepared in PFB Solution}

Formic acid at a concentration of $10 \mathrm{wt} \%$ was prepared in PFB at room temperature. Some solid precipitates were suspended in the solution as shown in Figure 20. The sample was left for 30 minutes at room temperature and then it became a gel. Larsson and Nahringbauer discussed in their article that potassium hydrogen diformate was prepared in the lab by dissolving potassium formate in formic acid during heating (Larsson and Nahringbauer, 1968). The mixture was heated to $158^{\circ} \mathrm{F}$ and it returned to be a liquid with some solids, Figure 21.

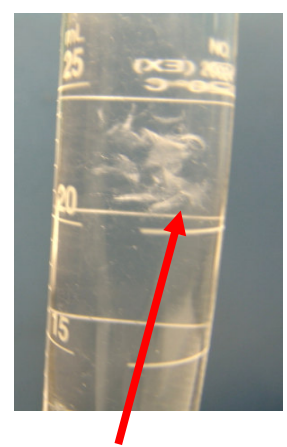

Suspended solids at room temperature

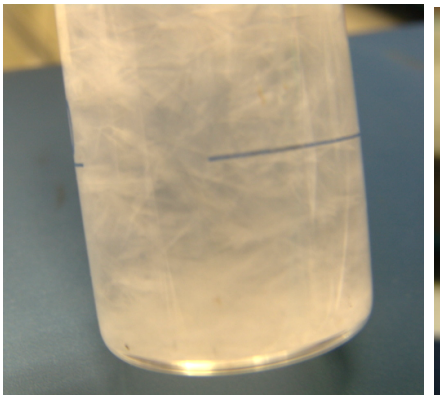

Gel fluid at room temperature

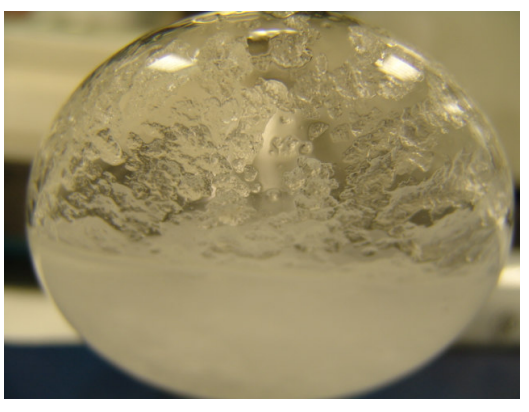

Figure 20: $10 \mathrm{wt} \%$ formic acid prepared in PFB solution at room temperature 
The precipitated solids were similar to salt crystals; they were filtered by using $1.2 \mu \mathrm{m}$ filter paper, Figure 22.
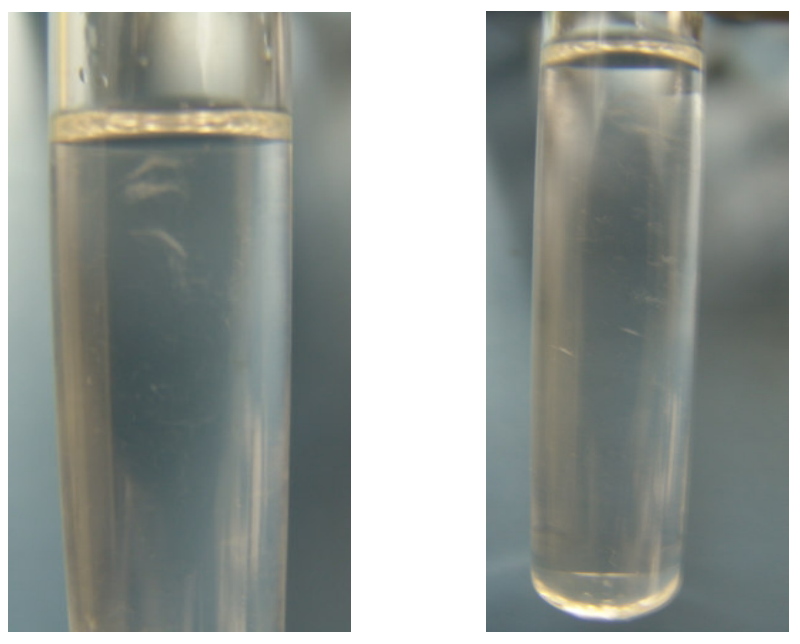

Figure 21: $10 \mathrm{wt} \%$ formic acid prepared in PFB solution at $158^{\circ} \mathrm{F}$
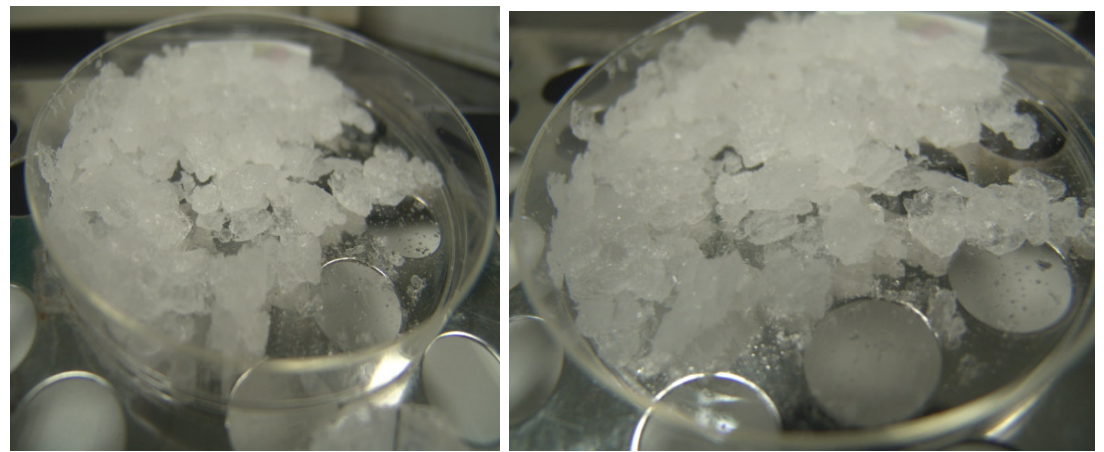

Figure 22: Solids filtered from the $10 \mathrm{wt} \%$ formic acid solution that prepared at room temperature

The $10 \mathrm{wt} \%$ formic acid solution was prepared at higher temperatures using a hot plate.

The mixture was clear with no precipitates as shown in Figure 23. The temperature condition during the mixing was $140^{\circ} \mathrm{F}$. 

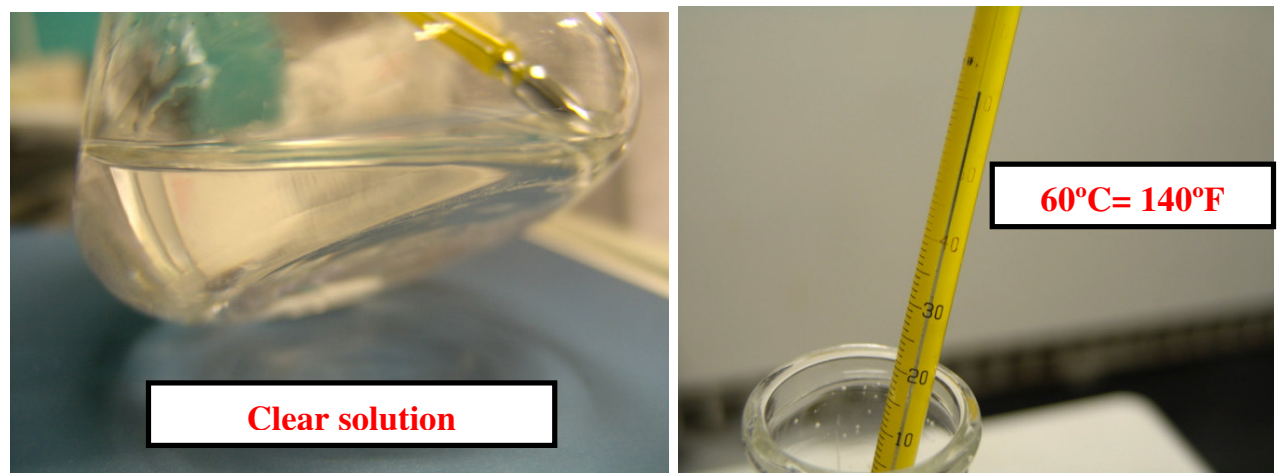

Figure 23: $10 \mathrm{wt} \%$ formic acid prepared in PFB solution at $140^{\circ} \mathrm{F}$

The mixture was loaded in the HPHT cell for 2 hours at reservoir temperature $\left(289^{\circ} \mathrm{F}\right)$ and at 200 psi, Figure 24. No precipitates were noticed at that temperature and also when the cell was disconnected to remove the sample. As noticed before, the sample became a gel when it cooled down to room temperature after 30 minutes.
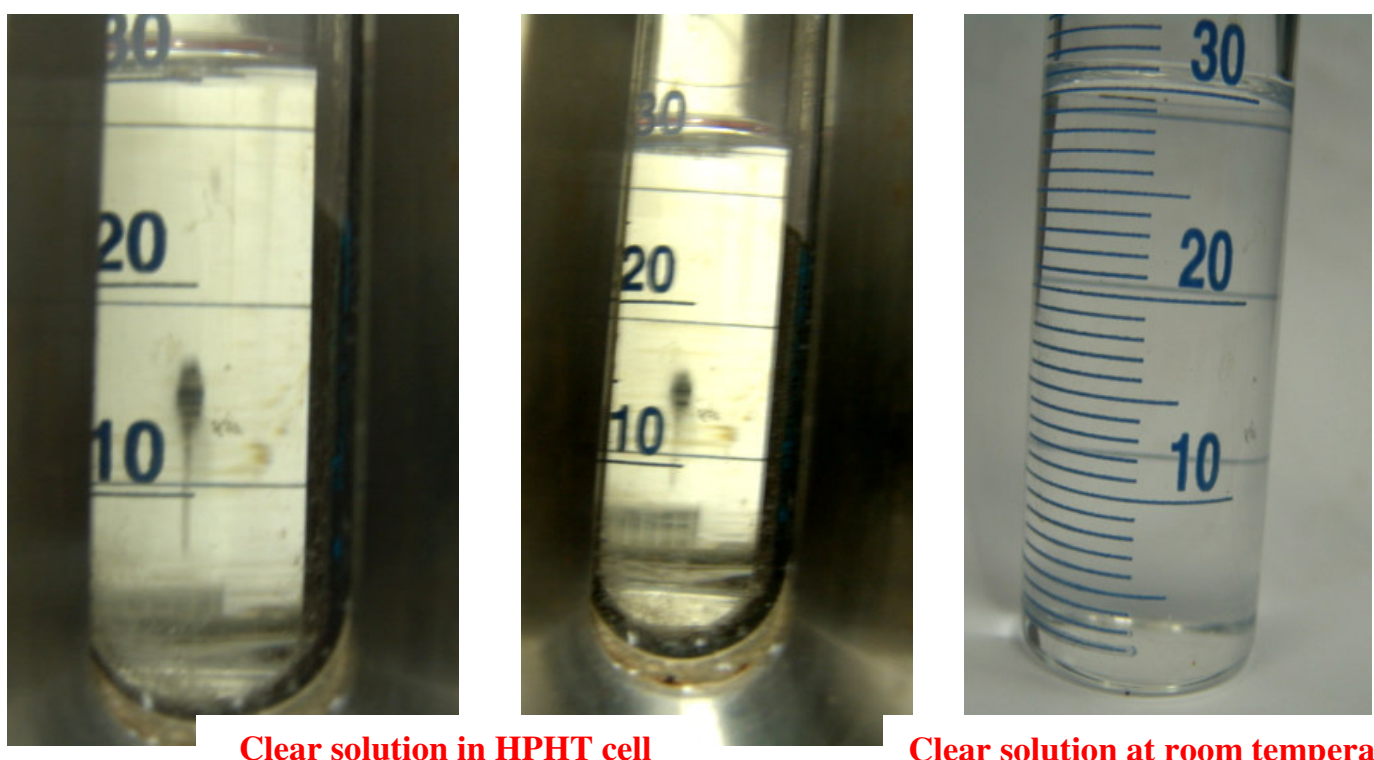

Clear solution in HPHT cell

Clear solution at room temperature

Figure 24: $10 \mathrm{wt} \%$ formic acid prepared in PFB solution at $289^{\circ} \mathrm{F}$ 


\subsubsection{0 wt\% Acetic Acid Prepared in PFB Solution}

Acetic acid was left to the end since it is a weak acid compared to formic and citric acids. A $10 \mathrm{wt} \%$ of acetic acid was prepared in PFB at room temperature and a good compatibility was noticed between the two fluids. The mixture was filtered through 1.2 $\mu \mathrm{m}$ filter paper to make sure no precipitates were existed. The same solution was prepared at $140^{\circ} \mathrm{F}$ and it was compatible during and after the mixing. At a higher temperature $\left(255^{\circ} \mathrm{F}\right)$, no precipitates were noticed for 20 hours. Acetic acid was the only compatible acid with PFB at room and high temperatures compared to other acids.

\subsubsection{5 and 10 wt\% Ethyl Lactate Ester Prepared in PFB Solution}

In section 3.1, compatibility of ethyl lactate ester was tested with potassium drilling fluid filtrate and it was compatible. Ester solution has been used lately to remove filter cake damage since it generates lactic acid as temperature increases with time (Moses and Harris, 2004). The ethyl lactate ester solution should be prepared in formate brine to increase the fluid density and also to use similar brine to the one in the drilling fluid.

Ethyl lactate ester was prepared first at room temperature and at a concentration of $10 \mathrm{wt} \%$. The ester solution showed a phase separation with PFB, Figure 25. The same mixture was re-prepared at $158^{\circ} \mathrm{F}$ and atmospheric pressure and the same separation was noticed. The prepared solution at $158^{\circ} \mathrm{F}$ was loaded in HPHT visual cell at temperature and pressure of $298^{\circ} \mathrm{F}$ and 300 psi, Figure 26. The mixture was kept in the cell for 20 hours. 


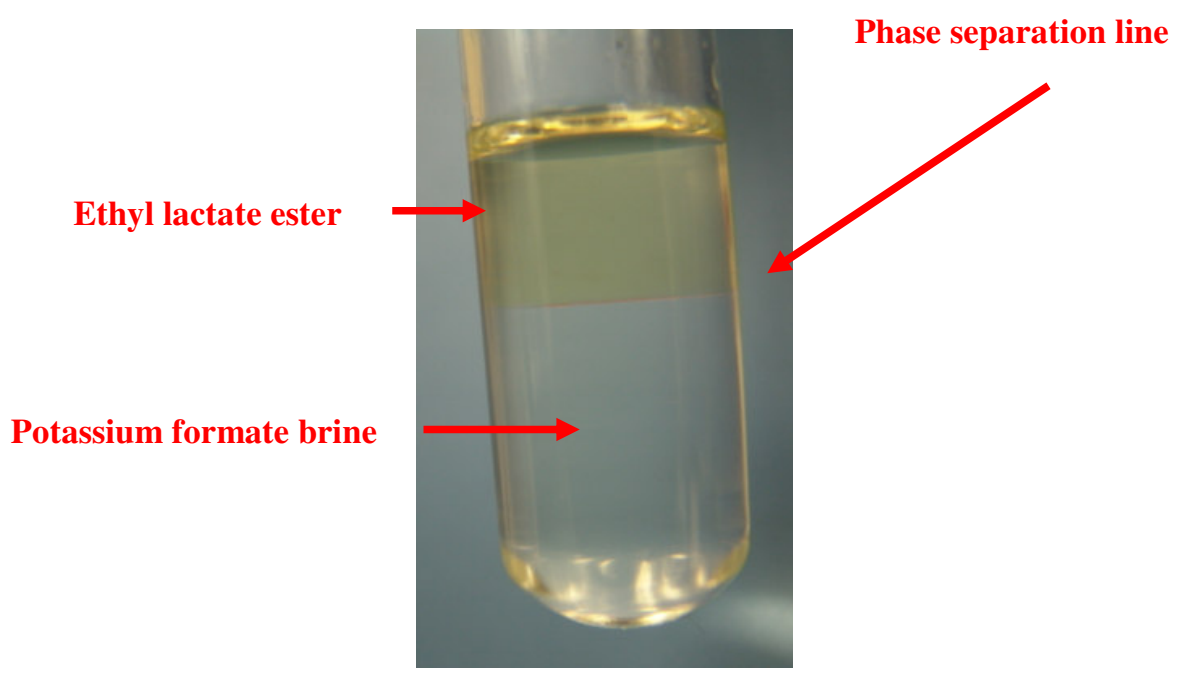

Figure 25: $10 \mathrm{wt} \%$ ethyl lactate ester prepared in PFB solution at room temperature

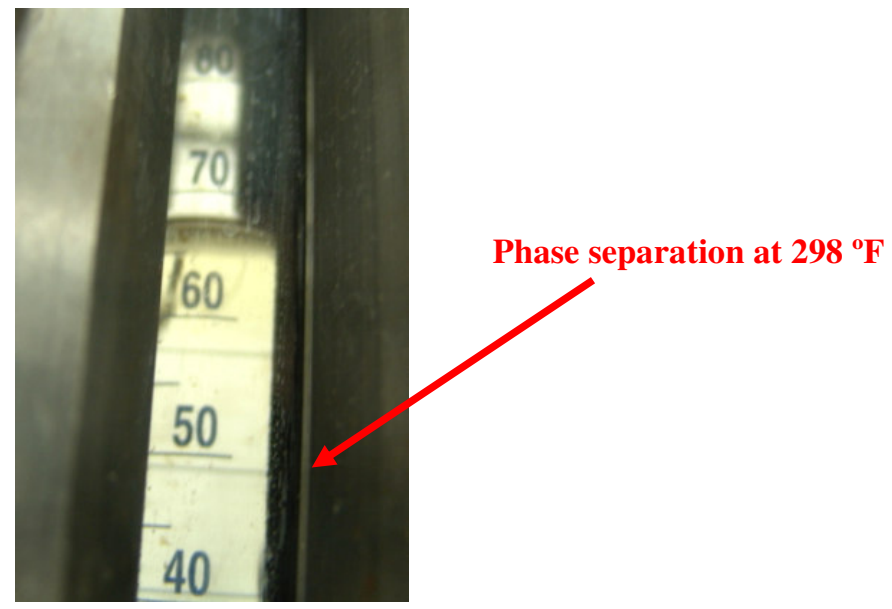

Figure 26: $10 \mathrm{wt} \%$ ethyl lactate ester prepared in PFB solution at $298^{\circ} \mathrm{F}$

The concentration of ethyl lactate ester was reduced to $5 \mathrm{wt} . \%$ and the mixtures were prepared in PFB at the same conditions. At room temperature, the phase separation was noticed and the ester was incompatible with PFB. Then, the mixture was heated to $158^{\circ} \mathrm{F}$ 
and the observation was similar to the room temperature test result. The phase separation was clear as temperature increased from room temperature to $158^{\circ} \mathrm{F}$, Figure 27.
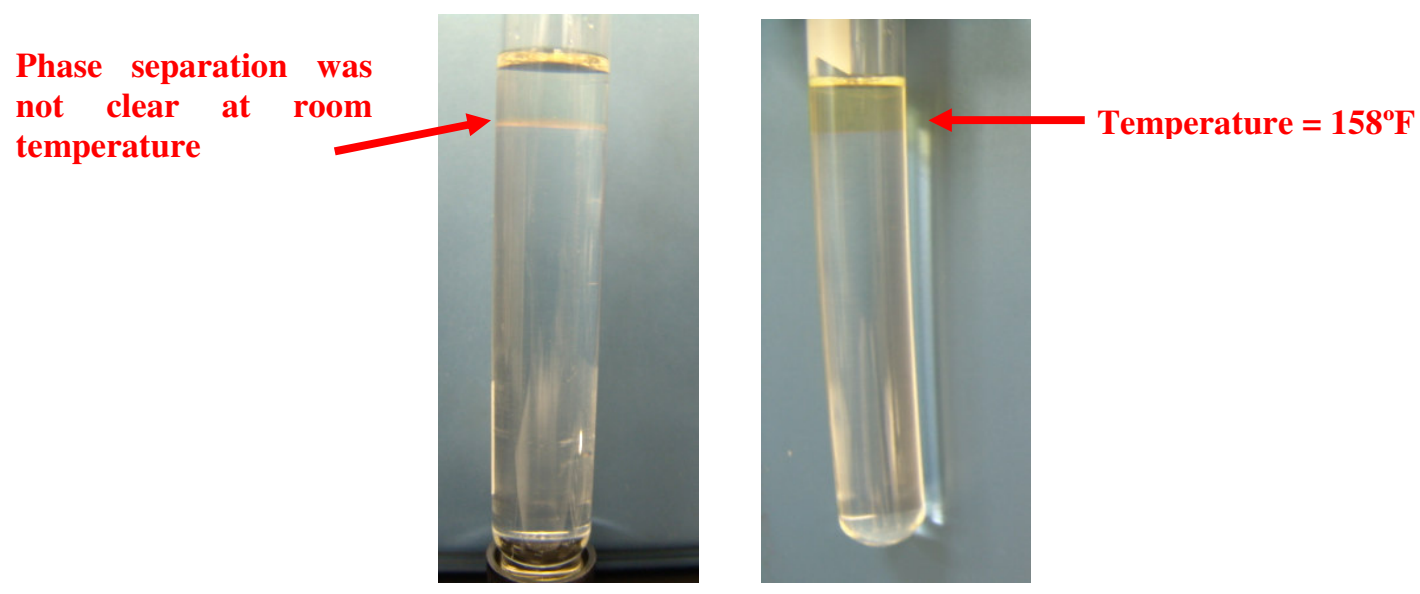

Figure 27: 5 wt $\%$ ethyl lactate ester prepared in PFB solution prepared at room temperature

\subsubsection{Chelating Agent (DTPA) Prepared in PFB Solution}

DTPA (Diethlenetriaminepentaacetic acid) was prepared in PFB at a ratio of 50:50; no precipitate or phase separation was noticed at room temperature. The DTPA was added to the PFB at $113^{\circ} \mathrm{F}$ and it was compatible, Figure 28. The same fluid was loaded in HPHT cell at $284^{\circ} \mathrm{F}$ and pressure of 200 psi. The sample was left in the cell for 24 hours. Small crystals were noticed after filtering the solution through $1.2 \mu \mathrm{m}$ filter paper. 


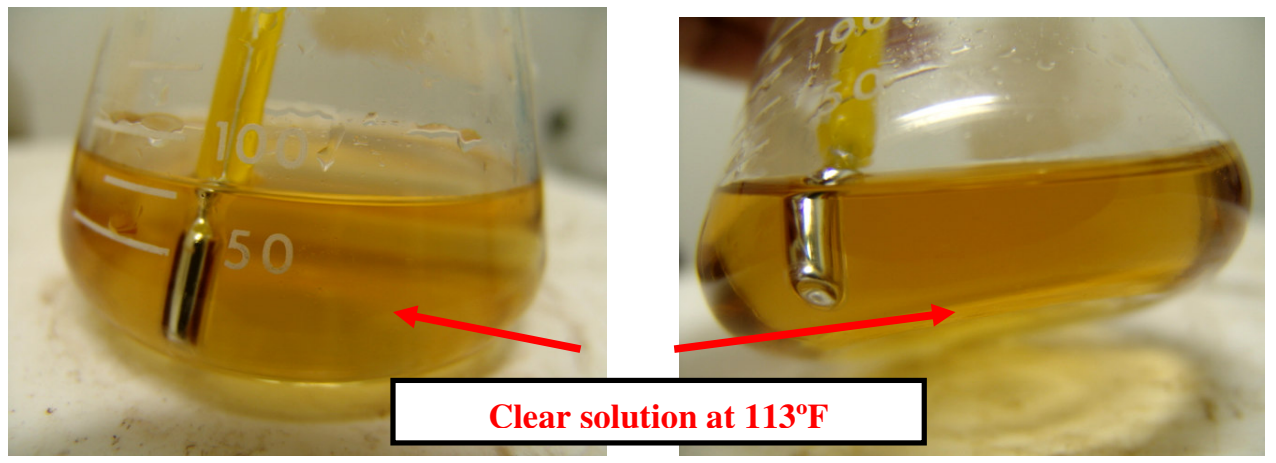

Figure 28: DTPA prepared in PFB solution at a ratio of 50:50

To examine the effect of the DTPA on the filter cake damage, a small portion of the filter cake layer was extracted and then placed in a $100 \mathrm{ml}$ graduated cylinder. The cylinder was loaded in the HPHT visual cell at a temperature and pressure of $284^{\circ} \mathrm{F}$ and 200 psi, respectively. The cake sample was soaked in the DTPA solution for 27 hours.

The cell was disconnected and the solution was filtered through $1.2 \mu \mathrm{m}$ filter paper. The chelating agent fluid was ineffective to dissolve the calcium carbonate particles because it was coated with biopolymers, Figure 29.

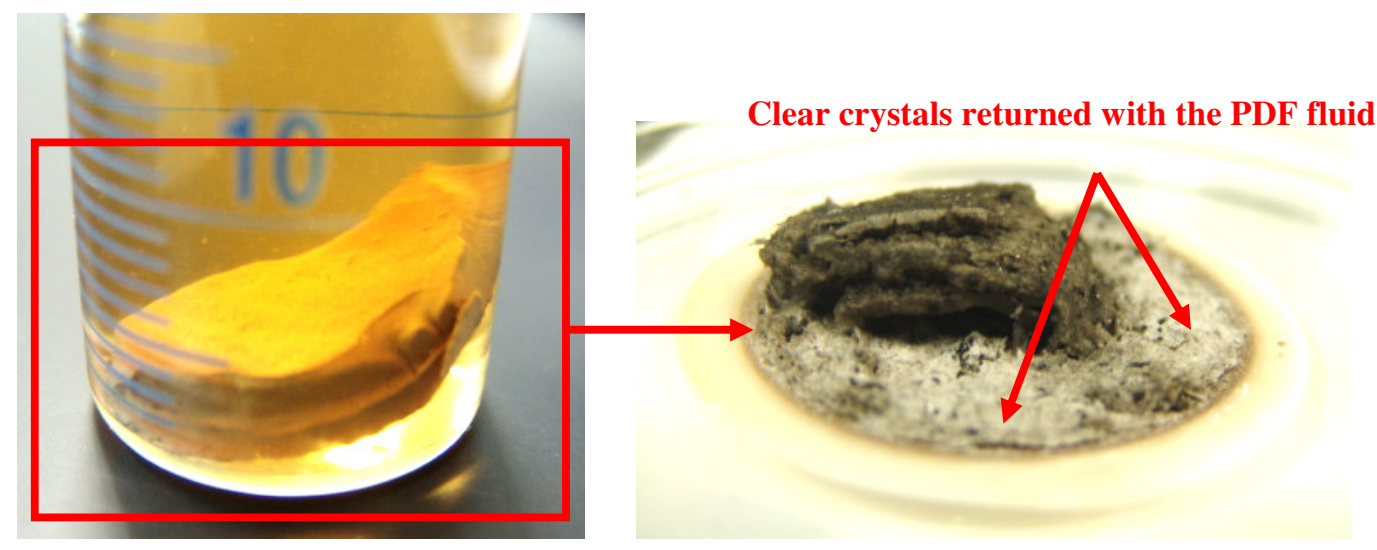

Filter cake after soaking

Figure 29: Effect of DTPA on filter cake 


\subsection{Xanthan and Cellulose Enzymes Prepared in PFB Solution}

The drilling fluid recipe that was used in the field had cellulose and xanthan polymers to reduce the fluid losses into the formation and to carry the drilling cuttings to the surface. Filter press experiments gave insufficient removing efficiency when organic acids were used to remove the filter cake damage as can be seen in Chapter IV. The xanthan and cellulose polymers were the main reason because they were covering the calcium carbonate particles in filter cake. Weak acids cannot dissolve or remove that polymer layer.

Enzymes have been used commonly to break down the polymer chains and hydrolyze it to small sugar units. Two classes of enzymes were received from a local service company and were used at a concentration of $10 \mathrm{wt} \%$. The enzymes were prepared in potassium formate brine at room temperature first and were compatible. The solution was prepared at $149^{\circ} \mathrm{F}$ to examine the fluid compatibility at higher temperatures as shown Figure 30.

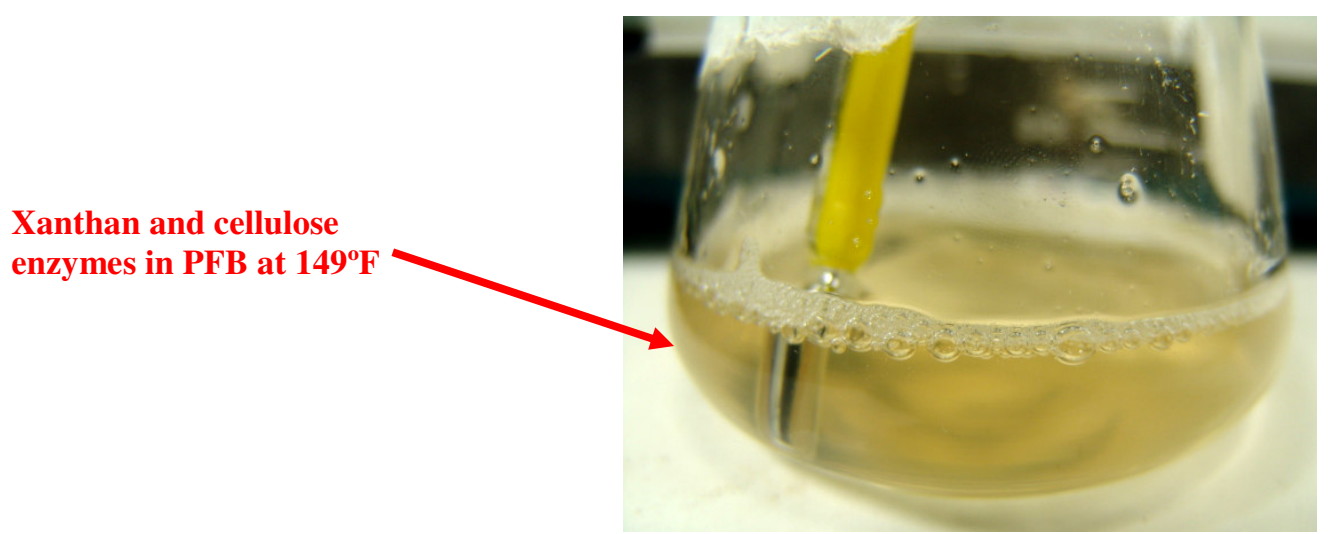

Figure 30: $10 \mathrm{wt} \%$ of xanthan and cellulose enzymes prepared in PFB solution 
A simple test was conducted in the HPHT visual cell by taking a small portion of the filter cake layer as shown in Figure 31. The graduated cylinder that is usually loaded in the visual cell was half filled with enzymes solution. The reason for that step was to ensure full fluid coverage to the filter cake sample. After that, the sample was placed in the cell and connected. The temperature and pressure of the cell were $284^{\circ} \mathrm{F}$ and $200 \mathrm{psi}$ for 23 hours. The test result showed the acid was needed with the enzyme solution to dissolve the calcium carbonate particles.

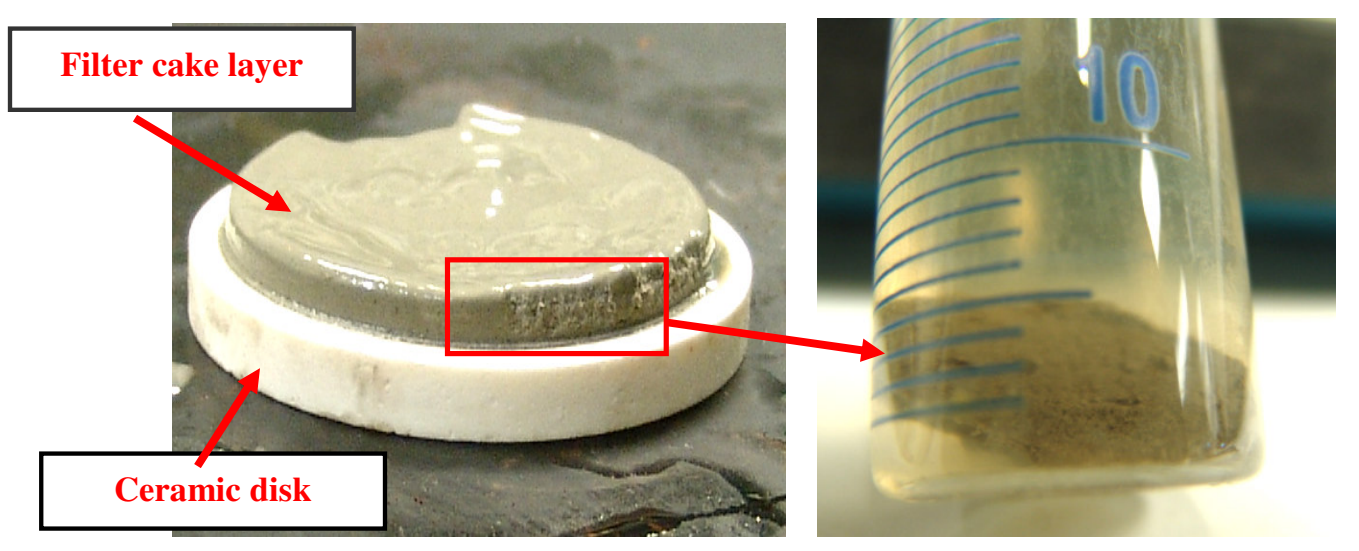

Figure 31: Effect of $10 \mathrm{wt} \%$ of xanthan and cellulose enzymes on the filter cake 


\section{CHAPTER IV}

\section{RESULTS AND DISCUSSION}

\subsection{Analysis of Fluids Compatibility Tests}

\subsubsection{DFF Mixed with UFB at Room Temperature}

X-Ray powder Diffraction (XRD) and ESEM techniques were utilized to determine the nature of the solids precipitates that were collected on the filter papers. The solids were precipitated as a result of mixing potassium formate drilling fluid filtrate and Unayzah formation brine at different volume ratios. At the beginning, only three samples of drilling fluid filtrate (DFF) and Unayzah formation brine (UFB) were mixed at ratios of: 10:90, 30:70 and 50:50.

\subsubsection{10\% DFF Mixed with 90\% UFB (Sample No. 1)}

A $10 \%$ of DFF was added slowly to $90 \%$ UFB and it was stirring during mixing to ensure proper mixing method. The XRD result of the precipitate shows halite $(\mathrm{NaCl})$ is a major component in the sample. The source of the halite is coming from the formation brine. Sylvite $(\mathrm{KCl})$ and calcite $\left(\mathrm{CaCO}_{3}\right)$ are noticed as minor components in the sample. Calcite was used as a drilling fluid additive while drilling the target zone and that is the main source. Calcium formate- $\mathrm{C}_{2} \mathrm{H}_{2} \mathrm{CaO}_{4}$ is also present in the sample.

Figure 32 shows the images and EDS X-ray spectrum of the precipitated solids on a filter paper. The secondary and backscattered electron images showed spherical $\mathrm{CaCO}_{3}$ particles that are dispersed in a polymer matrix. The $\mathrm{CaCO}_{3}$ particles are about 2 
$\mu \mathrm{m}$ in diameter and appeared to have been agglomerated by polymers in the fluid. Both ESEM and XRD show presence of $\mathrm{NaCl}, \mathrm{KCl}$ and small amounts of calcium formate and quartz in the precipitate. The source of the quartz is from the formation since the used drilling fluid is a field sample.

\subsubsection{30\% DFF Mixed with 70\% UFB (Sample No. 2)}

The XRD result shows calcium carbonates (calcite and vaterite $(\mathrm{CaCO} 3))$ are the major component of the sample. Calcium formate- $\mathrm{C}_{2} \mathrm{H}_{2} \mathrm{CaO}_{4}$ is also present in the sample. Figure 33 shows the images and EDS X-ray spectrum of the precipitated solids. The ESEM images show mainly spherical $\mathrm{CaCO}_{3}$ particles with some $\mathrm{KCl}, \mathrm{NaCl}$ and silicate particles. The $\mathrm{CaCO}_{3}$ particles are about $2 \mu \mathrm{m}$ in diameter and appeared to be coated with polymer. The spherical shape and $(\sim 2 \mu \mathrm{m})$ size of the $\mathrm{CaCO}_{3}$ particles suggest they could be vaterite, which is a metastable form of calcium carbonate. In the presence of water, vaterite would normally convert to calcite, however, polymer coating may have prevented transformation of vaterite to thermodynamically more stable calcite. XRD analysis indicates nearly equal amounts of calcite and vaterite in the sample, which suggests some of the vaterite may have transformed into calcite. 


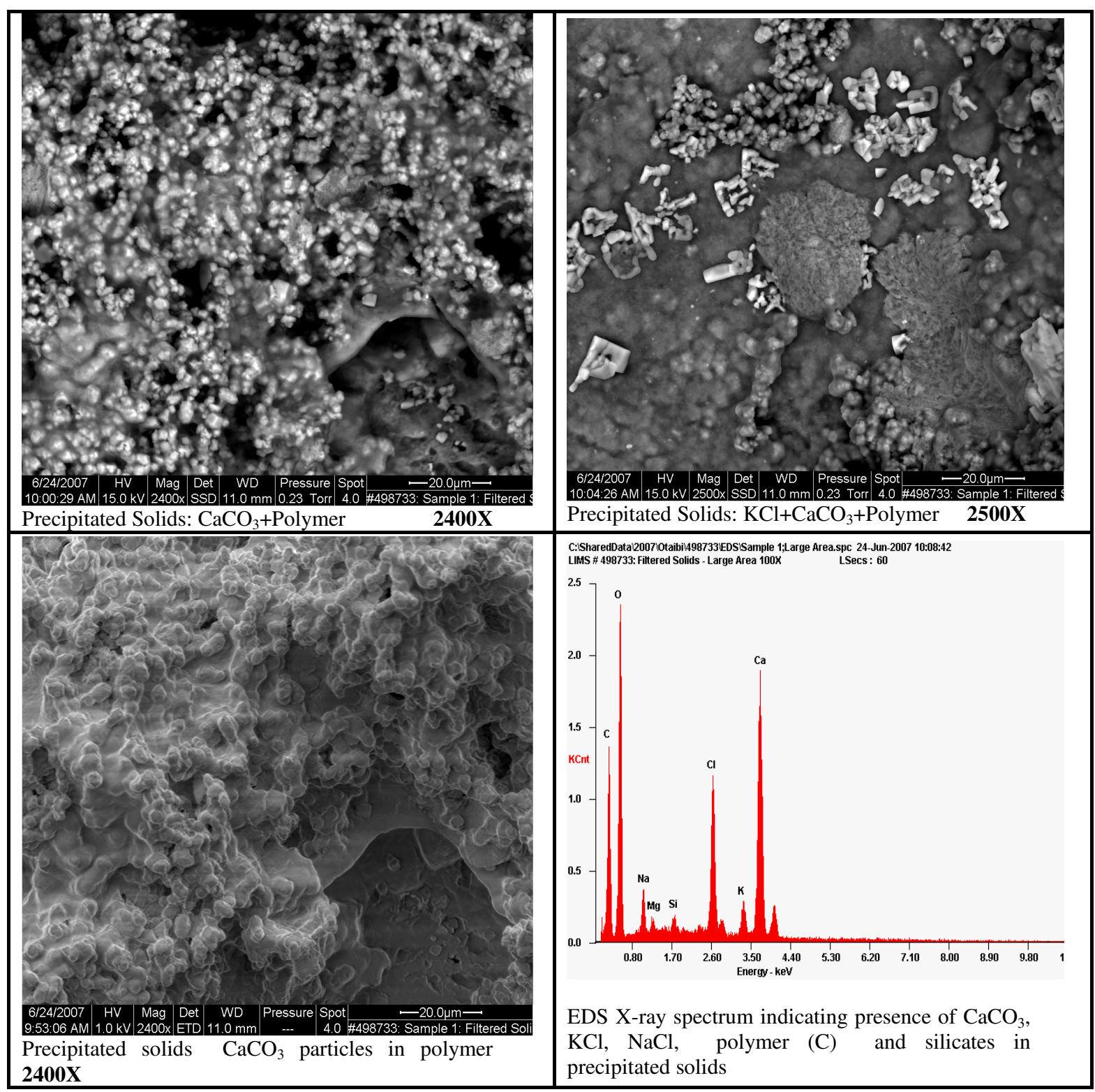

Figure 32: Secondary and backscattered electron images of precipitated solids in sample no. 1 


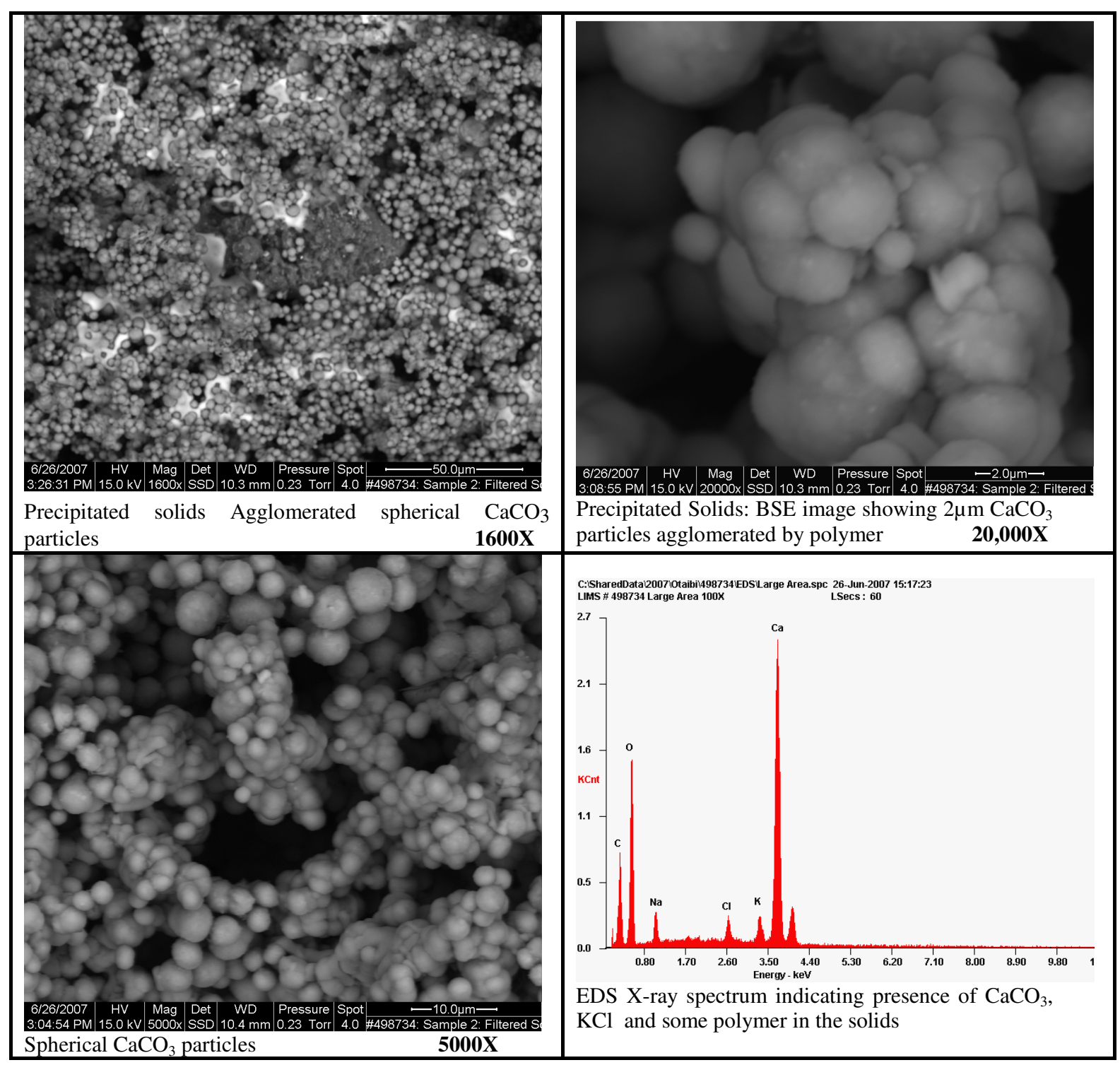

Figure 33: Secondary and backscattered electron images of precipitated solids in sample no. 2 


\subsubsection{50\% DFF Mixed with 50\% UFB (Sample No. 3)}

The XRD result shows Sylvite $(\mathrm{KCl})$ is a major component of the sample. Calcium carbonates (calcite and vaterite $\left.\left(\mathrm{CaCO}_{3}\right)\right)$ are also present in trace quantity.

The images and EDS X-ray spectrum of the precipitated solids in this sample are shown in Figure 34. The sample is predominantly $\mathrm{KCl}$ with small amounts of spherical $2 \mu \mathrm{m}$ particles of calcite and vaterite. The $\mathrm{KCl}$ unlike in other samples shows various forms of well developed crystalline structure of the cubic system. The $\mathrm{CaCO}_{3}$ particles also appeared to be agglomerated with polymer and seem to have co-precipitated with $\mathrm{KCl}$. The XRD analysis confirms the presence of $\mathrm{KCl}$, vaterite and calcite in this sample.

\subsubsection{UFB Mixed with PFB Solution at Room Temperature}

\subsubsection{10\% UFB Mixed with 90\% PFB}

Figure 35 shows backscattered electron images and EDS X-ray spectrum of the solids precipitated from mixing $10 \%$ UFB with $90 \%$ PFB at room temperature. The solids are mainly well crystallized $20-50 \mu \mathrm{m} \mathrm{KCl}$ crystals that appear to be bonded by a thin porous layer of K-rich organic compound.

\subsubsection{30\% UFB Mixed with 70\% PFB}

Figure 36 shows images and EDS X-ray spectra of the solids precipitated from mixing $30 \%$ UFB with $70 \%$ PFB at room temperature. The solids are mainly 10-50. $\mu$ m crystals of Ca-rich compound that was identified by XRD as calcium formate. The solids also contain small amounts of well developed crystals of $\mathrm{KCl}$. 


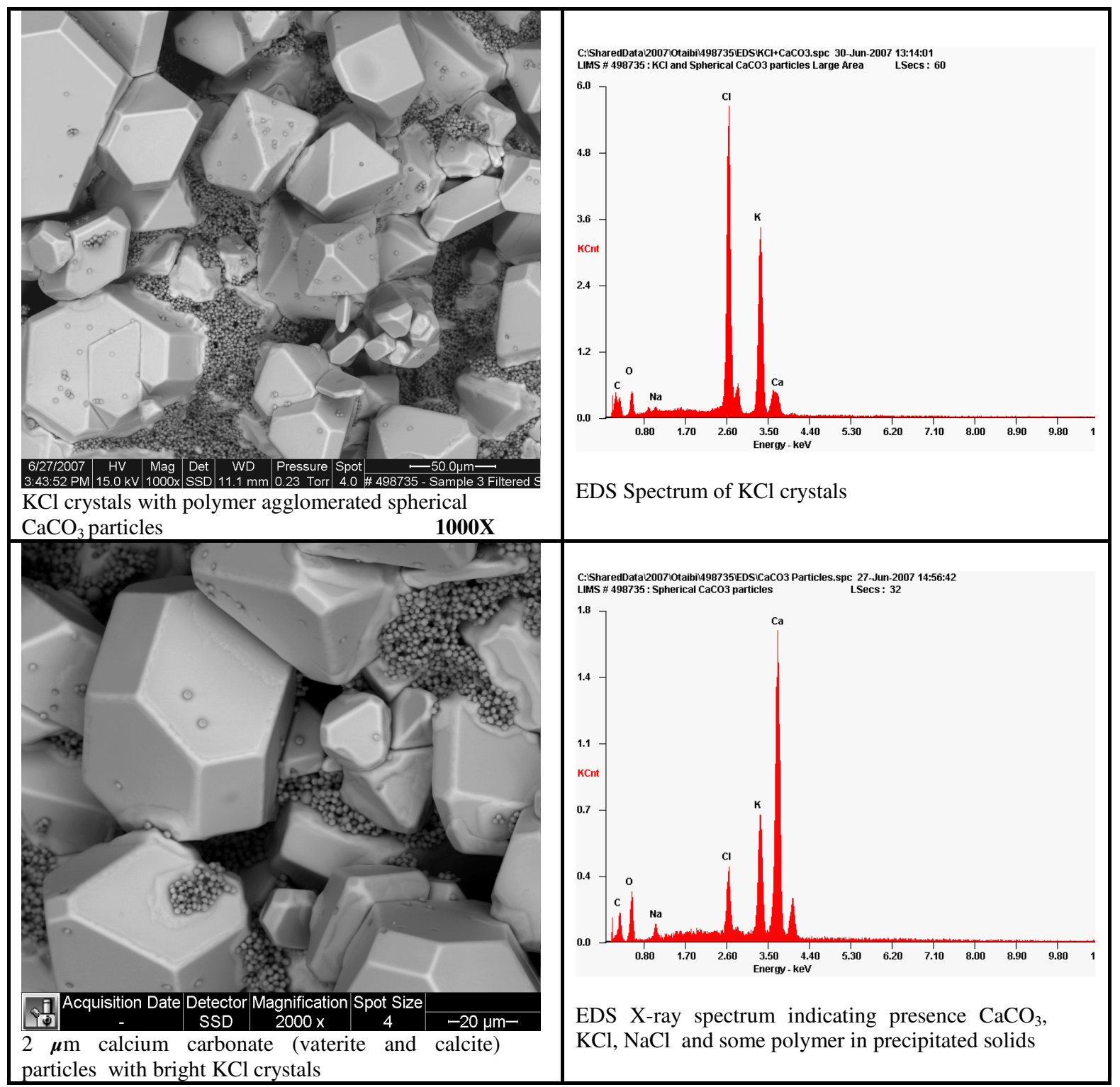

Figure 34: Secondary and backscattered electron images of precipitated solids in sample no. 3 


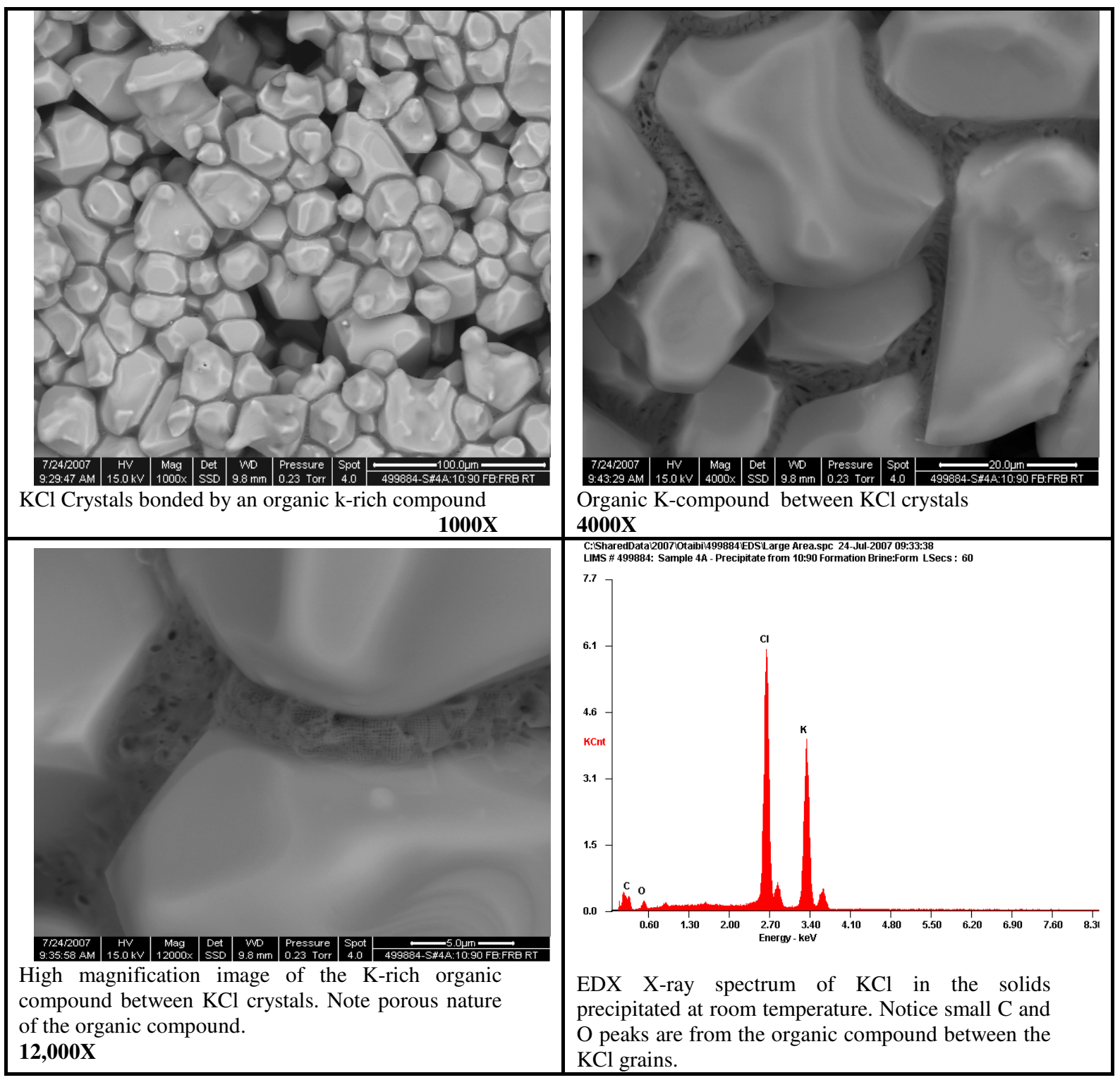

Figure 35: Backscattered electron images and EDS X-ray spectrum of the solids precipitates at room temperature from mixing $10 \%$ UFB with $90 \%$ PFB 


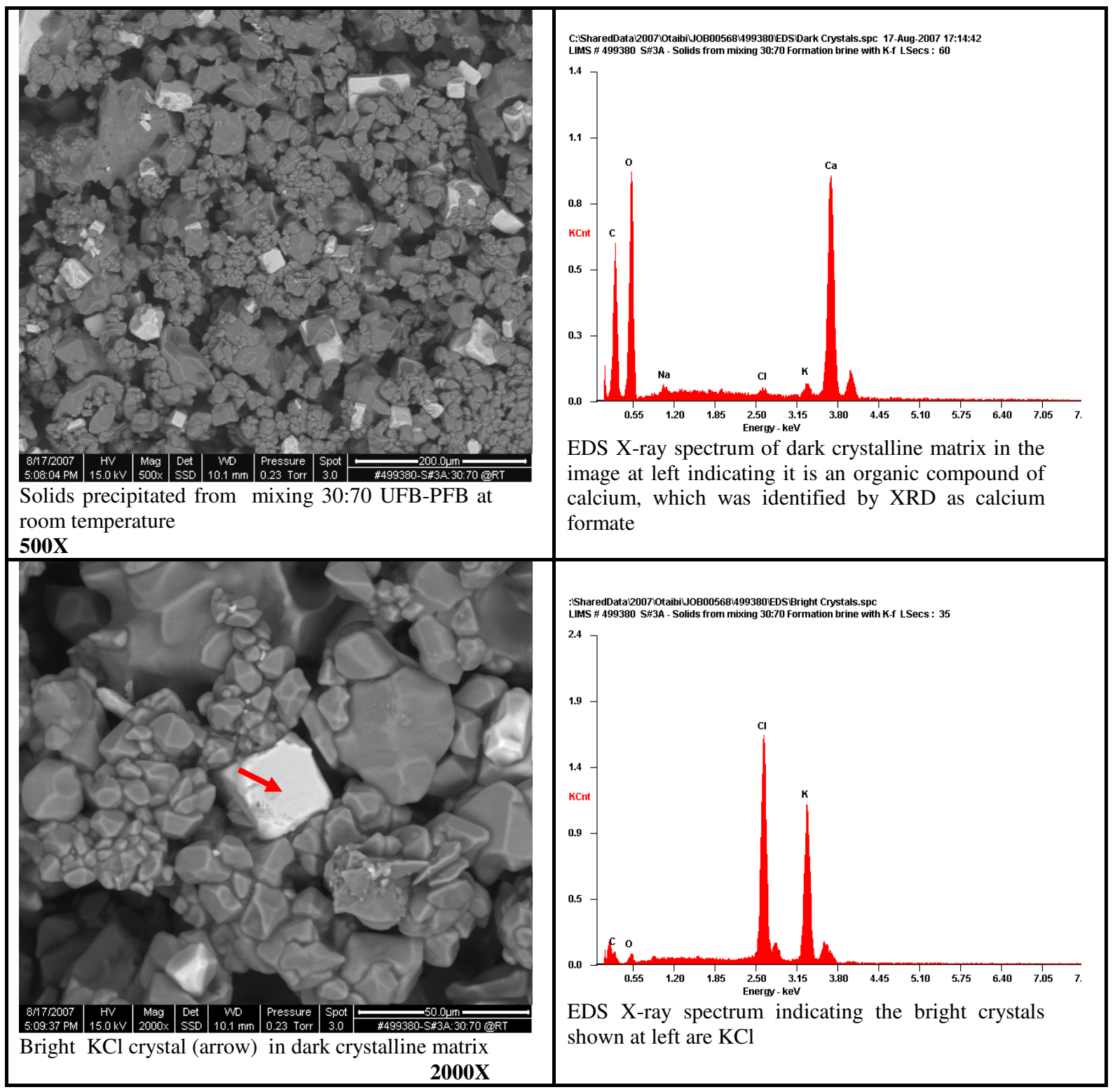

Figure 36: Backscattered electron images and EDS X-ray spectra of solids precipitated from mixing $30 \%$ UFB with $70 \%$ PFB at room temperature 


\subsubsection{50\% UFB Mixed with 50\% PFB}

The solids precipitates that resulted from mixing 50\% UFB with 50\% PFB at room temperature were analyzed by using only XRD technique. The result shows the solids mainly consist of $\mathrm{KCl}$.

\subsubsection{70\% UFB Mixed with 30\% PFB}

Figure 37 shows images and EDS X-ray spectrum of the solids precipitated from mixing 70\% UFB with $30 \%$ PFB at room temperature. This sample also shows well crystallized $\mathrm{KCl}$ grains in a dark matrix. The EDS spectra of the matrix suggests it is an organic compound of $\mathrm{K}$ and $\mathrm{Na}$, possibly $\mathrm{K}$-formate and Na-Formate that were added to the formate brine.

\subsubsection{90\% U FB Mixed with 10\% PFB}

The EDS X-ray spectrum and the images of the solids precipitated from mixing 90\% UFB with $10 \%$ PFB at room temperature are shown in Figure 38. The solids are mainly $\mathrm{KCl}$ and $\mathrm{NaCl}$ and what appears to be a very thin film of beam sensitive organic compound on filter paper. The elemental composition of the thin film could not be determined due to interference from the support filter paper. $\mathrm{KCl}$ and $\mathrm{NaCl}$ in this sample do not show crystalline form but appear as evaporated patches of brine. The EDS analysis also indicates presence of trace amount of $\mathrm{Ca}-\mathrm{Mg}$-Carbonate in the solids. 


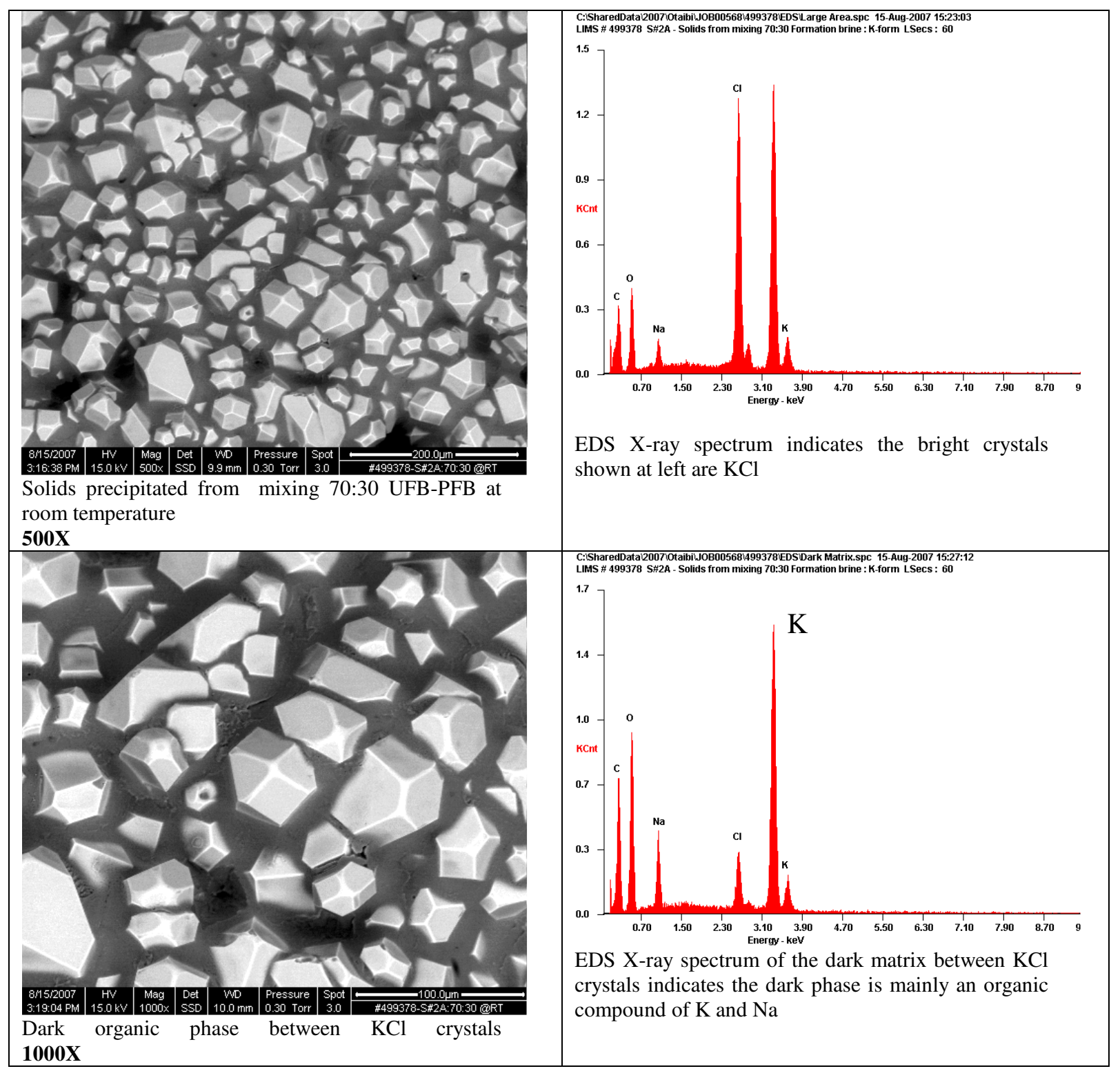

Figure 37: Backscattered electron images and EDS X-ray spectra of solids precipitated from mixing $70 \%$ UFB with $30 \%$ PFB at room temperature 


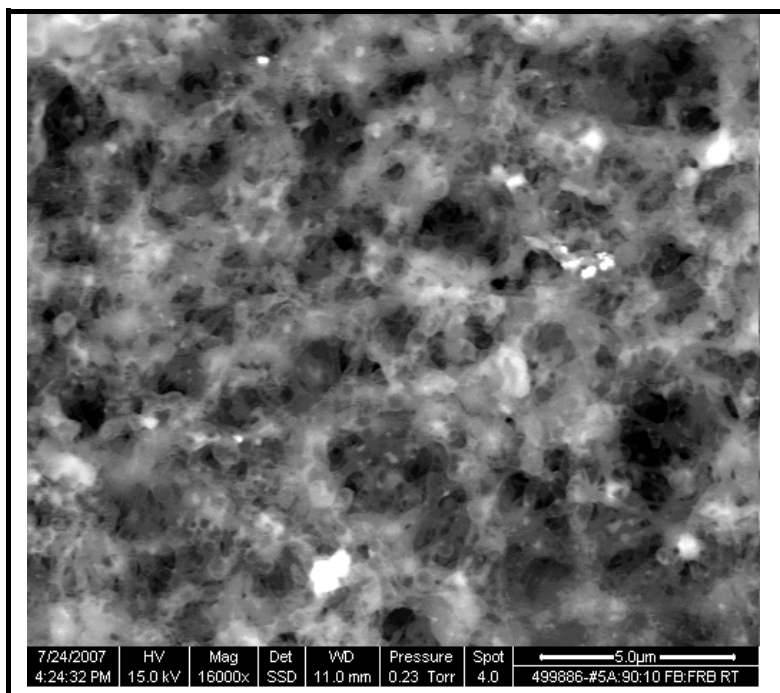

Thin film of an organic compound on filter paper $16,000 X$

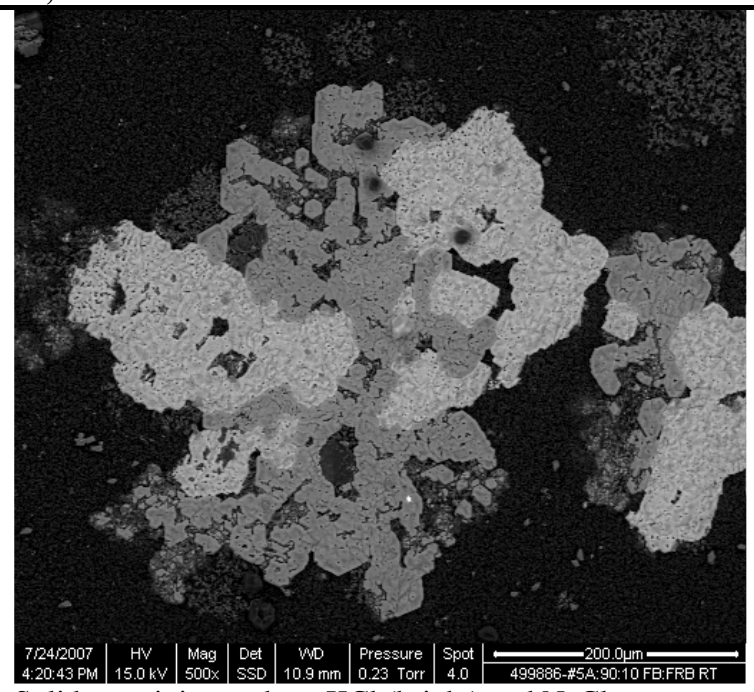

Solids precipitates show $\mathrm{KCl}$ (bright) and $\mathrm{NaCl}$

(gray) areas. Notice absence of crystalline form of

$\mathrm{KCl}$

$500 X$

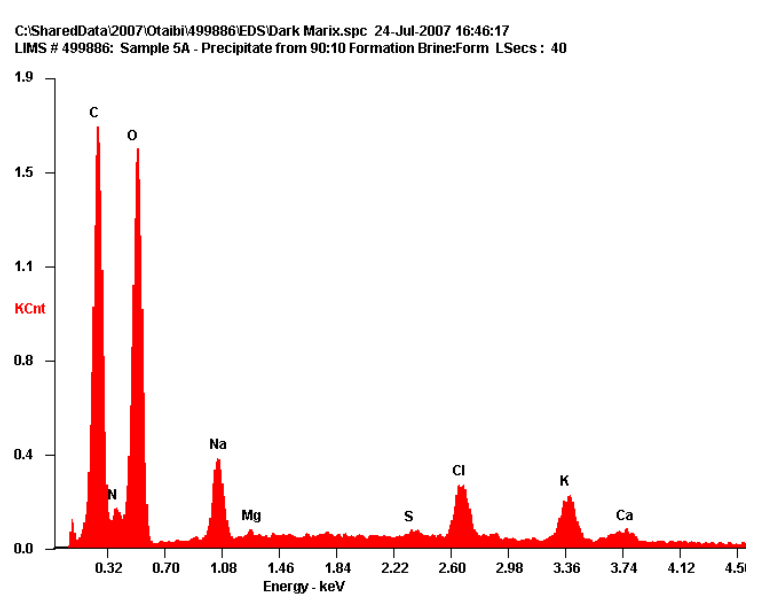

EDS X-ray spectrum indicating presence of $\mathrm{KCl}$, $\mathrm{NaCl}$ and possibly $\mathrm{Ca}-\mathrm{Mg}$ carbonate in the precipitate

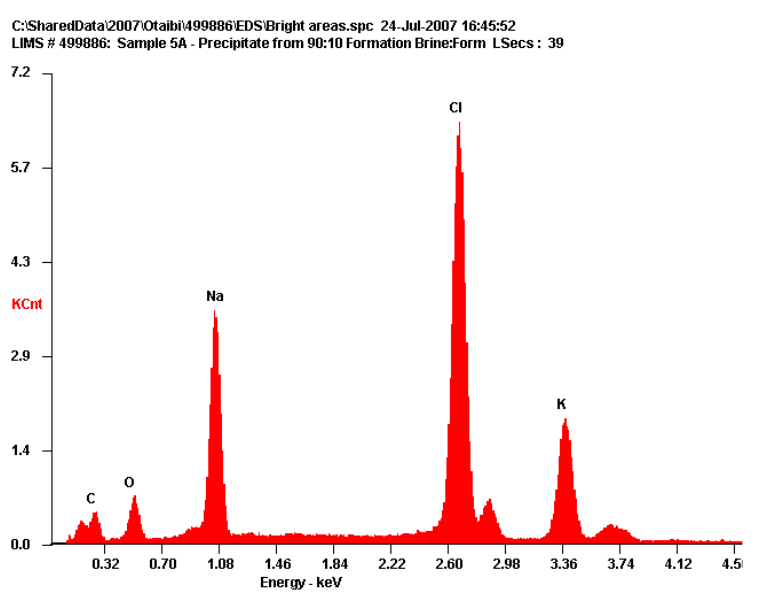

EDS X-ray spectrum indicating presence of $\mathrm{KCl}$ and $\mathrm{NaCl}$ with trace amount of an organic compound in the image shown on left.

Figure 38: Backscattered electron images and EDS X-ray spectrum of the solids precipitates at room temperature from mixing $90 \%$ UFB with $10 \%$ PFB 


\subsubsection{UFB Mixed with PFB Solution at High Temperature}

\subsubsection{10\% UFB Mixed with 90\% PFB}

Figure 39 shows the images and EDS X-ray spectrum of the solids precipitated from mixing $10 \%$ UFB with $90 \%$ PFB at an average temperature of $120^{\circ} \mathrm{F}$. As in the room temperature sample, this sample also shows well crystallized $\mathrm{KCl}$ grains bonded by $\mathrm{K}$ rich organic compound. However, the organic compound because of the higher temperature appears to have become more dense and compact and also shows sheet-like morphology.

\subsubsection{30\% UFB Mixed with 70\% PFB}

Figure 40 shows images and EDS X-ray spectra of the solids precipitated from mixing $30 \%$ UFB with $70 \%$ PFB at average temperature of $120^{\circ} \mathrm{F}$. The main solids as in the room temperature sample are also $10-50 \mu \mathrm{m}$ crystals of Ca-rich compound identified as calcium formate by $\mathrm{XRD}$, and a few crystals of $\mathrm{KCl}$. However, unlike the room temperature sample, this sample shows a Na-rich compound between Ca-formate grains. This Na-rich compound is highly unstable under the beam and appears to be Na-formate. 


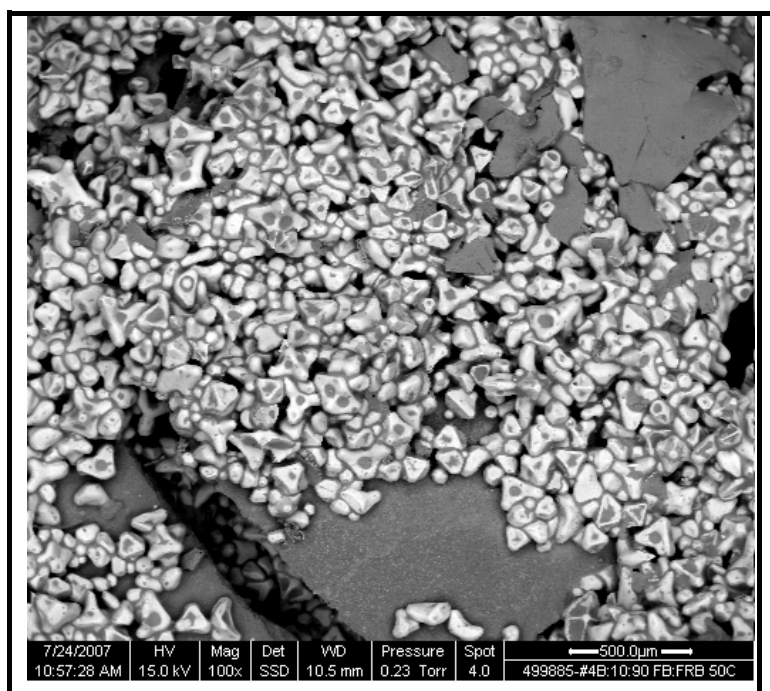

$\mathrm{KCl}$ Crystals (bright) and dark organic phase $100 \mathrm{X}$

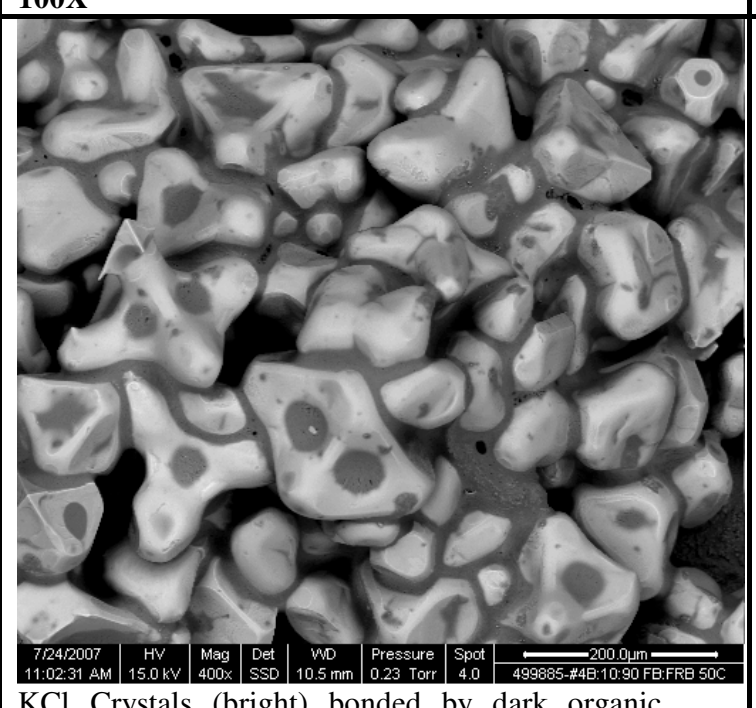

$\mathrm{KCl}$ Crystals (bright) bonded by dark organic phase

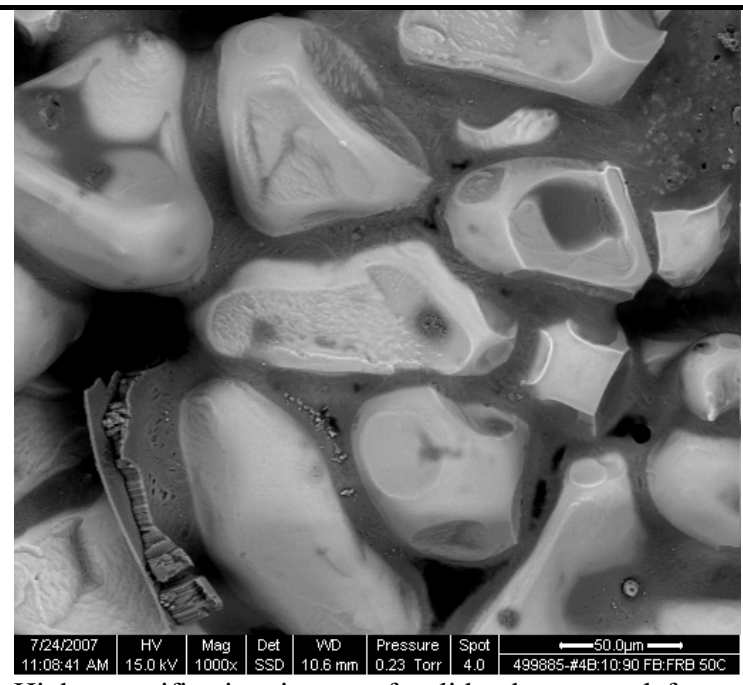

High magnification image of solids shown on left. Notice solid nature of the dark organic phase between bright $\mathrm{KCl}$ grains 1000X

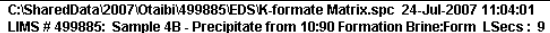

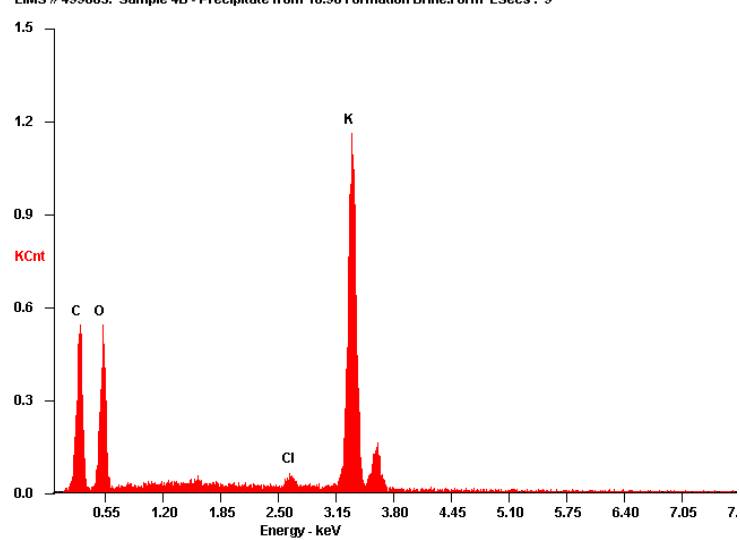

EDS X-ray spectrum indicating the dark organic phase between $\mathrm{KCl}$ grains is a K-rich organic compound.

Figure 39: Backscattered electron images and EDS X-ray spectrum of the solids precipitates from mixing $10 \%$ UFB with $90 \%$ PFB 


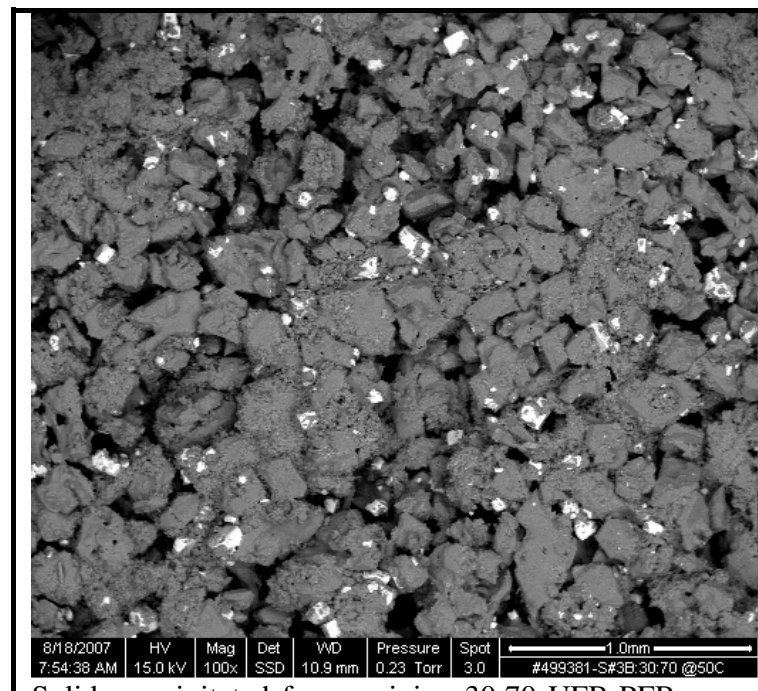

Solids precipitated from mixing 30:70 UFB-PFB at $120^{\circ} \mathrm{F}$

$100 \mathrm{X}$

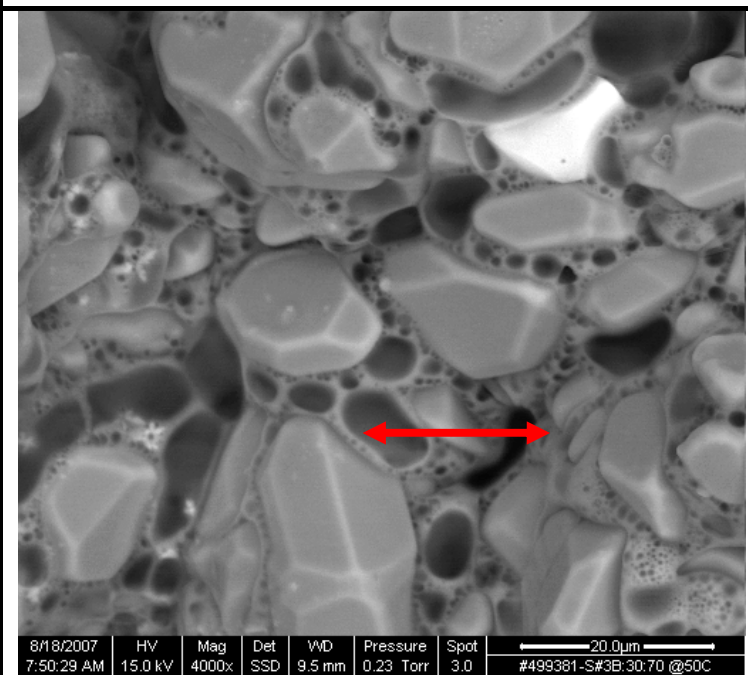

Solids precipitated from mixing 30:70 UFB-PFB are showing organic phase between Ca-formate crystals $4000 X$

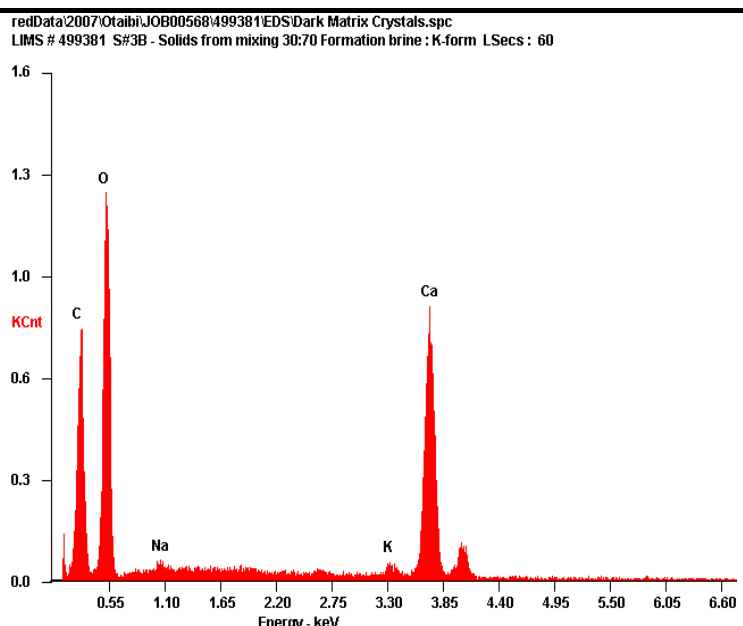

EDS X-ray spectrum indicating the dark crystalline matrix shown in the image at left is an organic compound of Calcium - identified by XRD as calcium formate

LMS \# 499381 S\#3B - Solids from mixing 30:70 Formation bris: $:$ form LSecs: 22

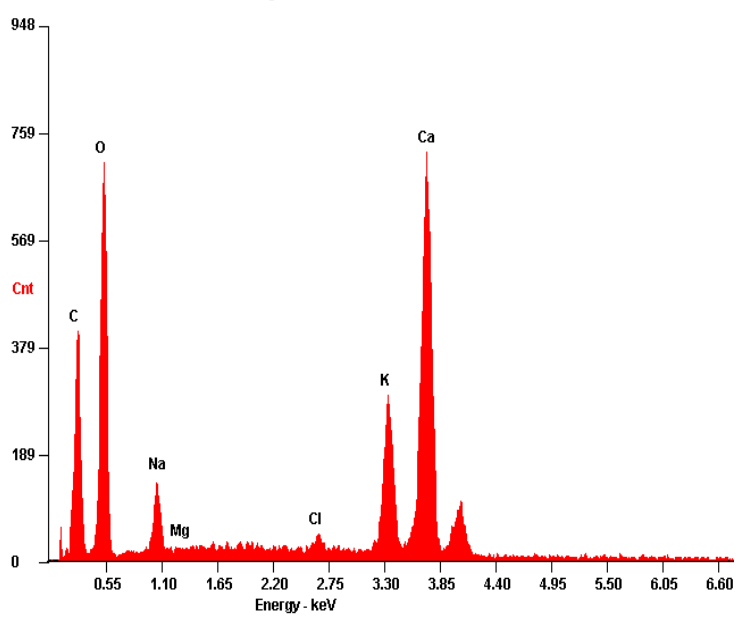

EDS X-ray of the bubbling phase between Ca-formate crystals shown at left indicating it is a Na-rich organic compound (Na-formate)

Figure 40: Backscattered electron images and EDS X-ray spectra of solids precipitated from mixing $30 / 70 \mathrm{UFB}-\mathrm{PFB}$ at $120^{\circ} \mathrm{F}$ 


\subsubsection{50\% UFB Mixed with 50\% PFB}

Figure 41 shows backscattered electron images and EDS X-ray spectrum of the solids precipitated from mixing $50 \%$ UFB with $50 \%$ PFB at an average temperature of $117.5^{\circ} \mathrm{F}$. The solids are mainly well crystallized grains of $\mathrm{KCl}$ in the $50-100 \mu \mathrm{m}$ size range and some smaller crystals that appear to be bonded to larger crystals by a thin film of $\mathrm{K}$ and Na-rich organic compounds.

\subsubsection{70\% UFB Mixed with 30\% PFB}

The images and EDS X-ray spectra of solids precipitated from mixing 70\% UFB with $30 \% \mathrm{PFB}$ at $115.5^{\circ} \mathrm{F}$ are shown in Figure 42 . Except for minor differences in the smoothness of the faces of precipitated crystals, the results show that there is virtually no difference in the composition of the solids between $115.5^{\circ} \mathrm{F}$ and room temperature samples. The precipitated solids at $115.5^{\circ} \mathrm{F}$ are also $\mathrm{KCl}$ crystals that are dispersed in an organic matrix. The EDS spectrum of the matrix suggests it could be K-formate with some Na-formate. 


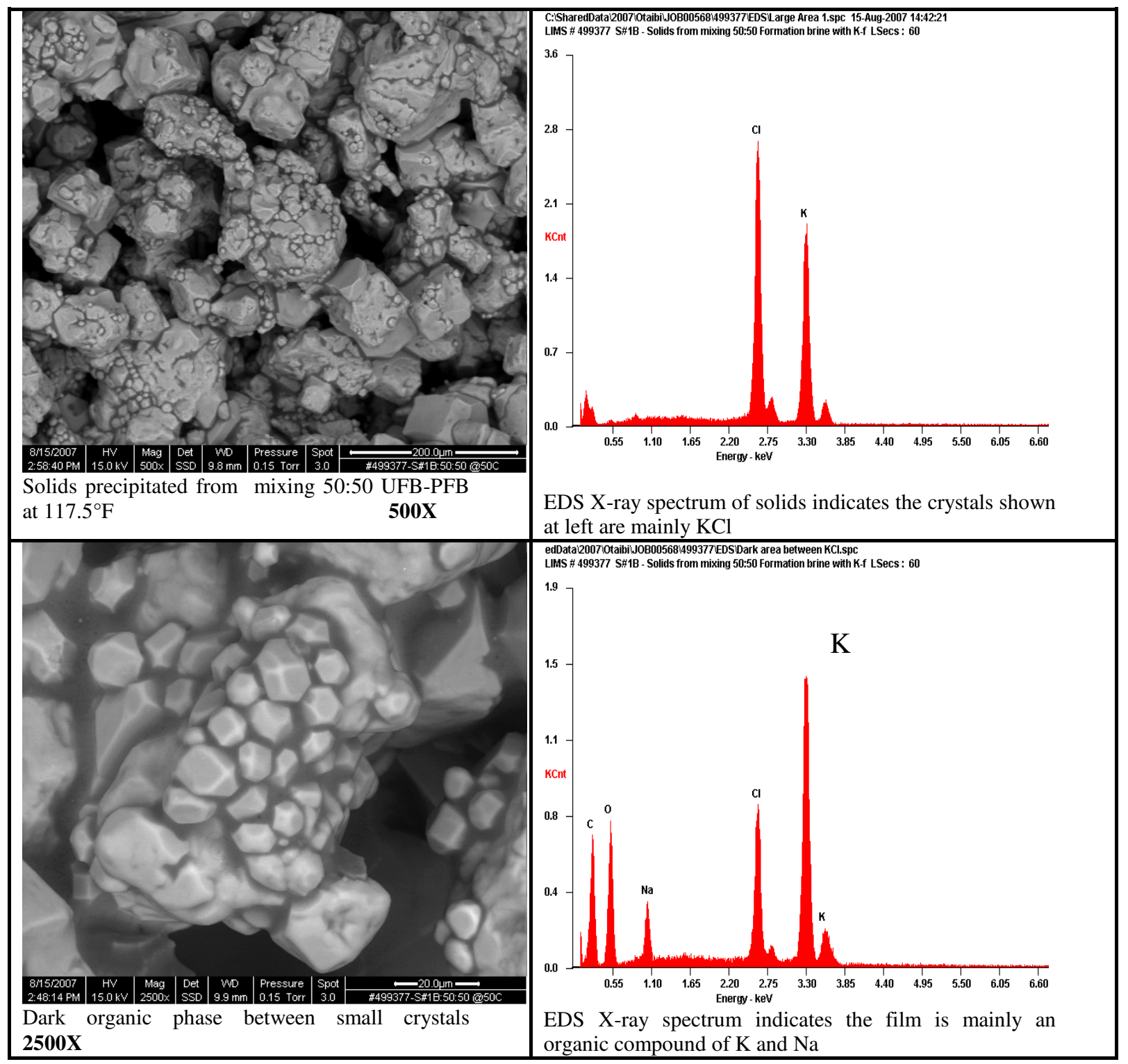

Figure 41: Backscattered electron images and EDS X-ray spectra of solids precipitated from mixing 50:50 UFB and PFB at $117.5^{\circ} \mathrm{F}$ 


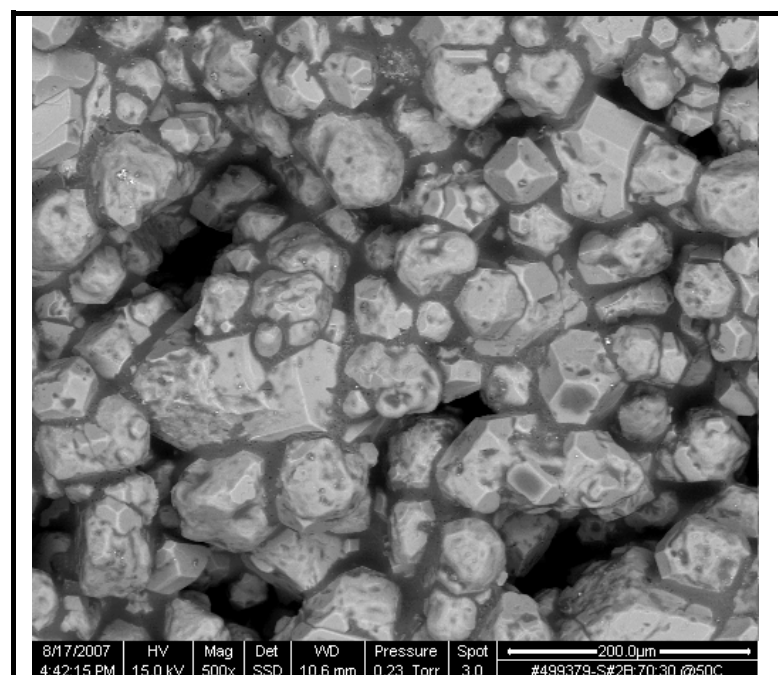

Solids precipitated from mixing 70:30 UFB-PFB at $115.5^{\circ} \mathrm{F}$

500X

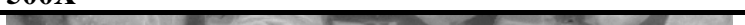

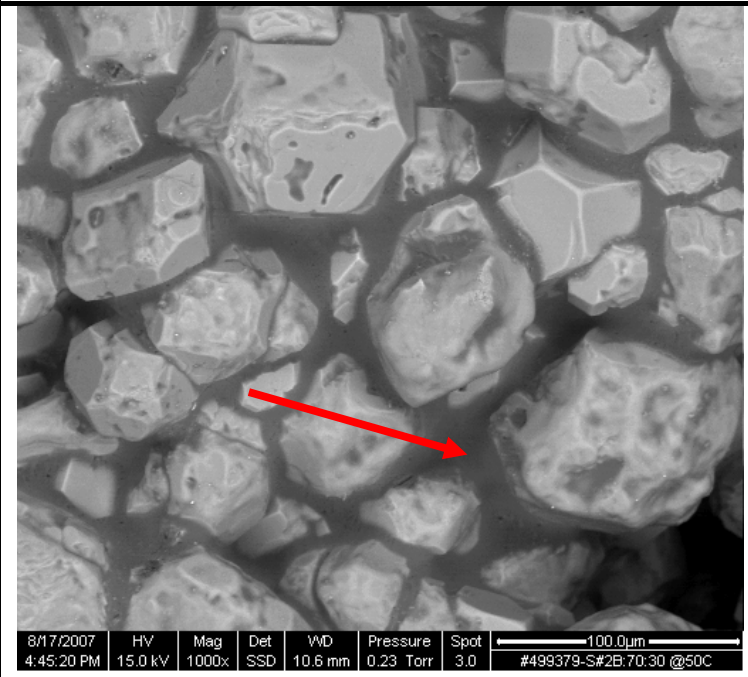

Dark organic phase (arrow) between $\mathrm{KCl}$ crystals 4000X

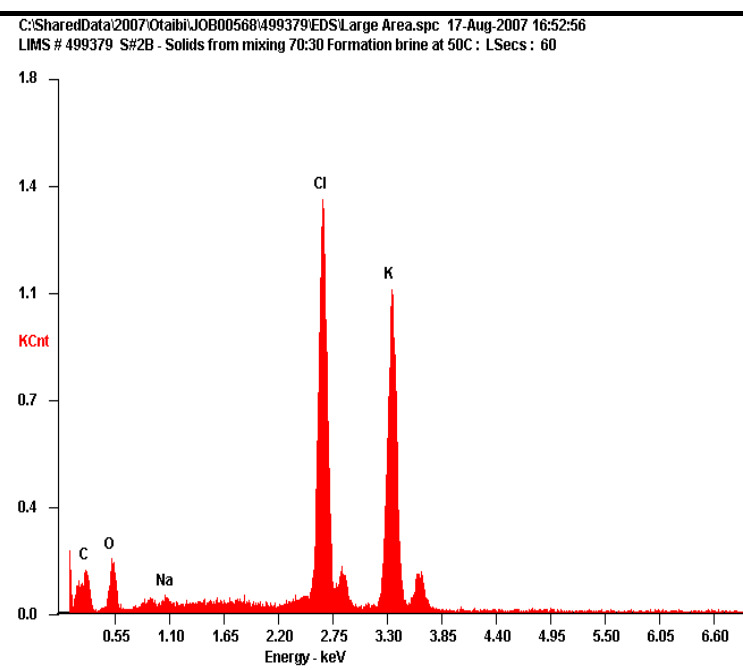

EDS X-ray spectrum indicates the bright crystals shown at left are $\mathrm{KCl}$

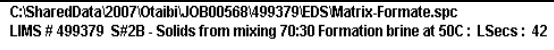

$\left.\begin{array}{l}1.4 \\ 1.1 \\ 0.8 \\ \text { KCnt } \\ 0.6 \\ 0.3- \\ 0.0\end{array}\right]$

K

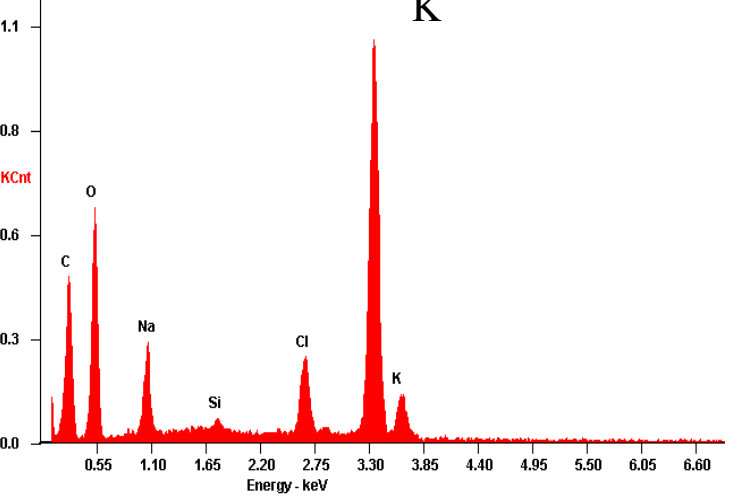

EDS X-ray spectrum of the dark phase between $\mathrm{KCl}$ crystals. The spectrum indicates the dark phase is mainly an organic compound of $\mathrm{K}$ and $\mathrm{Na}$

Figure 42: Backscattered electron images and EDS X-ray spectra of solids precipitated from mixing $70: 30 \mathrm{UFB}-\mathrm{PFB}$ at $115.5^{\circ} \mathrm{F}$ 


\subsubsection{90\% UFB Mixed with 10\% PFB}

The images and EDS X-ray spectrum and the images of the solids precipitated from mixing $90 \%$ UFB with $10 \%$ PFB at $122^{\circ} \mathrm{F}$ are shown in Figure 43 . The solids are mainly flakes of an unknown silicate phase that contains $\mathrm{Mg}, \mathrm{Al}$, and $\mathrm{Ca}$ besides $\mathrm{Si}$ and $\mathrm{O}$, needles of calcium carbonate, possibly aragonite and patches of $\mathrm{KCl}$ and $\mathrm{NaCl}$. Trace amounts of an organic compound also appear to be present as a thin film on filter paper. The presence of a significant amount of the silicate phase in this sample was unusual as it was not observed in the corresponding room temperature sample.

\subsubsection{Organic Acids Mixed with PFB Solution}

\subsubsection{10 wt\% Citric Acid Mixed with PFB at Room Temperature}

As discussed in the fluid compatibility part, citric acid was forming a solid ball at room temperature during the mixing with PFB. The ball was first separated from the solution, and then the solution was filtered through $1.2 \mu \mathrm{m}$ filter paper. All the solids were analyzed by utilizing both XRD and ESEM techniques.

The XRD result shows the ball solid mainly consists of potassium hydrogen citrate $\left(\mathrm{C}_{6} \mathrm{H}_{7} \mathrm{KO}_{7}\right)$ and potassium formate $\left(\mathrm{CHKO}_{2}\right)$. Background hump in diffractogram suggest presence of amorphous components in the sample. There are a few minor peaks are not identified in the sample. 


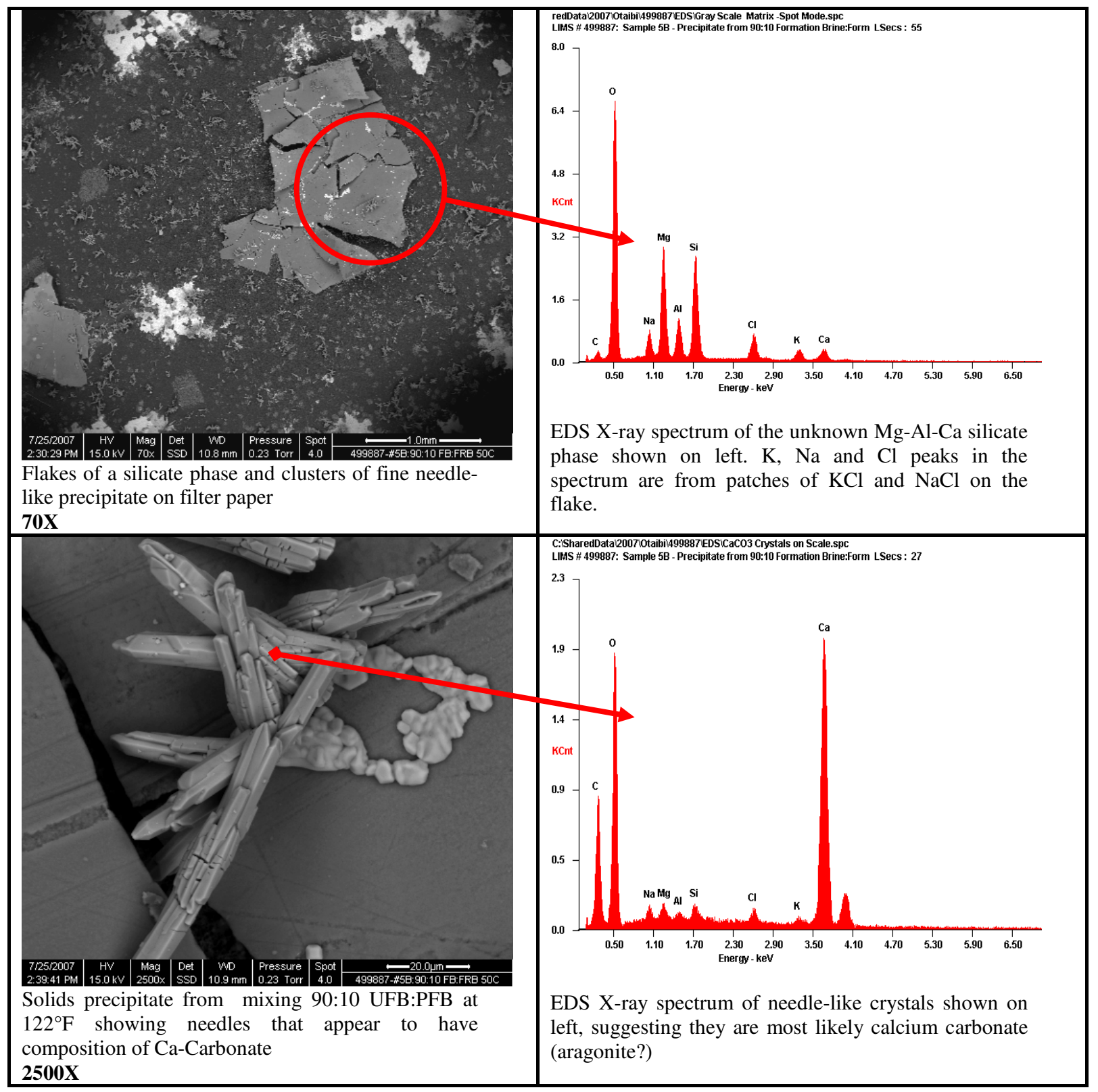

Figure 43: Backscattered electron images and EDS X-ray spectrum of the solids precipitates at $122^{\circ} \mathrm{F}$ from mixing $90 \%$ UFB with $10 \%$ PFB 
Figure 44 shows backscattered electron images and EDS X-ray spectra of the solids precipitated during mixing $10 \mathrm{wt} \%$ citric acid with PFB at room temperature. The solids in this sample show well defined crystalline form and a bimodal size distribution. The EDS analysis of the large $(\sim 20 \mu \mathrm{m})$ and small $(<5 \mu \mathrm{m})$ crystals indicate that they both contain $\mathrm{K}, \mathrm{O}$ and $\mathrm{C}$, which suggests they are most likely organic compounds of potassium. The XRD analysis indicates the solids are a mixture of K-formate and Kcitrate. This indicates that the two types (sizes) of crystals observed in the ESEM probably correspond to two different compounds, namely K-citrate and K-formate. However, because of the qualitative nature of light element analysis in the ESEM it was not possible to determine which size crystals correspond to which compound.

The filtered solid on the paper contains minor quantities of potassium hydrogen citrate $\left(\mathrm{C}_{6} \mathrm{H}_{7} \mathrm{KO}_{7}\right)$ and potassium formate $\left(\mathrm{CHKO}_{2}\right)$. Potassium chlorate $\left(\mathrm{KClO}_{3}\right)$ might also be present in the sample. Background hump in diffractogram suggest major portion of the sample consists of amorphous components. No precipitates were noticed when the mixture was prepared at high temperature.

Figure 45 shows the images and EDS X-ray spectra of the solids filtered from a mixture of $10 \mathrm{wt} \%$ citric acid and PFB at room temperature. As in the previous sample, this sample shows well crystallized grains and their EDS spectra show $\mathrm{K}, \mathrm{O}$ and $\mathrm{C}$, indicating the solids are mainly organic compounds of potassium. The XRD analysis indicates K-formate and K-citrate are the main two phases in the sample, which suggests there is no noticeable difference between the two samples. 

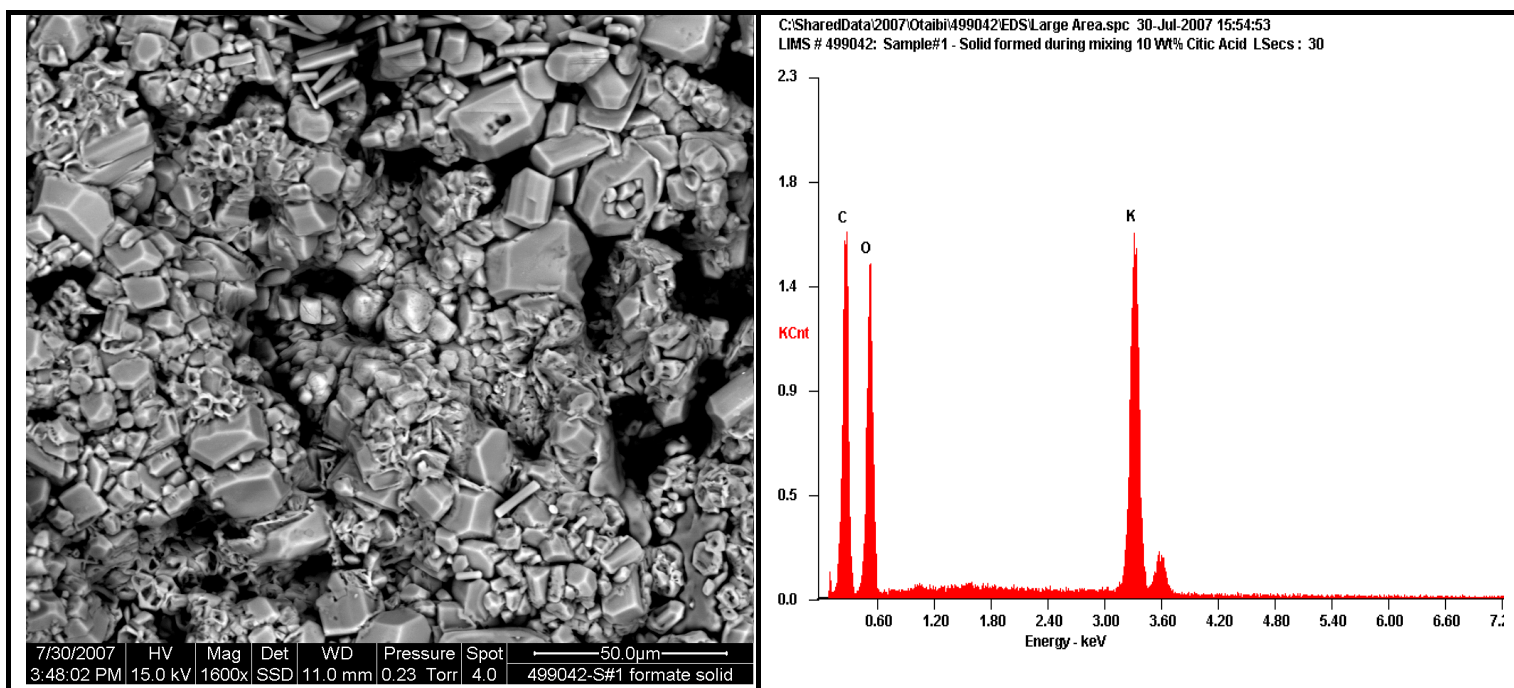

Solids precipitated from mixing $10 \mathrm{wt} \%$ citric acid with PFB at room temperature

$1600 X$

EDS X-ray spectrum of solids indicates the sample is mainly an organic compound of potassium.

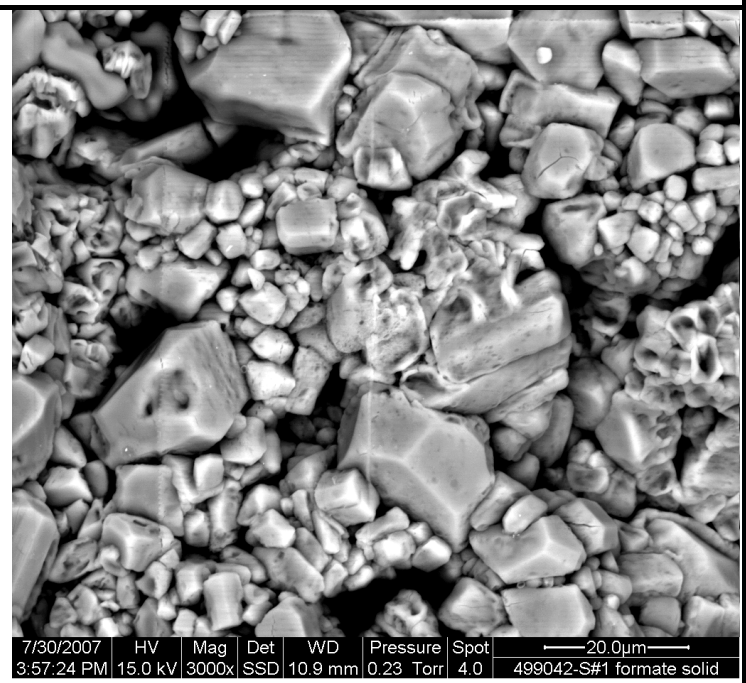

Solids precipitated from mixing $10 \mathrm{wt} \%$ citric acid with PFB at room temperature

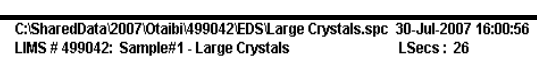

3000X

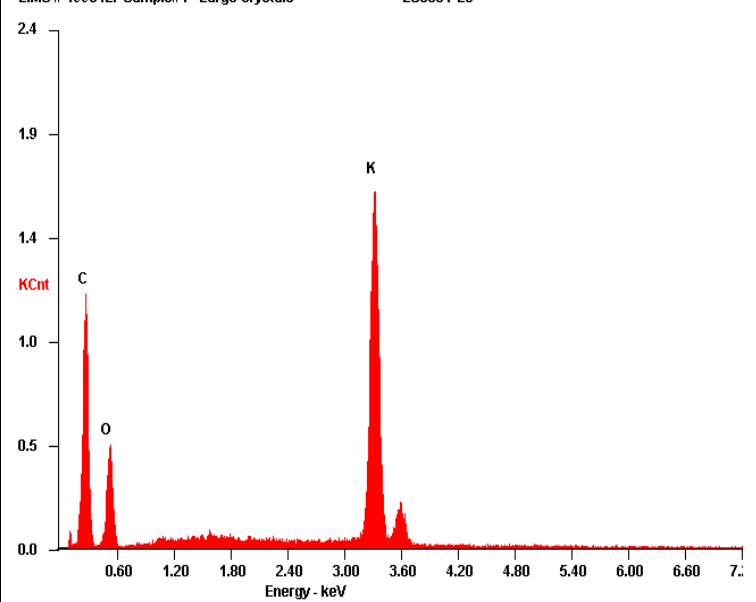

EDS X-ray spectrum of the large crystals seen in the image on left.

Figure 44: Backscattered electron images and EDS X-ray spectra of solids precipitated during mixing of $10 \mathrm{wt} \%$ citric acid with PFB at room temperature 


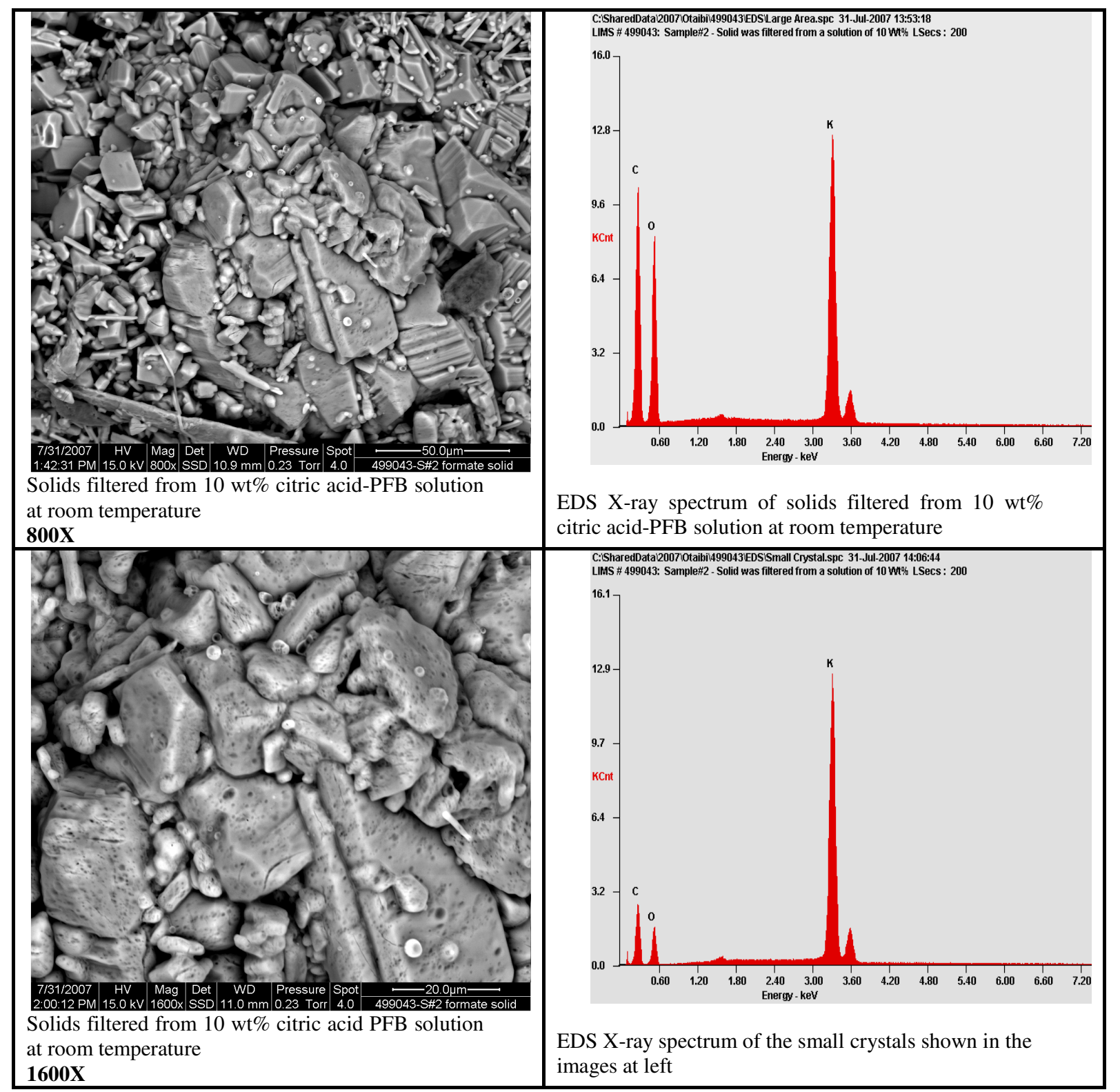

Figure 45: Backscattered electron images and EDS X-ray spectra of solids filtered from $10 \mathrm{wt} \%$ citric acid-PFB solution at room temperature 


\subsubsection{10 wt\% Formic Acid Mixed with PFB at Room Temperature}

Formic acid shows incompatibility with PFB solution at room temperature. At high temperatures, the mixture was compatible but when temperature reduced to the room temperature, it became a gel. The precipitates were analyzed by XRD first, and the result shows it is potassium hydrogen formate compound $\left(\mathrm{C}_{2} \mathrm{H}_{3} \mathrm{KO}_{4}\right)$.

Figure 46 shows images and EDS X-ray spectra of the solid formed from reaction of $10 \%$ formic acid with PFB. The results indicate the wet solid which crystallized under high vacuum in the microscope has the composition of K-hydrogen formate. Such wet corrosive solids are not suitable for examination in the ESEM since during initial pump down cycle the samples dry out and the corrosive gases released could easily damage to the delicate components of the microscope. In addition, the samples can also show some drying artifacts that might be not present in the original sample. 


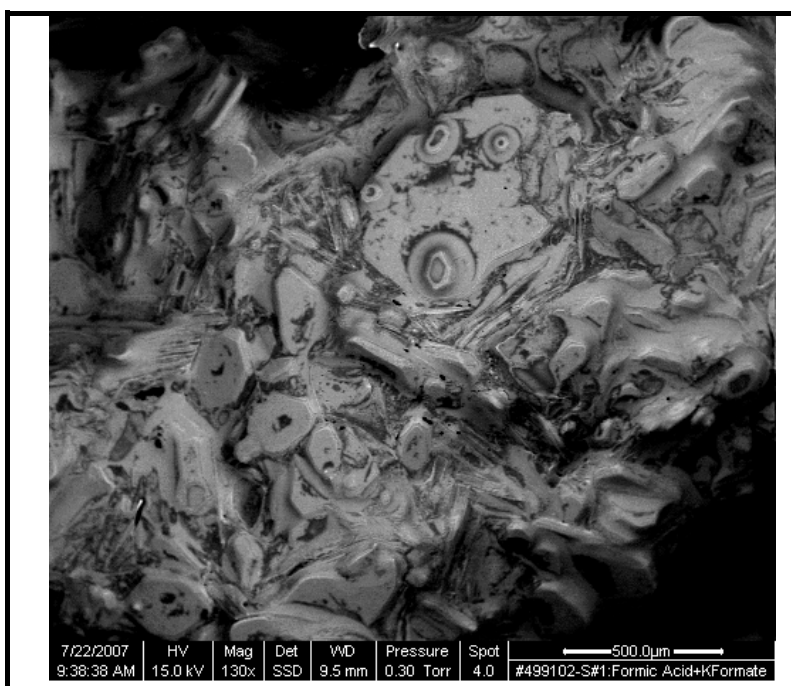

Solids from reacting $10 \%$ formic acid with PFB showing crystals of K-hydrogen formed upon drying in the microscope.

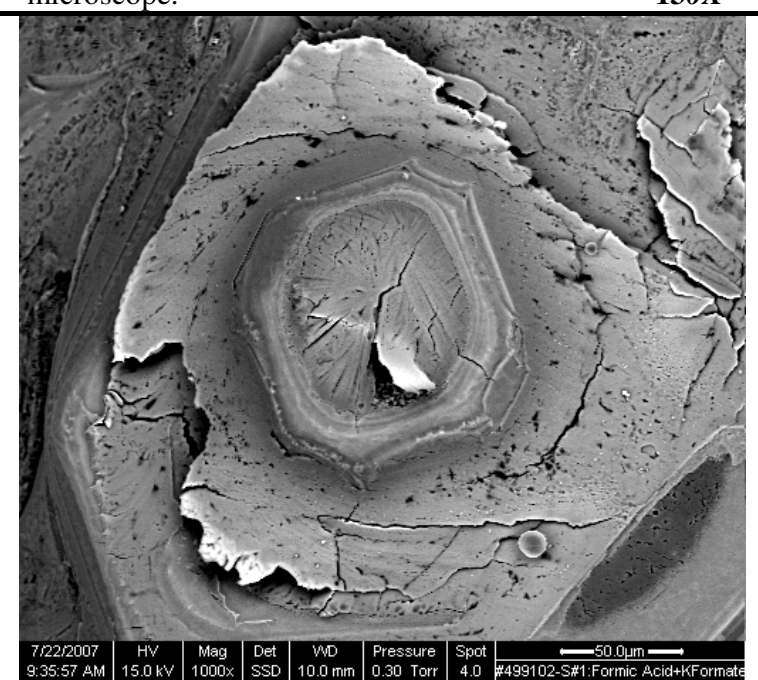

High magnification image of solids shown above $1000 \mathrm{X}$

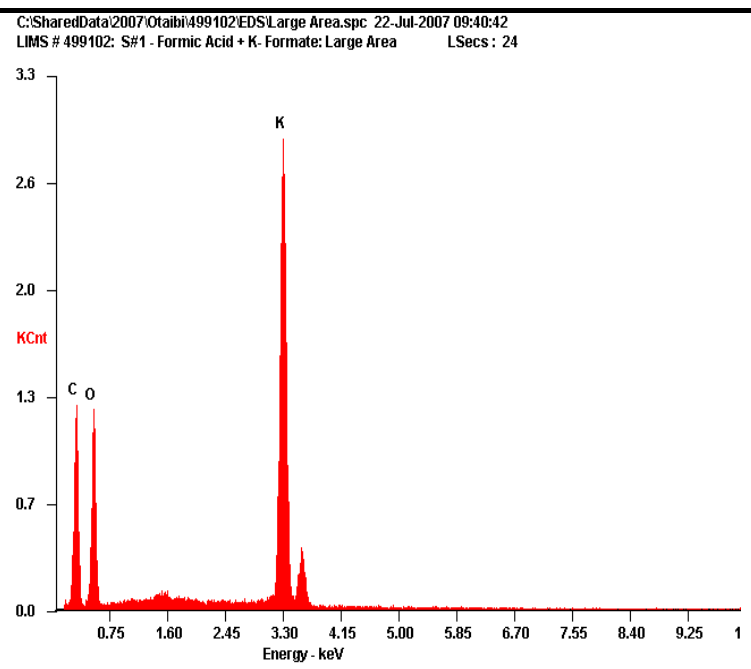

EDSX-ray spectrum indicating the solids has K-hydrogen formate composition

EDSX-ray spectrum of the area at right indicating the solids have K-hydrogen formate composition

Figure 46: Backscattered electron images and EDS Spectra of solids formed from $10 \%$ formic acid reaction with PFB at room temperature 


\subsection{Analysis of Dynamic HPHT Filter Press Cell Experiments}

\subsubsection{Drilling Fluid Experiment}

Field drilling fluid samples were used in all lab experiments and that sample was collected from a rig site while drilling a gas well. The drilling fluid formulation and properties are shown in Table 2. $1.2 \mu \mathrm{m}$ filter paper was utilized at the beginning to filter the drilling fluid solids at room temperature. It was difficult to filter all solids at room temperature. Therefore, the filter paper was replaced twice. A static HPHT filter press was employed to make sure most of the solids are filtered. A 3- $\mu$ m ceramic disk was used, instead of the filter paper, at temperature and pressure of $300^{\circ} \mathrm{F}$ and $200 \mathrm{psia}$, respectively. Then, the solids were dried in the oven at a temperature of $194^{\circ} \mathrm{F}$ for 3 hours. Solid samples presented on both filter papers and ceramic disk were analyzed by using XRD technique. Table 6 shows XRD result for the solids, they were mainly calcite and dolomite. Dolomite concentration was more than $15 \mathrm{wt} \%$ and the source of that were the impurities of the calcium carbonate particles, which used in drilling fluid. The source of the barite was the drilling fluid that was used to drill the upper hole section. A minor quantity of quartz was present in the filter cake. Core plugs samples from an offset well were crushed and sent to XRD for analysis. The results showed $97 \mathrm{wt} \%$ of the solids was quartz $\left(\mathrm{SiO}_{2}\right)$ and the rest $3 \mathrm{wt} \%$ was kaolinite $\left(\mathrm{Al}_{2} \mathrm{Si}_{2} \mathrm{O}_{5}\left(\mathrm{OH}_{5}\right)\right.$. 
Table 6: Solids filtered from field drill-in fluid sample

\begin{tabular}{|l|l|c|c|c|c|}
\hline \multirow{3}{*}{ Compound } & \multirow{3}{*}{ Formula } & \multicolumn{3}{|c|}{ Filter Paper Size (1.2 $\boldsymbol{\mu m})$} & Ceramic Disk (3 $\boldsymbol{\mu m})$ \\
\cline { 3 - 5 } & & Filtration conditions at room temperature & \multirow{2}{*}{ at 250 $\mathrm{F}$ and 200 psi } \\
\cline { 3 - 6 } & & Filter paper \# 1 & Filter paper \# 2 & Filter paper \# 3 & \\
\cline { 3 - 6 } & & \multicolumn{4}{|c|}{ Concentration, wt\% } \\
\hline Calcite & $\mathrm{CaCO}_{3}$ & 72 & 66 & 72 & 71 \\
\hline Dolomite & $\mathrm{CaMg}_{\left(\mathrm{CO}_{3}\right)_{2}}$ & 17 & 20 & 16 & 17 \\
\hline Barite & $\mathrm{BaSO}_{4}$ & 6 & 8 & 6 & 7 \\
\hline Quartz & $\mathrm{SiO}_{2}$ & 5 & 6 & 6 & 5 \\
\hline
\end{tabular}

\subsubsection{5 vol\% Ethyl Lactate Ester (ELE)}

Potassium chloride brine was used to measure the base flow rate, through $3-\mu \mathrm{m}$ undamaged disk, at a temperature of $303^{\circ} \mathrm{F}$ and a pressure of 50 psia. Then, formate drilling fluid was loaded in the filter press cell at the same temperature and 200 psia overbalanced pressure. The motor shaft rotated at $100 \mathrm{rpm}$ to simulate the dynamic condition while drilling operation. The cumulative filtrate volume was collected as a function of time. The cell was disconnected and the filter cake thickness was measured, Figure 47. A 5 vol.\% ethyl lactate ester (ELE) solution was prepared in $\mathrm{KCl}$ brine solution as shown in Table 7. The ester solution, $200 \mathrm{ml}$, was soaked for 30 minutes in the cell after the reservoir temperature was reached. Then, the stem valve at the bottom of the cell cap was fully opened. The objective behind this step was to determine the breakthrough time after dissolving the filter cake layer. The breakthrough time of the reaction was expected to be between 3 to 4 hours since it is a weak acid. Most of the ester solution passed through the valve within 4 minutes. The solution channeled through the weakest point in the ceramic disk. Small cracks were created on the face of the disk 
as shown on Figure 47. The flow rate of $\mathrm{KCl}$ brine through the ceramic disk was measured before the damage and after soaking the disk with ester solution. Removing efficiency can be calculated based on the initial and final brine flow rate. The soaking time for the ester solution was not enough to clean the filter cake. The remaining solids on the disk were sent to XRD, EDXRF and ESEM for further analysis. The result showed 58 wt $\%$ calcite $\left(\mathrm{CaCO}_{3}\right), 15 \mathrm{wt} \%$ sylvite $(\mathrm{KCl}), 10 \mathrm{wt} \%$ dolomite $\left(\mathrm{CaMg}\left(\mathrm{CO}_{3}\right)_{2}\right)$ and $10 \mathrm{wt} \%$ barite $\left(\mathrm{BaSO}_{4}\right)$. The EDXRF analysis is given in Table 8 .

\section{clear cracks}

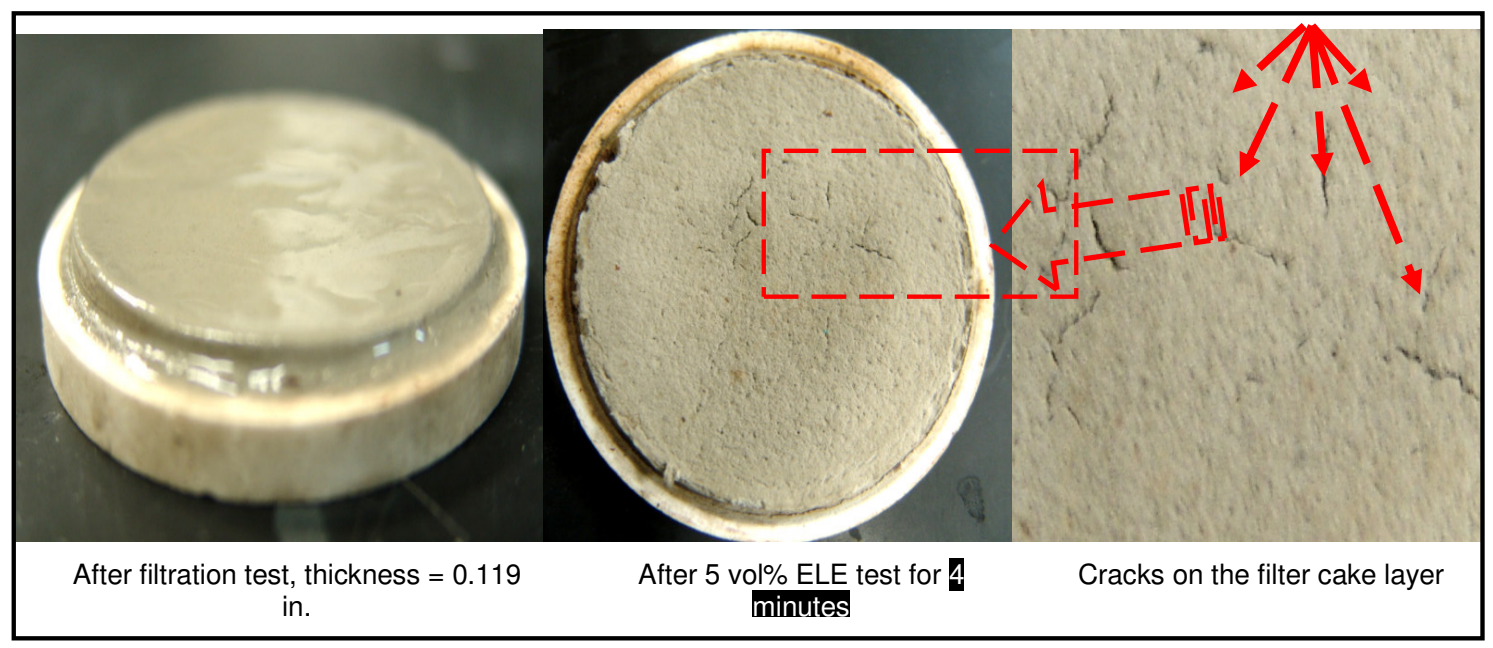

Figure 47: Filter cake after filtration test and 5 vol\% ethyl lactate ester (ELE), temperature $=303^{\circ} \mathrm{F}$ and pressure $=200 \mathrm{psi}$. 
Table 7: Formula of ethyl lactate ester cleaning solution

\begin{tabular}{|l|c|c|c|}
\hline \multicolumn{1}{|c|}{ Component } & \multicolumn{2}{c|}{ Quantity for 5 and 10 vol\% solution } & Units \\
\hline Water & 94.5 & 89.5 & $\mathrm{~cm}^{3}$ \\
\hline $\mathrm{KCl}$ & 5 & 5 & $\mathrm{~g}$ \\
\hline Acid Precursor & 5 & 10 & $\mathrm{~cm}^{3}$ \\
\hline Nonionic Surfactant & 0.2 & 0.2 & $\mathrm{~cm}^{3}$ \\
\hline Corrosion inhibitor & 0.3 & 0.3 & $\mathrm{~cm}^{3}$ \\
\hline $\mathrm{pH} @ 79^{\circ} \mathrm{F}$ & 3.59 & 3.00 & - \\
\hline Density @ 79 $\mathrm{F}$ & 64.93 & 65.05 & $1 \mathrm{~b} / \mathrm{ft}^{3}$ \\
\hline
\end{tabular}

Table 8: EDXRF result for solids on the surface of the ceramic disk after 5 vol\% ethyl lactate ester

\begin{tabular}{|l|c|c|c|c|c|c|c|c|c|c|c|c|c|c|}
\hline Element & $\mathrm{Ca}$ & $\mathrm{Ba}$ & $\mathrm{K}$ & $\mathrm{Cl}$ & $\mathrm{Si}$ & $\mathrm{Na}$ & $\mathrm{Mg}$ & $\mathrm{S}$ & $\mathrm{Al}$ & $\mathrm{Fe}$ & $\mathrm{Sr}$ & $\mathrm{Mn}$ & $\mathrm{P}$ & $\mathrm{Zn}$ \\
\hline Concentration & 23 & 8.3 & 8.2 & 7.3 & 4.7 & 1.8 & 1.6 & 0.9 & 0.6 & 0.4 & 700 & 600 & $<500$ & $<500$ \\
\hline Unit & \multicolumn{10}{|c|}{ wt. $\%$} \\
\hline
\end{tabular}

The ESEM results confirmed the presence of the previous compounds in XRD test in addition to $7 \mathrm{wt} \%$ quartz $\left(\mathrm{SiO}_{2}\right)$. The disk was broken to small pieces to do a cross section analysis. The EDS X-ray spectrum of the solids below the disk surface is shown in Figure 48 suggests presence of calcite, barite, sylvite and some silicates in the solids. The SEM image of the disk cross-section showed bright $\mathrm{KCl}$ layer on the surface and very fine particles trapped in the pores to about $50 \mu \mathrm{m}$ below surface, Figures 49 and 50 . The EDS X-ray spectrum of filter cake solids on the ceramic disk surface indicated presences of $\mathrm{CaCO}_{3}, \mathrm{BaSO}_{4}, \mathrm{SiO}_{2}$ and possibly some clay particles, Figure 51. Trace amounts of heavy mineral zircon (zirconium silicate), and a few $\mathrm{Fe}-\mathrm{Cr}$ particles were also observed in the disk just below the surface. 


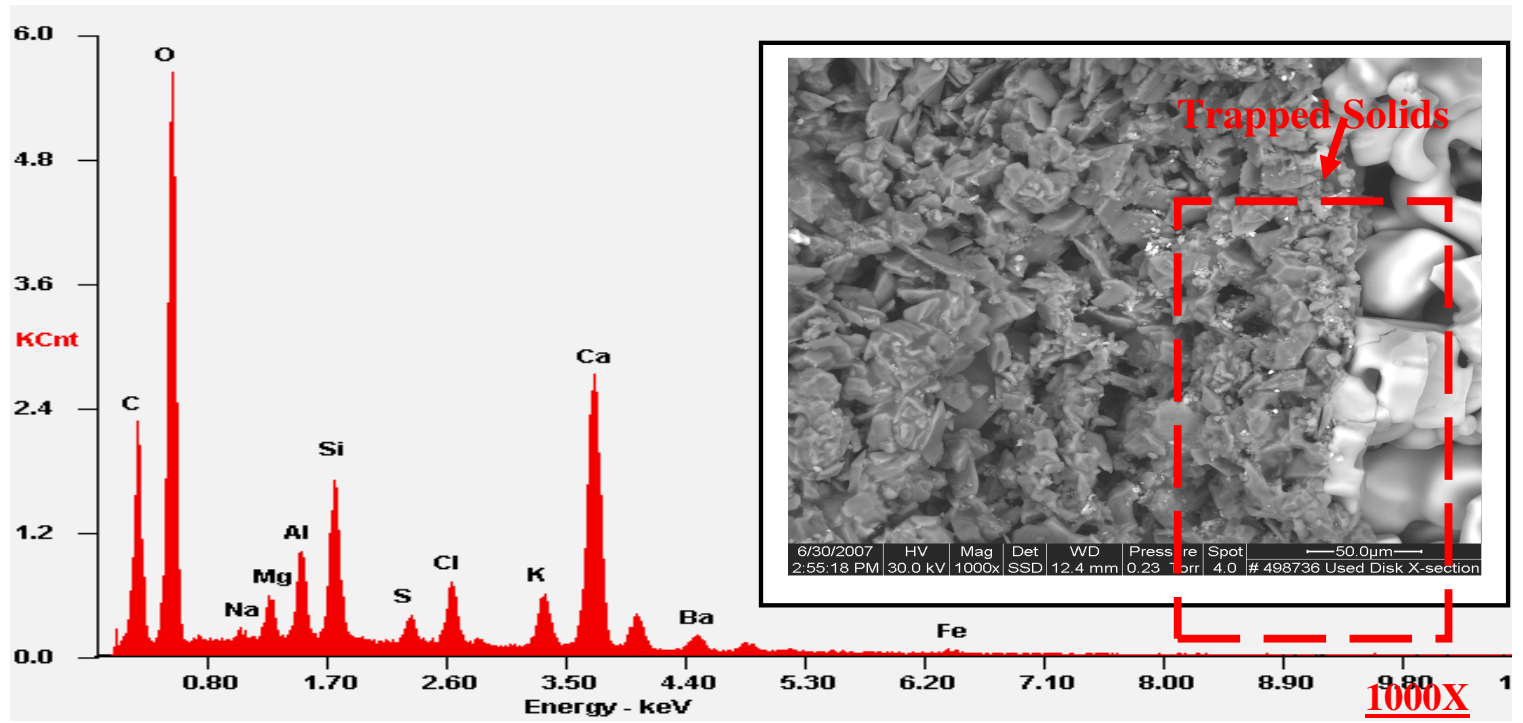

Figure 48: EDS X-ray spectrum of the disk cross-section after 5 vol\% ethyl lactate ester

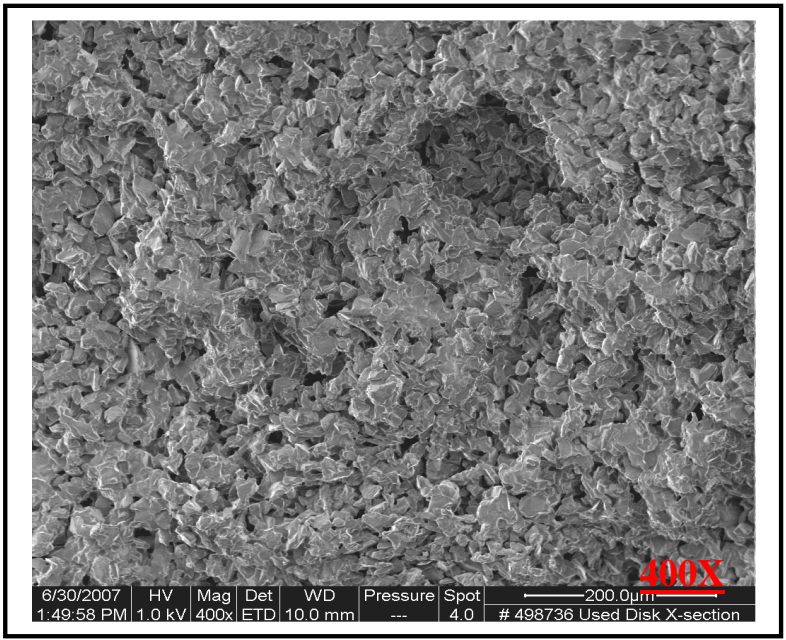

Figure 49: BSE image of the disk cross-section $\mathrm{KCl}$ patches in the interior of the disk 


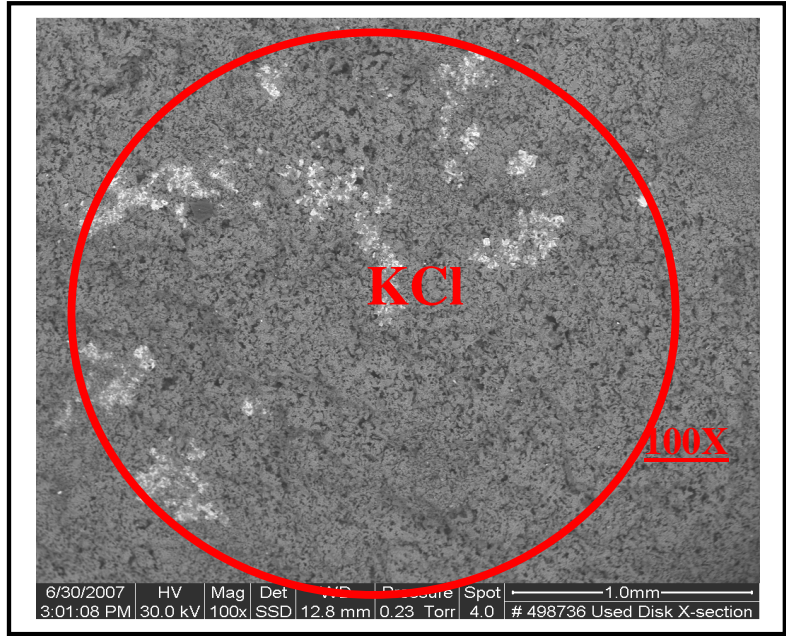

Figure 50: BSE image of the disk showing bright showing absence of solids in the interior of the disk

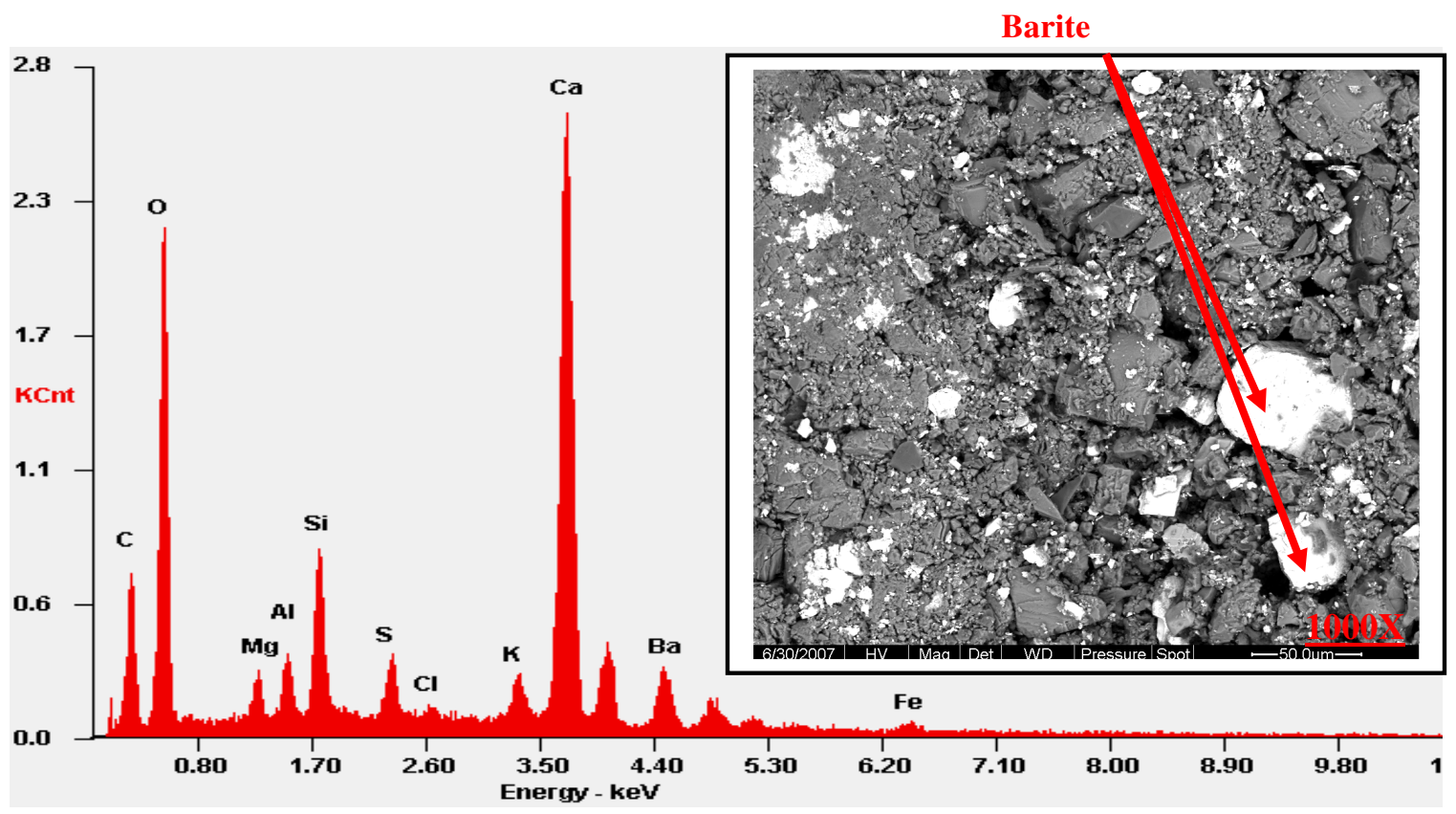

Figure 51: EDS X-ray spectrum of filter cake solids on ceramic disk 


\subsubsection{5 vol\% ELE for 5 hours}

The second experiment was conducted by following the same procedure in the first test. The same drilling and cleaning fluids were used in this test and the only difference was the soaking time. The thickness of the filter cake was 0.18 in. after the filtration test step. A base flow rate was measured by using $\mathrm{KCl}$ fluid after the damage was created and the result was negligible. The 5 vol\% lactate ester solution was left 5 hours for soaking, at a temperature range between 300 to $315^{\circ} \mathrm{F}$. The generated lactic acid solution was able to dissolve most of the filter cake and the removing efficiency was above 80\%, Figure 52.

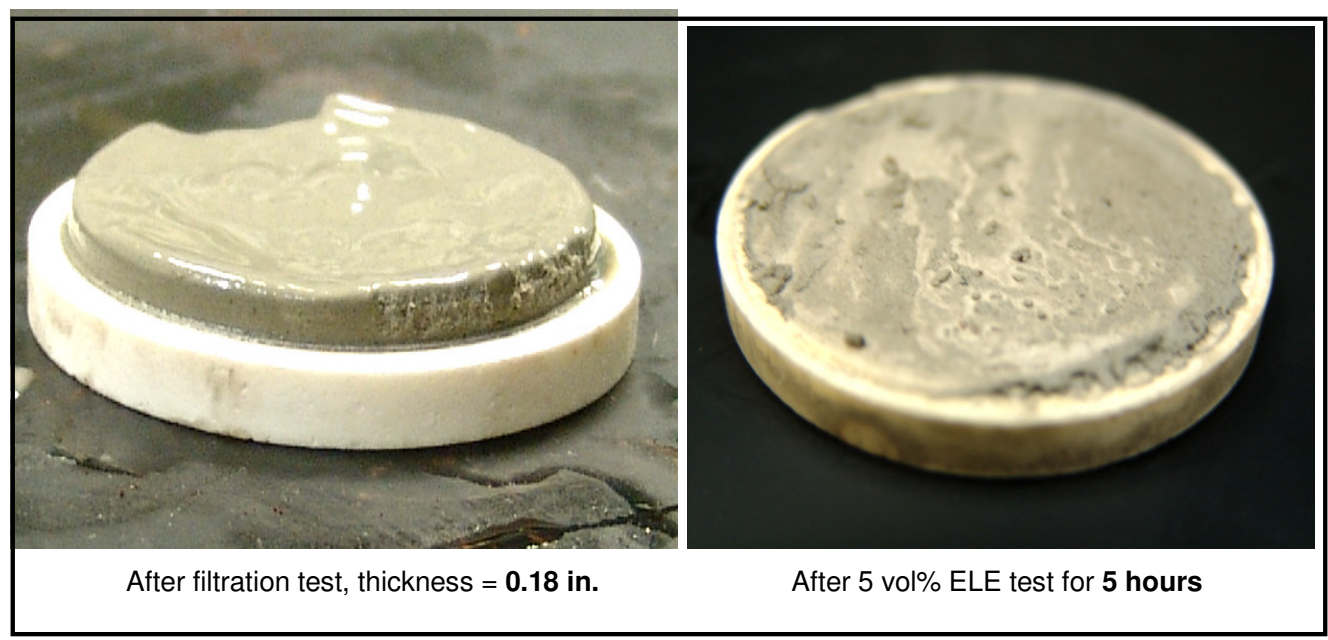

Figure 52: Filter cake after filtration test and 5 vol\% ethyl lactate ester (ELE), temperature $=300-315^{\circ} \mathrm{F}$ and pressure $=200$ psi.

\subsubsection{0 vol\% ELE}

In this experiment, the concentration of the ester solution was increased to be $10 \mathrm{vol} \%$ to dissolve more calcium carbonate particles. The cake thickness was 0.119 in. and the test temperature was $298^{\circ} \mathrm{F}$. The cell was filled with $\mathrm{KCl}$ brine to measure the flow through 
the damaged disk. The recorded brine volume through the cake was almost zero. The ELE solution was soaked for $5 \mathrm{hrs}$ at temperature and pressure of $304^{\circ} \mathrm{F}$ and $200 \mathrm{psi}$, respectively. Increasing the concentration of the ester solution did significant improve the filter cake cleanup efficiency as shown in Figure 53.

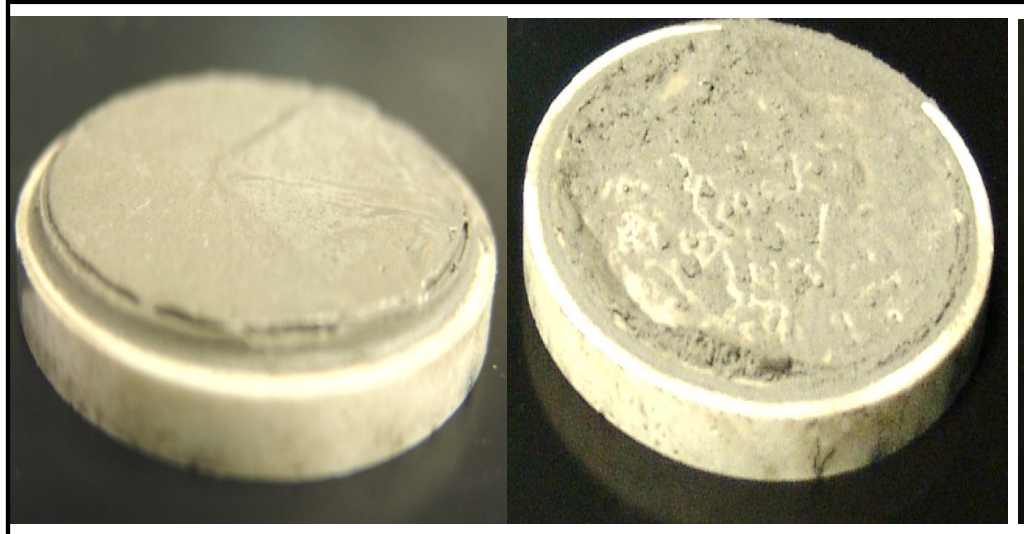

After filtration test, thickness $=\mathbf{0 . 1 2}$ in.
After 10 vol\% ELE test for 5 hours

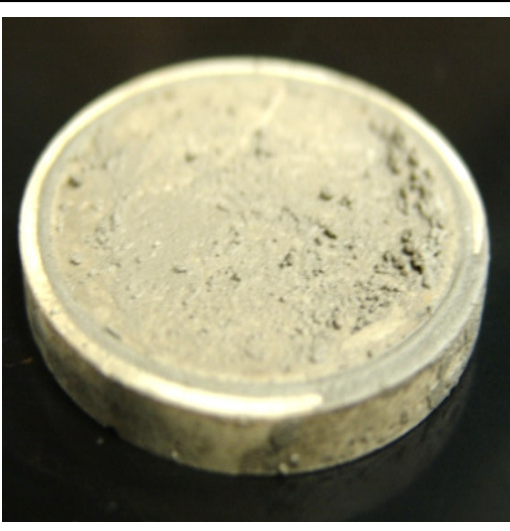

After last stage of $\mathrm{KCl}$ brine test

Figure 53: Filter cake after filtration test and 10 vol\% ethyl lactate ester (ELE), temperature $=300^{\circ} \mathrm{F}$ and pressure $=200$ psi.

\subsubsection{Solids-free Potassium Formate Brine}

Solids-free potassium formate brine has been commonly used in the field to remove the filter cake damage at both static and dynamic conditions. The aim of this experiment was to examine the effect of formate brine in removing filter cake damage mechanically. The same procedure was followed, as done in previous experiments, and the cake thickness was found to be 0.16 in. The solids-free potassium formate brine was loaded in the cell and the rotating shaft was fixed at $100 \mathrm{rpm}$ simulating field operation. The cell 
temperature was kept at $300^{\circ} \mathrm{F}$ and the pressure at 200 psi. The cell was rotating for 5 hours, and the formate brine solution was able to remove only a small portion of the external filter cake layer as shown in Figure 54.

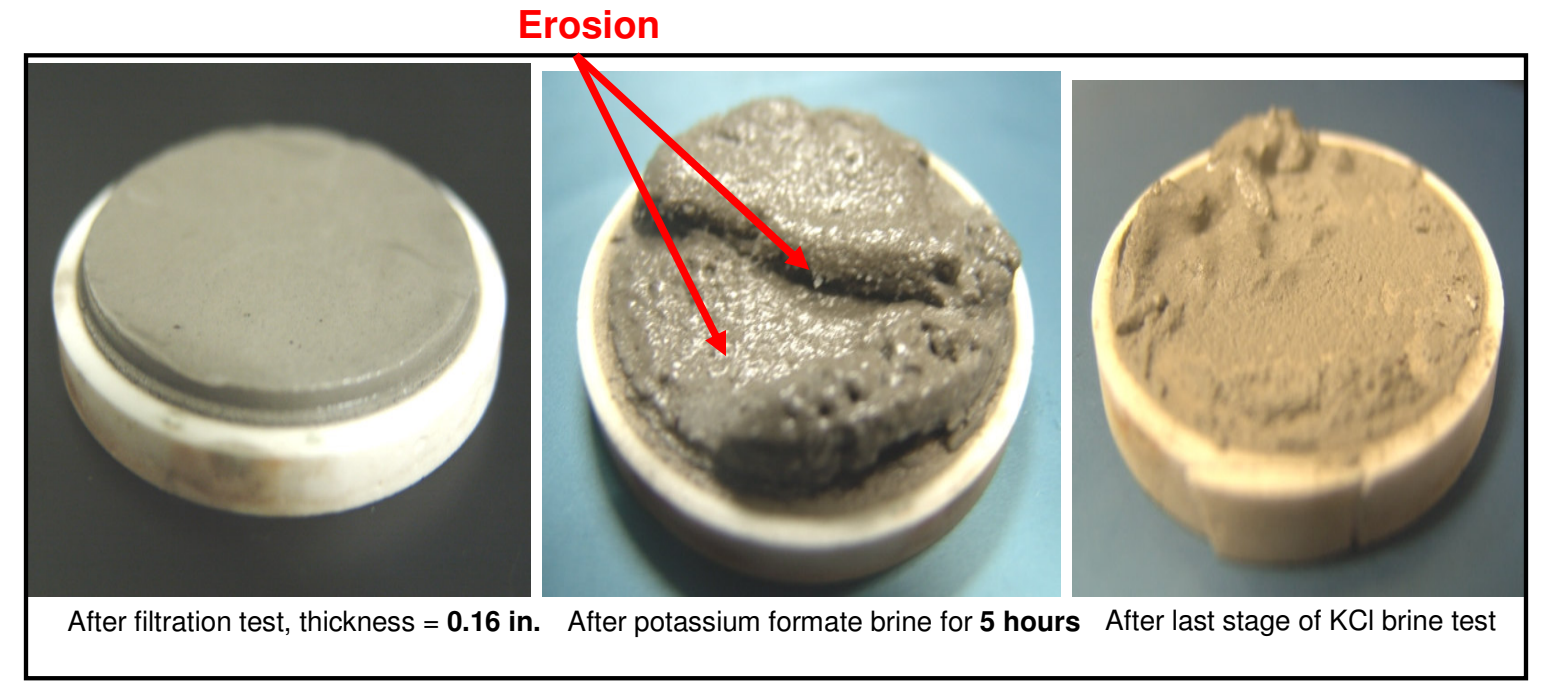

Figure 54: Filter cake after filtration test and solids-free potassium formate brine, temperature $=300^{\circ} \mathrm{F}$ and pressure $=200$ psi.

\subsection{6 $10 w t \%$ Citric Acid}

Organic acids are usually added to potassium formate brine to dissolve the filter cake solids as mentioned earlier in the introduction section. A $10 \mathrm{wt} \%$ citric acid was prepared in potassium formate brine at temperature of $122^{\circ} \mathrm{F}$. At room temperature, the acid formed a sticky ball of solid while mixing the solution and for that reason it was reprepared at higher temperature. The filter cake thickness was 0.20 in. at $301^{\circ} \mathrm{F}$ and 200 psi, Figure 55. The citric acid was able to thin the filter cake, but not remove it completely. The removing efficiency after using citric acid was $44 \mathrm{wt} \%$. 


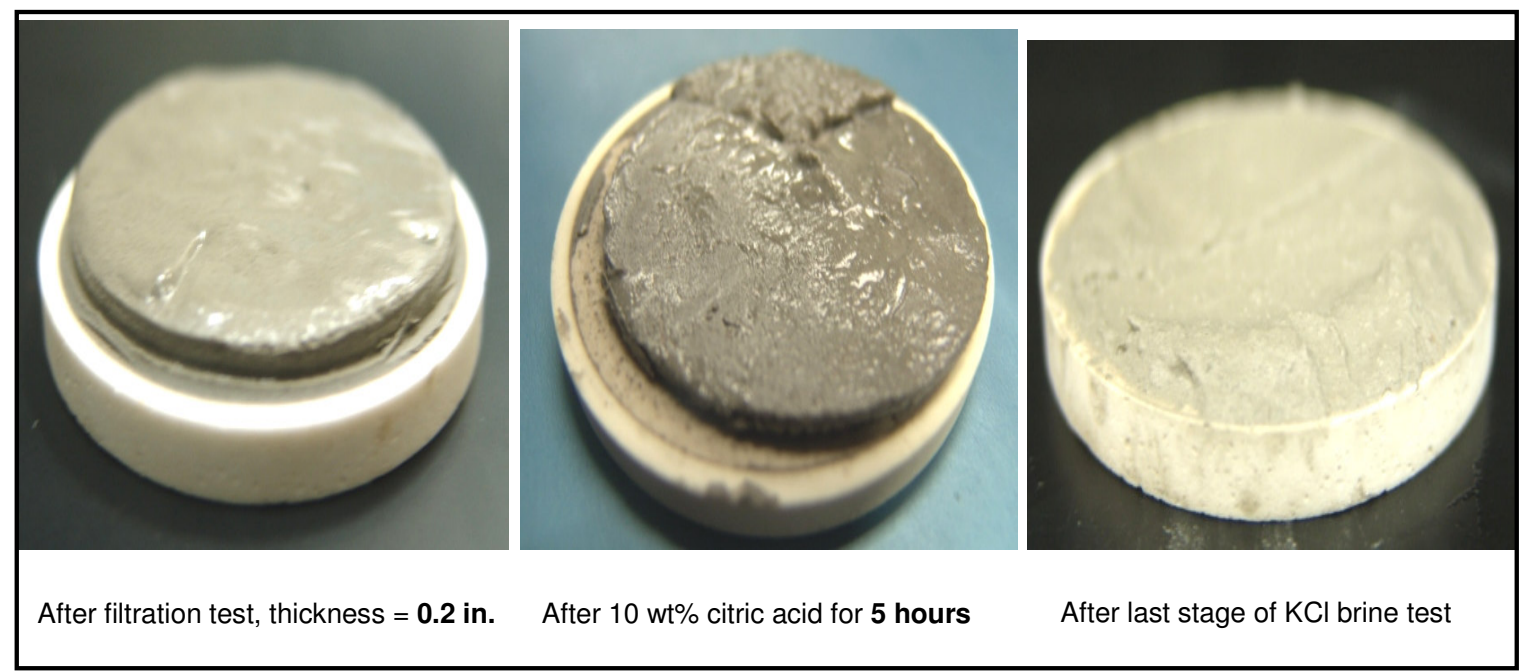

Figure 55: Filter cake after filtration test and $10 \mathrm{wt} \%$ citric acid solution, temperature $=301^{\circ} \mathrm{F}$ and pressure $=200 \mathrm{psi}$

\subsection{7 $10 w t \%$ Formic Acid}

In this experiment, formic acid was tested to remove the filter cake damage. $10 \mathrm{wt} \%$ formic acid was added to the potassium formate brine at temperature of $122^{\circ} \mathrm{F}$. A corrosion inhibitor was mixed in this and the previous acid solutions to avoid any corrosion to the filter press cell at HPHT. The $\mathrm{pH}$ and the density of the fresh solution were 6.6 and $93 \mathrm{pcf}$, respectively at temperature of $72^{\circ} \mathrm{F}$. The formic acid solution was able to remove only $24 \mathrm{wt} \%$ of the filter cake solids, Figure 56 . The cell was then disconnected after soaking the solution for 5 hrs. The $\mathrm{pH}$ of the returned liquid was almost similar to the fresh one, 6.8 . 


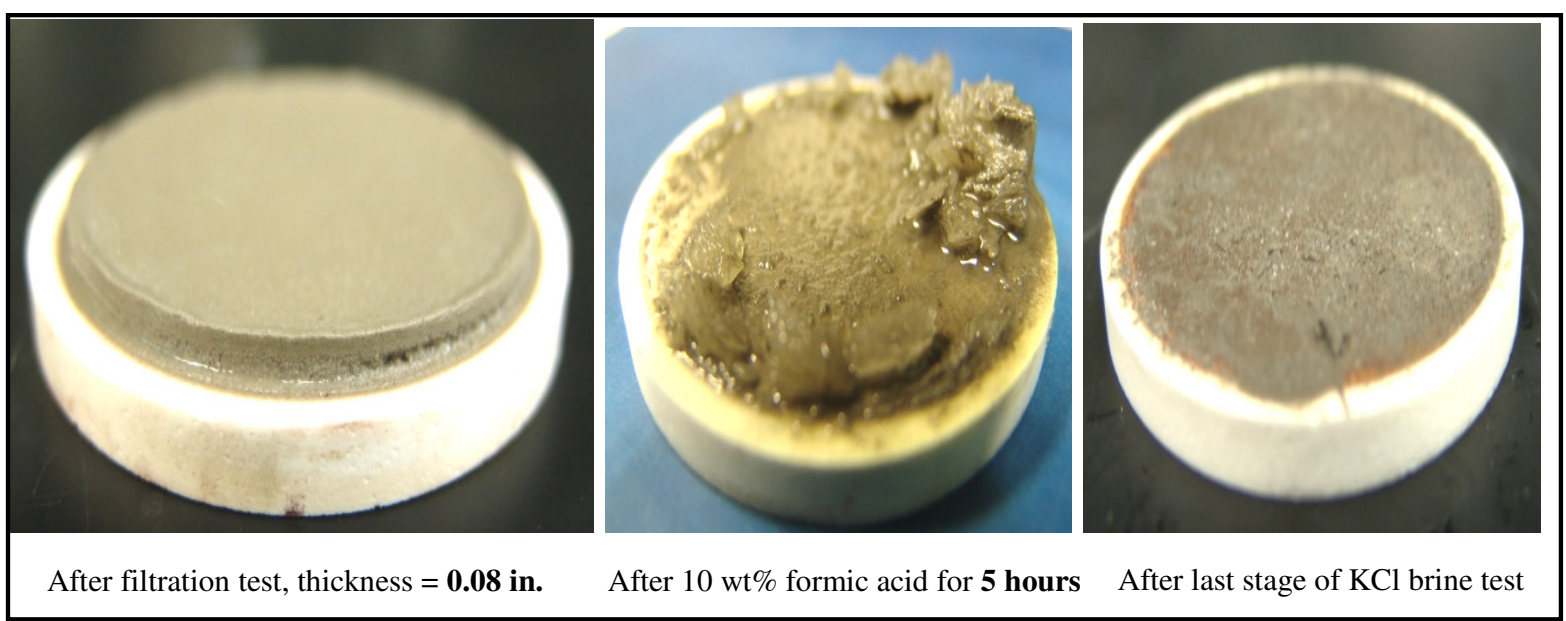

Figure 56: Filter cake after filtration test and $10 \mathrm{wt} \%$ formic acid solution, temperature $=304^{\circ} \mathrm{F}$ and pressure $=200 \mathrm{psi}$

\subsection{8 $10 w t \%$ Acetic Acid}

$10 \mathrm{wt} \%$ acetic acid was mixed in potassium formate brine at room temperature. The acid showed a good compatibility with the formate brine at room and high temperatures. The solution $\mathrm{pH}$ and the density were measured at temperature of $72^{\circ} \mathrm{F}$ and were equal to 7.35 and 89.27 pcf, respectively. The acetic acid solution was soaked for 5 hrs at temperature and pressure of $300^{\circ} \mathrm{F}$ and $200 \mathrm{psi}$. The removing efficiency was measured at the end of the test and was only $28 \mathrm{wt} \%$, Figure 57. 


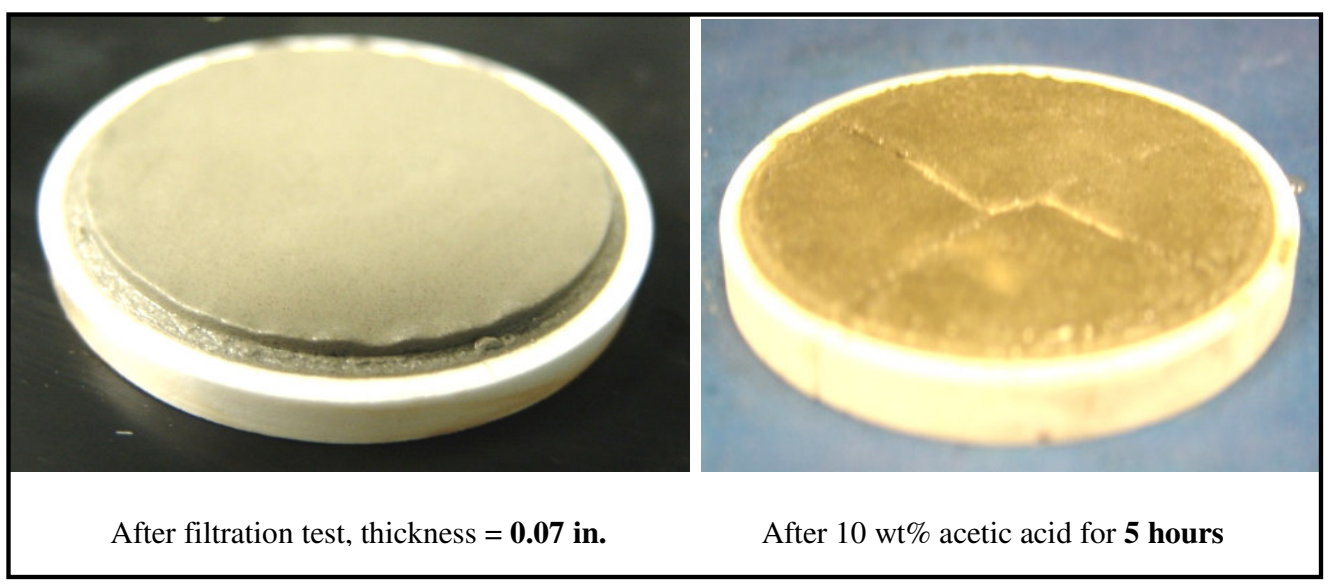

Figure 57: Filter cake after filtration test and $10 \mathrm{wt} \%$ acetic acid solution, temperature $=300^{\circ} \mathrm{F}$ and pressure $=200 \mathrm{psi}$

\subsubsection{0 wt\% Acetic Acid Mixed with 10 wt\% Cellulose Enzyme}

Previous experiments showed that organic acids alone can not remove and dissolve most of the filter cake damage. Polymers coated the calcium carbonate particles and that will act as a barrier between the acids and the particles. $10 \mathrm{wt} \%$ cellulose enzymes and 10 wt\% acetic acid were mixed properly with PFB solution at room temperature. The mixture was compatible at room temperature and no precipitate was noticed. The temperature of the cell was fixed on $242^{\circ} \mathrm{F}$ because most of the enzymes fluids do not work at temperatures above $250^{\circ} \mathrm{F}$ and that might cause some precipitations. The mixture was left soaking in the cell for 17.5 hours because the enzymes need enough time to have a complete reaction with the polymers. After most of the cellulose polymer chains were broken, the acetic acid start the reaction with the calcium carbonate particles that covered previously by polymers. The removing efficiency result was excellent and more than $85 \%$ of the filter cake was successfully removed, Figure 58. Xanthan enzyme 
was not used in this experiment because most of the polymers that retained on the filter cake were cellulose since its function was reducing the drilling fluid losses.

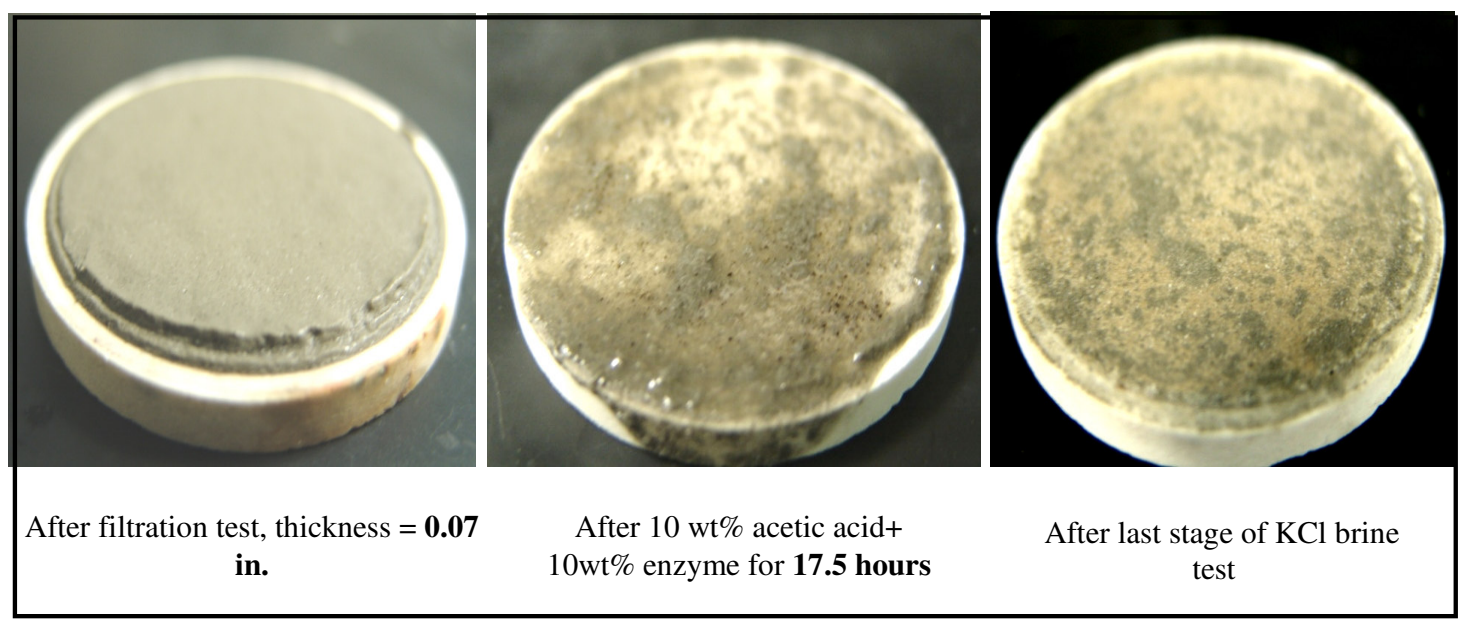

Figure 58: Filter cake after filtration test and $10 \mathrm{wt} \%$ acetic acid mixed with $10 \mathrm{wt} \%$ enzyme solution, temperature $=242^{\circ} \mathrm{F}$ and pressure $=220 \mathrm{psi}$

\subsubsection{0 wt\% Acetic Acid Mixed with 5 wt\% Cellulose Enzyme}

The objective of this experiment is to determine the effect of $5 \mathrm{wt} \%$ cellulose enzyme in acetic acid solution on the polymeric materials and $\mathrm{CaCO}_{3}$ compared to the previous test (10 wt $\%$ enzyme). Figure 59 shows that the $5 \mathrm{wt} \%$ enzyme solution was not able to breakdown most of the polymer chains to lower sugar units. The soaking time was almost equal for both tests. The removing efficiency, based on initial and final brine flow rate, was below $40 \%$. So, $10 \mathrm{wt} \%$ cellulose enzyme mixed with $10 \mathrm{wt} \%$ acetic acid solution is the optimum cleaning formula to remove the polymer and dissolve the calcium carbonate particles in the filter cake layer. 


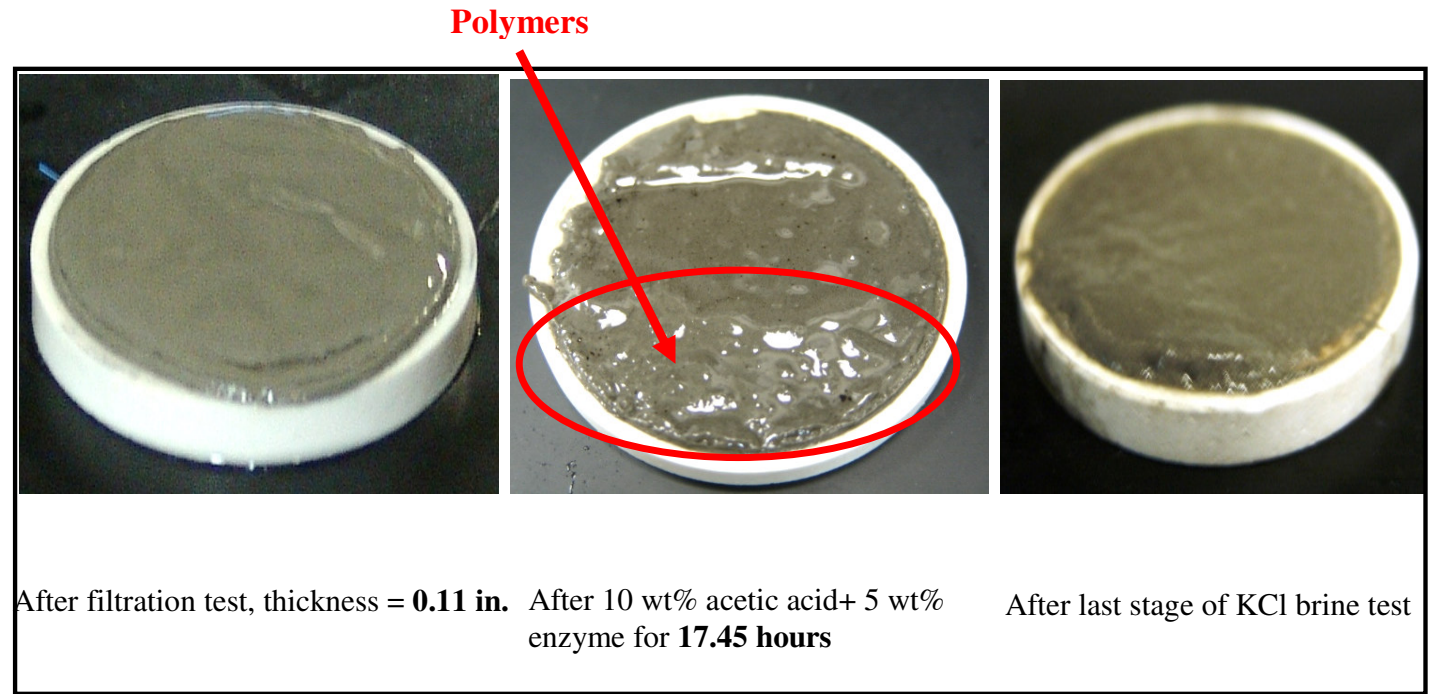

Figure 59: Filter cake after filtration test and $10 \mathrm{wt} \%$ acetic acid mixed with $5 \mathrm{wt} \%$ enzyme solution, Temperature $=251^{\circ} \mathrm{F}$ and pressure $=200 \mathrm{psi}$

\subsection{Surface Tension Experiments}

The PFB solution surface tension is very important to be measured since it is used both in drilling, completion, and workover fluids. The surface tension of the acids solution will be changed when mixed with PFB fluid. Surface tension measurements were done at wide range of temperatures and at a pressure of $72 \mathrm{psi}$.

\subsubsection{PFB solution}

The PFB fluid was used as received from the field without any dilution. The density was measured and equal to $94.8 \mathrm{pcf}$ at room temperature. The surface tension was measured at a wide range of temperature condition. At room temperature, the PFB solution gave 
$63.7 \mathrm{mN} / \mathrm{m}$ of surface tension. As temperature increased to $122^{\circ} \mathrm{F}$, the surface tension decreased slightly to $63.1 \mathrm{mN} / \mathrm{m}$. The general trend of the surface tension was increased, as temperature increased above $200^{\circ} \mathrm{F}$. Figure 60 shows that behavior and it is up normal because the surface tension usually decreased as temperature increased. The surface tension experiment was repeated several times to make sure there was no experimental error; the same behavior was noticed in all experiments. The instrument was calibrated in each test by measuring the surface tension of the water.

\subsubsection{0 wt\% Formic Acid Prepared in PFB Solution}

A $10 \mathrm{wt} \%$ formic acid was mixed in PFB solution at $130^{\circ} \mathrm{F}$ to avoid any solid precipitation at room temperature condition. The sample was loaded in the instrument to measure its' surface tension at high temperatures. The surface tension at room temperature was $66.2 \mathrm{mN} / \mathrm{m}$. Then, it decreased, as temperature increased above $122^{\circ} \mathrm{F}$ as shown in Figure 61. 


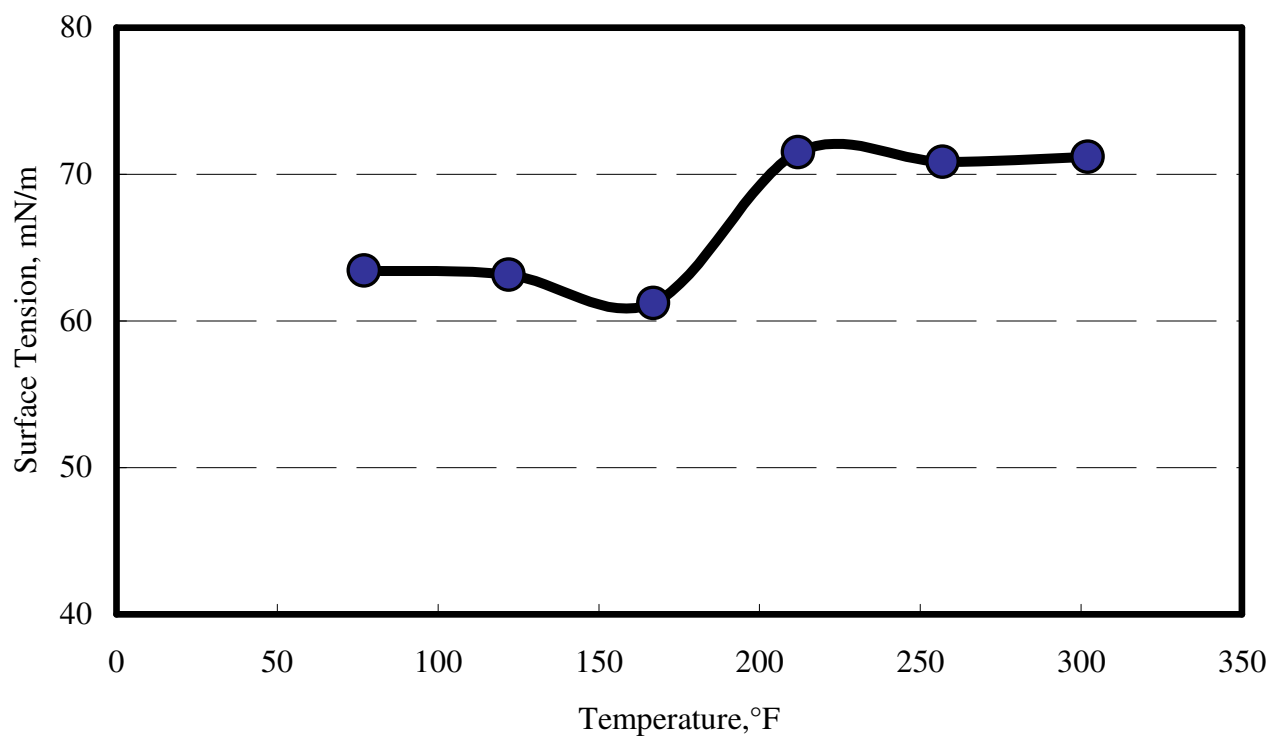

Figure 60: Surface tension of PFB at high temperature

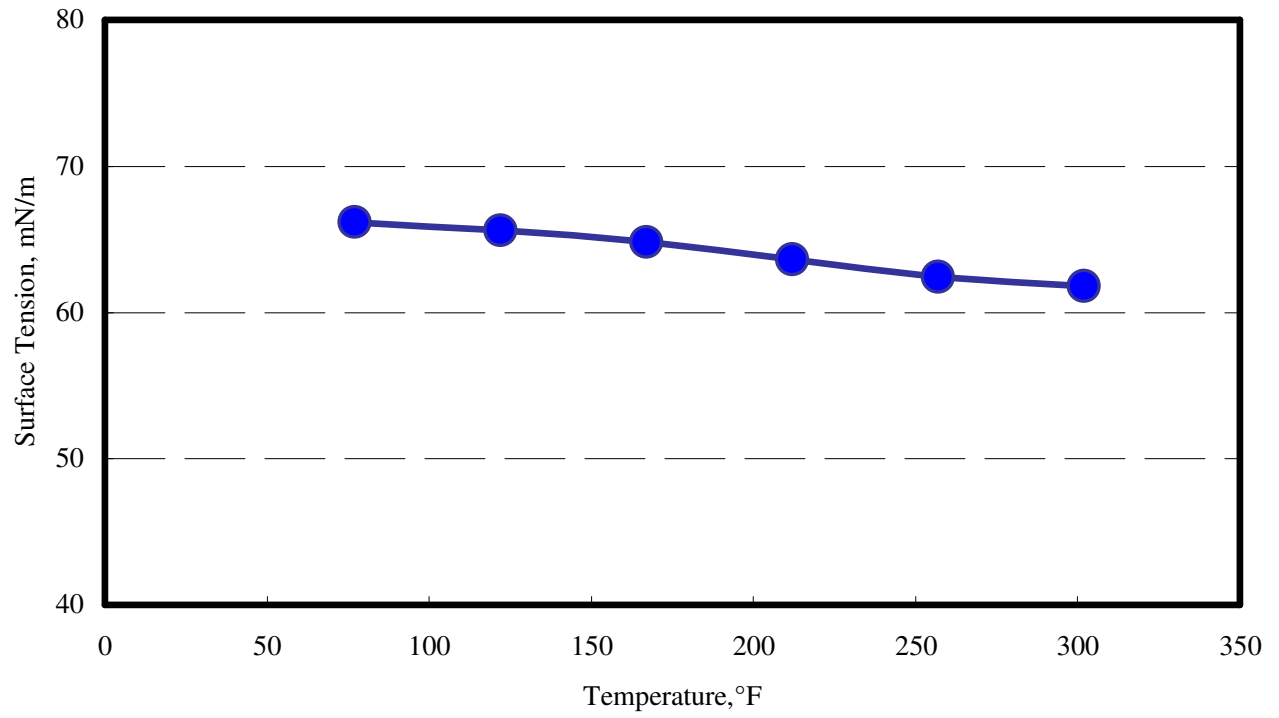

Figure 61: Surface tension of $10 \mathrm{wt} \%$ formic acid at high temperature 


\subsection{3 $10 w t \%$ Acetic Acid Prepared in PFB Solution}

Acetic acid, as mentioned in chapter III, was not precipitating when mixed with PFB solution at room temperature. A $10 \mathrm{wt} \%$ acetic acid was prepared and then the surface tension was measured. The surface tension was equal to $50 \mathrm{mN} / \mathrm{m}$ and then it remained almost constant as temperature increased, Figure 62.

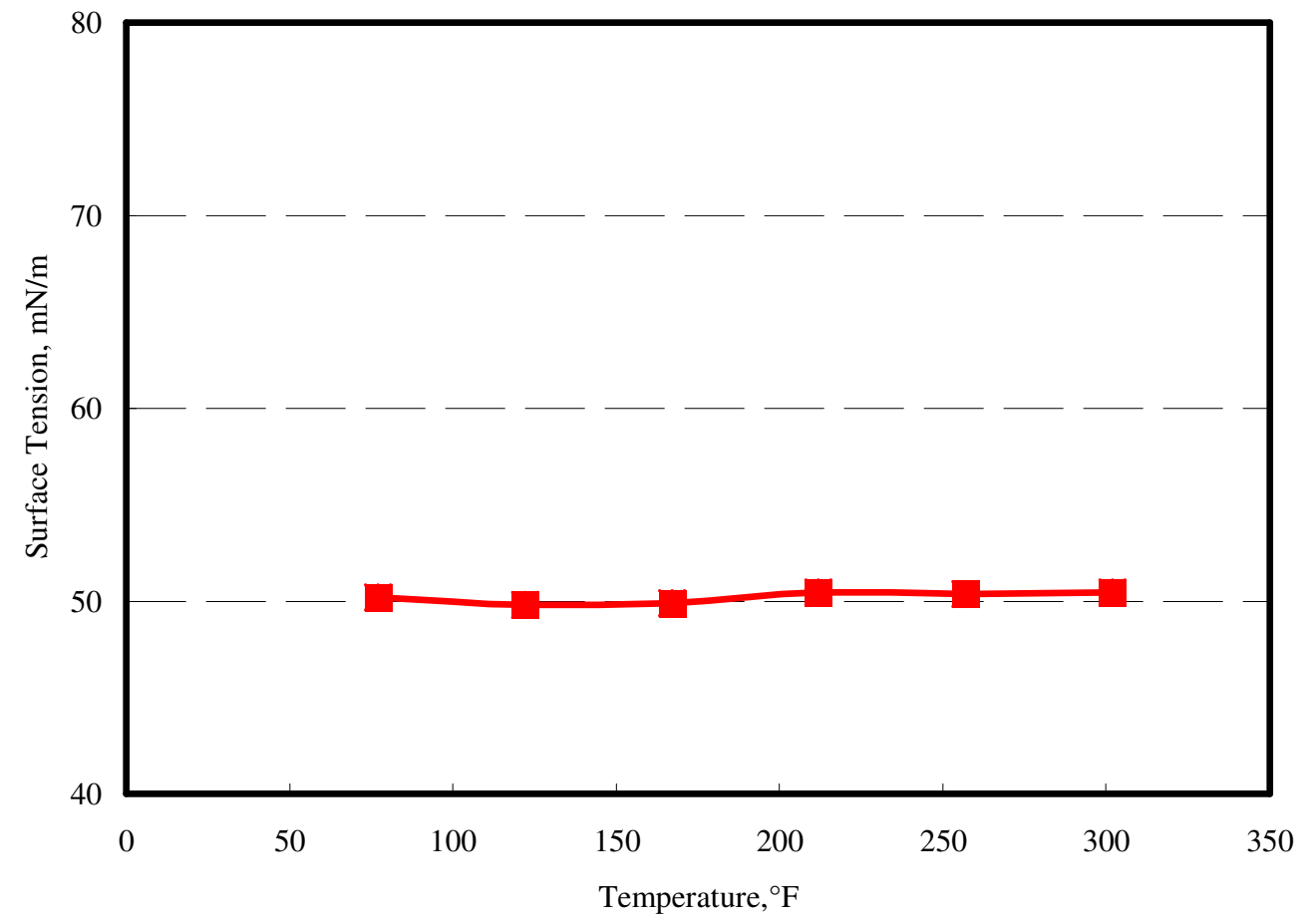

Figure 62: Surface tension of $10 \mathrm{wt} \%$ acetic acid at high temperature 


\section{CHAPTER V}

\section{CONCLUSIONS}

Based on the experimental results and analysis of the data, the following conclusions may be drawn.

1. The DFF was compatible with 10 vol\% ethyl lactate ester at room temperature and $300^{\circ} \mathrm{F}$.

2. Mixing DFF with UFB at different ratios showed solid precipitates at room conditions.

3. A significant amount of settled solids were observed when PFB was mixed with UFB at ratio 50:50 and at room and high temperatures.

4. Citric and formic acids at $10 \mathrm{wt} \%$ were incompatible with PFB; they resulted in some suspended and settled solids at room temperature.

5. No solid precipitate was noticed when citric and formic acids were mixed with PFB at high temperature.

6. A $10 \mathrm{wt} \%$ of acetic acid was compatible with PFB at ambient and high temperature conditions.

7. A phase separation was noticed when ethyl lactate ester was mixed with PFB solution.

8. Chelating agent and enzymes solution were compatible with PFB solution. 
9. A 10 vol\% of ethyl lactate ester was prepared in $\mathrm{KCl}$ brine, and it was compatible. Excellent filter cake removing efficiency was attained by the generated lactic acid.

10. Lab experiment indicated that free-solids formate brine can cause some erosion to the filter cake damage and will not remove filter cake completely.

11. Organic acids were not able to cleanup the filter cake damage efficiently. The calcium carbonate particles were covered by the polymers and thus acted as a barrier to the acids to react with the calcite particles.

12. Polymers backbone and side chains in the filter cake can be broken by using specific enzymes.

13. Enzymes-acetic acid solution gave the highest removing efficiency result compared to other cleaning fluids.

14. The surface tension of formic acid was the highest compared to lactic, acetic acids and potassium formate brine. 


\section{NOMENCLATURE}

$\begin{array}{ll}\text { MRC } & \text { Maximum reservoir contact } \\ \text { DIF } & \text { Drill-in fluid } \\ \text { WBM } & \text { Water-based mud } \\ \text { OBM } & \text { Oil-based mud } \\ \text { ECD } & \text { Equivalent circulation density } \\ \text { DFF } & \text { Drilling fluid filtrate } \\ \text { wt\% } & \text { Weight percent } \\ \text { vol.\% } & \text { Volume percent } \\ \text { UFB } & \text { Unyazah formation brine } \\ \text { PAC } & \text { Polyanionic cellulose } \\ \text { PFB } & \text { Potassium formate brine } \\ \text { UFB } & \text { Unyazah formation brine } \\ \text { HPHT } & \text { High pressure high temperature } \\ \text { lb/ft } & \\ & \end{array}$




\section{REFERENCES}

Al Moajil A.M., Nasr-El-Din, H.A., and Al-Aamri, A.D. 2007. Evaluation of In-Situ Generated Acids for Filter-Cake Cleanup. Paper SPE 107537 presented at the SPE European Formation Damage, The Hague, The Netherlands, 30 May-1 June.

Al Otaibi, M.B. and Nasr-El-Din, H.A. 2005. Chemical Treatments for Removal of Drill-in-Fluid Damage in Horizontal-Multilateral Wells: Lab Studies and Case Histories. Paper SPE 94043 presented at the SPE Europec/EAGE Conference, Madrid, Spain, 13-16 June.

Al Otaibi, M.B., Al Mojil, A.M., and Nasr-El-Din, H.A. 2006. In-Situ Acid System to Clean Up Drill-in Fluid Damage in High-Temperature Gas Wells. Paper SPE 103846 presented at the IADC/SPE Asia Pacific Drilling Technology Conference and Exhibition, Bangkok, Thailand, 13-15 November.

Battistel, E., Bianchi, D., Fornaroli, M., Guglielmetti, G., Europa, P. and Cobianco, S. 2005. Enzyme Breakers for Chemically Modified Starches. Paper SPE 94702 presented at the SPE Formation Damage Control Conference, Sheveningen, The Netherlands, 25-27 May.

Bouwmeester, R.C and Van Gijtenbeek, K.A. 2005. Compositions and Methods Including Formate Brines for Conformance Control. U.S. patent No. 20040035580 (January 2005).

Bradshaw, R., Hodge R., Wolf, N.O., Knox, D., Hudson, C. and Evans, E. 2006. Formate-Based Reservoir Drilling Fluid Resolves High-Temperature Challenges in the Natuna Sea. Paper SPE 98347 presented at the International Symposium and Exhibition on Formation Damage Control, Lafayette, Louisiana, 15-17 February.

Buijse, M., de Boer, P., Breukel, B., and Burgos, G. Organic Acids in Carbonate Acidizing. SPEPF 19 (3): 128-134 (August 2004).

Bungert, D., Maikranz, S., Sundermann, R., Downs, J., Benton, W. and Dick, M.A. 2000. The Evolution and Application of Formate Brines in High 
Temperature/Pressure Operations. Paper SPE 59191 presented at the IADC/SPE Drilling Conferences, New Orleans, Louisiana, 23-25 February.

Byrne, M., Paty, I., George, L., Downs, J., and Turner, J. 2002. Formate Brines: A Comprehensive Evaluation of their Formation Damage Control Properties Under

Realistic Reservoir Conditions. Paper SPE 73766 presented at the SPE International Symposium and Exhibition on Formation Damage Control, Lafayette, Louisiana, 20-21 February.

Ding, Y., Herzhaft, B. and Renard G. Near-Wellbore Formation Damage Effects on Well Performance: A Comparison between Underbalanced and Overbalanced Drilling. SPEPO 21 (1): 51-57 (February 2006).

Downs, J.D., Blaszczynski, M., Turner, J. and Harris, M. 2006. Drilling and Completing Difficult HP/HT Wells with the Aid of Cesium Formate Brines - A Performance Review. Paper SPE 99068 presented at the IADC/SPE Drilling Conference, Miami, Florida, 21-23 February.

Downs, J.D., Howard, S.K. and Carnegie, A. 2005. Improving Hydrocarbon Production Rates through the Use of Formate Fluids - A Review. Paper SPE 97694 presented at the SPE International Improved Oil Recovery Conference in Asia Pacific, Kuala Lumpur, Malaysia, 5-6 December.

Downs, J.D. 1993. Formate Brines: Novel Drilling and Completion Fluids for Demanding Environments. Paper SPE 25177 presented at the SPE International Symposium on Oilfield Chemistry, New Orleans, Louisiana, 2-5 March.

Hands, N., Francis, P., Whittle, A. and Rajasingam, D. Optimizing a Long Multilateral Gas Well's Inflow Performance. World Oil Journal, 1-7, (April 1999).

Hands, N., Kowbel, K., Maikrans, S. and Nouris, R. Drill-in Fluid Reduces Formation Damage, Increases Production Rates. OGJ, 65-69, (13 July 1998).

Huang, T., Ostensen, L., and Hill, A.D. 2000. Carbonate Matrix Acidizing with Acetic Acid. Paper SPE 58715 presented at the SPE International Symposium on Formation Damage Control, Lafayette, Louisiana, 23-24 February. 
Hussain, A., Kumar, A. Garni, S.A. and Shammari, M.A. 2005. Optimizing Maximum Reservoir Contact Wells: Application to Saudi Arabian Reservoirs. Paper SPE 10395 presented at the SPE International Petroleum Technology Conference, Doha, Qatar, 21-23 November.

Javora, P.H., Stevens, R., Devine, C., Firmin, G., et al. Comprehensive Testing Validates Deepwater Fluid Selection: Planning Can Avoid Expensive Lessons. Offshore Journal, 67 (4): 86-90 (April 2007).

Larsson, G. and Nahringbauer, I. Hydrogen Bond Studies.XXIII. The Crystal Structure of Potassium Hydrogen Diformate. Journal of Acta. Crystallographica, 24: 666-672, (May 1968).

Leschi, P., Demarthon, G., Davidson, E. and Clinch, D. 2006. Delayed-Release Acid System for Cleanup of Al Khalij Horizontal Openhole Drains. Paper SPE 98164 presented at the SPE International Symposium and Exhibition on Formation Damage Control, Lafayette, Louisiana, 15-17 February.

Liu, X. and Civan F.1994. Formation Damage and Skin Factor Due to Filter Cake Formation and Fines Migration in the Near-Wellbore Region. Paper SPE 27364 presented at the SPE International Symposium on Formation Damage Control, Lafayette, Louisiana, 7-10 February.

Lomba, R.F.T., deSá, C.H.M. and Brandão, E.M.. A New Approach to Evaluate Temperature Effects on Rheological Behavior of Formate-Based Fluids. Journal of Energy Resources Technology, 124 (3): 141-145 (2002).

Longeron, D.G., Alfenore, J., Salehi, N., Saintpère, S. 2000. Experimental Approach to Characterize Drilling Mud Invasion, Formation Damage and Cleanup Efficiency in Horizontal Wells with Openhole Completions. Paper SPE 58737 presented at the SPE International Symposium on Formation Damage Control, Lafayette, Louisiana,. 23-24 February.

McKay, G., Bennett, C.L. and Gilchrist, J.M. 2000. High Angle OHGP's In Sand/Shale Sequences: A Case History Using a Formate Drill-In Fluid. Paper 
SPE 58731 presented at the SPE International Symposium on Formation Damage Control, Lafayette, Louisiana, 23-24 February.

Melbouci, M. and Sau Arjun, C. 2006. Water-Based Drilling Fluids. U.S. patent No. 20060019834 (January 2006).

Messler, D., Broach, M. and Benson, D. 2004. A Potassium Formate Milling Fluid Breaks the $400^{\circ}$ Fahrenheit Barrier in a Deep Tuscaloosa Coiled Tubing Cleanout. Paper SPE 86503 presented at the SPE International Symposium and Exhibition on Formation Damage Control, Lafayette, Louisiana, February 2-4.

Moses, V. and Harris, R.E. 2004. Acidising Underground Reservoirs. E.P. patent No. WO25731 (November 2004).

Nasr-El-Din, H.A., Al Otaibi, M.B., Al-Qahtani, A.A., and McKay, I.D. 2005. Laboratory Studies of In-Situ Generated Acid to Remove Filter Cake in Gas Wells. Paper SPE 96965 presented at the SPE Annual Technical Conference and Exhibition, Dallas, Texas, 9-12 October.

Njobuenwu, D.O. and Wobo, C.A. Effect of Drilled Solids on Drilling Rate and Performance. Journal of Petroleum Science and Engineering, 55, 3-4: 271-276 (February 2007).

OFI Testing Equipment. Dynamic HTHP Filter Press. www.ofite.com. 25 July 2007. Oswald, R.J., Knox, D. and Monem, M.R. 2006. Taking Nondamaging Fluids to New Extremes: Formate-Based Drilling Fluids for High-Temperature Reservoirs in Pakistan. Paper SPE 98391 presented at the International Symposium and Exhibition on Formation Damage Control, Lafayette, Louisiana, 15-17 February. Pitoni, E., Ballard, D.A. and Kelly, R.M. 1999. Changes in Solids Composition of Reservoir Drill in Fluids during Drilling and the Impact on Filter Cake Properties. Paper SPE 54753 presented at the SPE European Formation Damage Conference, The Hague, The Netherlands, 31 May-1 June.

Saasen, A. et al. 2002. Drilling HT/HP Wells Using a Cesium Formate Based Drilling Fluid. Paper SPE 74547 presented at the IADC/SPE Drilling Conferences, Dallas, Texas, 26-28 February. 
Schlumberger. Completion Fluids. www.slb.com. 15 March 2007.

Simpson, M.A., AbdRabAlreda, S.H., Al-Khamees, S.A., Zhou, S., Treece, M.D. and Al-Ansari, A.A. 2005. Overbalanced Pre-Khuff Drilling of Horizontal Reservoir Sections with Potassium Formate Brines. Paper SPE 92407 presented at the SPE Middle East Oil \& Gas Show and Conference, Bahrain, 12-15 March.

Svendsen, Ø., Saasen, A., Vassøy, B., Skogen, E., Mackin, F., and Normann, S.H. 1998. Optimum Fluid Design for Drilling and Cementing a Well Drilled with Coiled Tubing. Paper SPE 50405 presented at the SPE International Conference on Horizontal Well Technology, Calgary, Alberta, 1-4 November.

Svendsen, Ø., Toften, J.K., Marshall, D.S., and Hermansson, C.L. 1995. Use of a Novel Drill-in/Completion Fluid Based on Potassium Formate Brine on the First Open Hole Completion in the Gulfaks Field. Paper SPE 29409 presented at the IADC/SPE Drilling Conferences, Amsterdam, The Netherlands, 28 February- 2 March.

Svoboda, C. Optimizing High-Temperature Kill Pills: The Åsgard Experience. SPEDC 21-26 (March 2002).

Weekse, A., Grant, S., and Urselmann, R. 2002. Expandable Sand Screen: Three New World Records in the Brigantine Field. Paper SPE 74549 presented at the IADC/SPE Drilling Conference, Dallas, Texas, 26-28 February.

Yildiz, T. 2006. The Impact of Nonuniform Formation Damage on Long-Term Well Performance. Paper SPE 98123 presented at the SPE International Symposium and Exhibition on Formation Damage Control, Lafayette, Louisiana, 15-17 February. 


\section{VITA}

NAME:

PERMANENT ADDRESS:

EDUCATION:
Mohammed B. Alotaibi

Saudi Aramco

Dhahran, 31311

P.O.Box, 10311

Saudi Arabia

B.S., Chemical Engineering (Cum Laude)

King Fahd University of Petroleum and Minerals,

Dhahran, Saudi Arabia

February 2002

M.S., Petroleum Engineering

Texas A\&M University, May 2008 